\title{
DETERMINAÇÃO DA CONDUTIVIDADE HIDRAULICA DE SOLOS A PARTIR DA CURVA DE RETENÇÃO DE ÁGUA
}

\author{
ELOY ANTONIO PAULETTO \\ Engenhelro Agrônomo
}

Orientador: PAULO LEONEL LIBARDI

Tese apresentada à Escola
Superior de Agricultura "Luiz de
Queiroz", da Universidade de São
Paulo, para obtenção do título
de Doutor em Agronomia. Área
de Concentração: Solos e Nutrição
de Plantas.

PIRACICABA

Estado de São Paulo - Brasil

Fevereiro - 1986 
$\bar{A}$ minha esposa, Maria Coralia, e minha filha, Livia, D E D I C O 


\section{AGRADECIMENTOS}

Meu reconhecimento às pessoas e às instituições que tornaram possivel a realização deste trabalho, especialmente:

- Ao Prof. Dr. Paulo Leonel Libardi, pela firme orientação, ensinamentos e amizade que sempre me tem dedicado.

- Ao Prof. Dr. Zilmar Ziller Marcos, pela amizade, orientação e apoio.

- Ao Enge Agrọ Paulo Augusto Manfron; pela amizade, cooperação e labuta diāria na condução da parte experimental.

- Ao Engo Agro Ariovaldo Luiz Turatti, pela amizade e sempre pronta colaboração na resolução de problemas junto à UFPEL.

- Aos amigos Sergio Oliveira Moraes, João Eduardo Pilotto, Hamilton Justino Vieira, Homero Bergamaschi, Sebastião Alberto de Oliveira, Francisco Mandeli, Renato dos Santos, Ana Rita Fagundes Rodrigues, Paulo José Hamakawa, Celso Luiz Prevedello, Beatriz M.S. Prevedello, Rivail Salvador Lourenço, Alvaro Pires da Silva, Otávio Minoru Matsumoto, Josē Barbosa Cabral, Hermes Alves Almeida, José Ademir Rodrigues, Daciano Stenico e outros que, de alguma forma, colaboraram na realização deste trabalho.

- Aos Professores do Curso de Pös-Graduação em Solos e Nutrição de Plantas da ESALQ/USP, por todos os ensinamentos recebidos.

- Aos Funcionärios Luiz Angeleli e Manoel Israel, pela ajuda no experimento em sua parte de campo. 
- Ā Faculdade de Agronomia "Eliseu Maciel" - UFPEL, e à Escola Superior de Agricultura "Luiz de Queiroz" - USP, pela oportunidade de realização do Curso.

- Ao Plano Institucional de Capacitação Docente da CAPES, pela Bo1sa de Estudos.

Enfim, a todos aqueles que, direta ou indiretamente, contribuiram para que este trabalho se tornasse realidade. 
CONTEÚDO

Pāgina

1. INTRODUÇ $\tilde{A}_{0}$

4. MATERIAL E METODOS

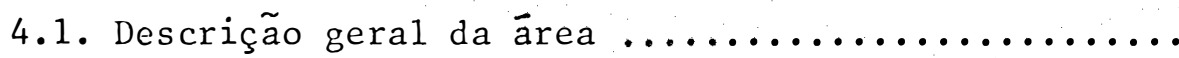

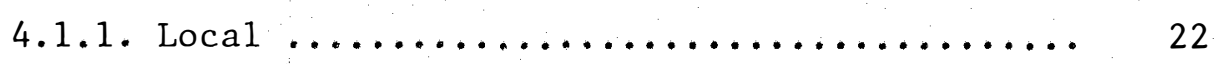

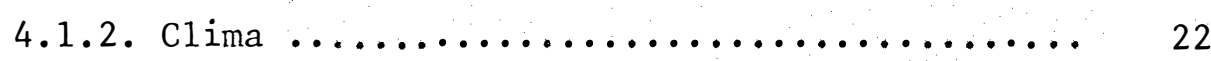

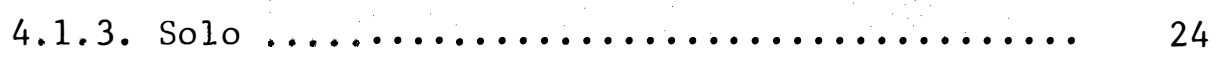

4.2. Delineamento experimental ................ 30

4.3. Curvas de retenção da ăgua no solo ........... 30

4.4. Condutividade hidrāulica do solo ............ 31

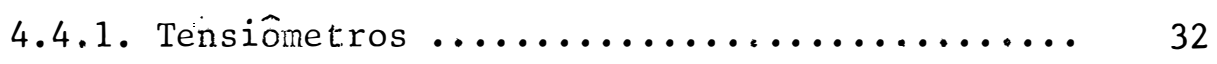

4.4.2. Procedimentos experimentais para obtenção da

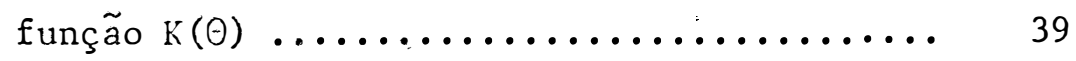

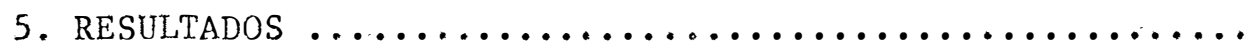

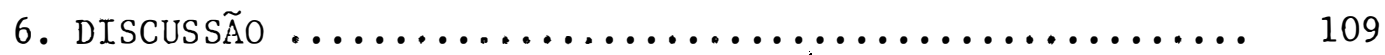

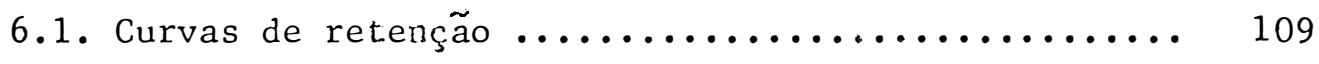

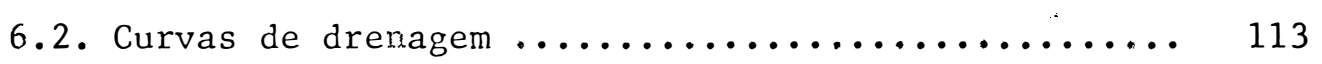

6.3. Método proposto ....................... 114

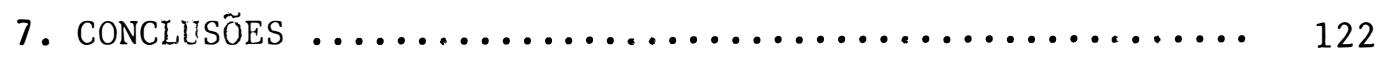

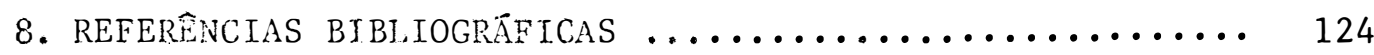




\section{LISTA DE FIGURAS}

Figura

1 - Localização do experimento no campo experimental da ESALQ/USP, próximo ao Posto Agrometeorológico. $A=$ ārea subsolada; $B=$ ārea não subsolada $\ldots$.

2 - Localização das parcelas experimentais nas āreas subsolada e não subsolada $\ldots . \ldots \ldots \ldots \ldots \ldots \ldots$

3 - Esquema da parcela experimental da Terra Roxa

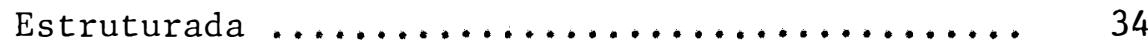

4 - Esquema de um tensiômetro instalado no campo ... 36

5 - Curvas de retenção da água no solo para as profundidades de 15 e $30 \mathrm{~cm}$, do Latossolo Verme-

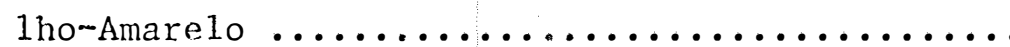

6 - Curvas de retenção da água no solo para as profundidades de 45 e $60 \mathrm{~cm}$, do Latossolo Verme 1ho-Amarelo

7 - Curvas de retenção da água no solo para as profundidades de 75 e $90 \mathrm{~cm}$, do Latossolo Verme1ho-Amarelo

8 - Curvas de retenção da água no solo para as profundidades de 105,120 e $135 \mathrm{~cm}$, do Latossolo Verme 1ho-Amarelo $\ldots \ldots \ldots \ldots \ldots \ldots \ldots \ldots$

9 - Curvas de retenção da āgua no solo para a pro- 
fundidade de $15 \mathrm{~cm}$ das āreas não subsolada e sub-

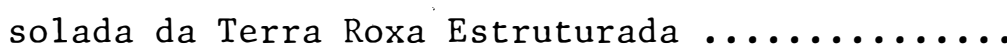

10 - Curvas de retenção da água no solo para a profundidade de $30 \mathrm{~cm}$ das āreas não subsolada e sub-

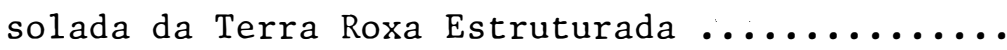

11 - Curvas de retenção da água no solo para a profundidade de $45 \mathrm{~cm}$ das āreas não subsolada e subsolada da Terra Roxa Estruturada ............

12 - Curvas de retenção da água no solo para a profundidade de $60 \mathrm{~cm}$ das äreas não subsolada e sub-

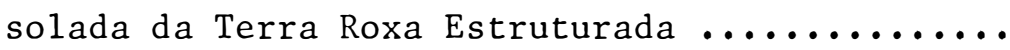

13 - Curvas de retenção da água no solo para a profundidade de $75 \mathrm{~cm}$ das āreas não subsolada e subsolada da Terra Roxa Estruturada ............

14 - Curvas de retenção da água no solo para a profundidade de $90 \mathrm{~cm}$ das áreas não subsolada e subsolada da Terra Roxa Estruturada ............

15 - Curvas de retenção da água no solo para a profundidade de $105 \mathrm{~cm}$ das áreas não subsolada e subsolada da Terra Roxa Estruturada ............

16 - Curvas de retenção da água no solo para a profundidade de $150 \mathrm{~cm}$ das áreas não subsolada e sub-

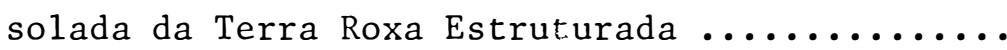


17 - Curvas de retenção da água no solo para a profundidade de $195 \mathrm{~cm}$ das áreas não subsolada e subsolada da Terra Roxa Estruturada ............

18 - Umidade volumétrica em função do tempo de drena gem, para as profundidades 15,30 e $45 \mathrm{~cm}$ do La-

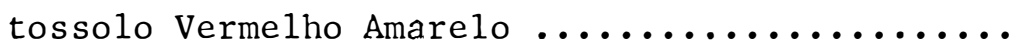

19 - Umidade volumétrica em função do tempo de drenagem, para as profundidades 60, 75 e $90 \mathrm{~cm}$ do Latossolo Vermelho Amarelo

20 - Umidade volumétrica em função do tempo de drenagem para as profundidades 105,120 e $135 \mathrm{~cm}$ do La-

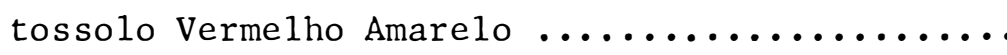

21 - Ümidade volumétrica em função do tempo de drenagem, para a profundidade de $15 \mathrm{~cm}$, nas parcelas 1,2 e 3 da Terra Roxa Estruturada - Ārea não subsolada..$\ldots \ldots \ldots \ldots \ldots \ldots \ldots \ldots \ldots \ldots$

22 - Umidade volumétrica em função do tempo de drenagem, para a profundidade de $30 \mathrm{~cm}$, nas parcelas 1,2 e 3 da Terra Roxa Estruturada - Ârea não subsolada

23 - Umidade volumétrica em função do tempo de drenagem, para a profundidade de $45 \mathrm{~cm}$, nas parcelas 1, 2 e 3 da Terra Roxa Estruturada - Ārea não 
subsolada

24 - Umidade volumétrica em função do tempo de drenagem, para a profundidade de $60 \mathrm{~cm}$, nas parcelas 1, 2 e 3 da Terra Roxa Estruturada - Ārea não subsolada $\ldots . . \ldots \ldots \ldots \ldots \ldots \ldots \ldots \ldots \ldots \ldots$

25 - Umidade volumétrica em função do tempo de drenagem, para a profundidade de $75 \mathrm{~cm}$, nas parcelas 1, 2 e 3 da Terra Roxa Estruturada - Ārea não subsolada

26 - Umidade volumétrica em função do tempo de drenagem, para a profundidade de $90 \mathrm{~cm}$, nas parcelas 1, 2 e 3 da Terra Roxa Estruturada - Ārea não subsolada $\ldots \ldots \ldots \ldots \ldots \ldots \ldots \ldots \ldots \ldots \ldots$

27 - Umidade volumétrica em função do tempo de drenagem, para a profundidade de $105 \mathrm{~cm}$, nas parcelas 1,2 e 3 da Terra Roxa Estruturada - Ārea não subsolada $\ldots \ldots \ldots \ldots \ldots \ldots \ldots \ldots \ldots \ldots \ldots \ldots$

28 - Umidade volumétrica em função do tempo de drenagem, para a profundidade de $150 \mathrm{~cm}$, nas parcelas 1,2 e 3 da Terra Roxa Estruturada - Área não subsolada

29 - Umidade volumétrica em função do tempo de drenagem, para a profundidade de $195 \mathrm{~cm}$, nas parcelas 
1,2 e 3 da Trerra Roxa Estruturada - Ârea não

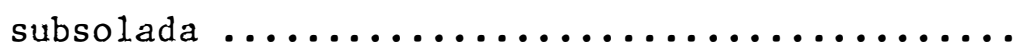

30 - Umidade volumétrica em função do tempo de drenagem, para a profundidade de $15 \mathrm{~cm}$, nas parcelas 1, 2 e 3 da Terra Roxa Estruturada - Ārea subsolada

31 - Umidade volumétrica em função do tempo de drenagem, para a profundidade de $30 \mathrm{~cm}$, nas parcelas 1,2 e 3 da Terra Roxa Estruturada - Ārea subsolada

32 - Umidade volumétrica em função do tempo de drenagem, para a profundidade de $45 \mathrm{~cm}$, nas parcelas 1,2 e 3 da Terra Roxa Estruturada - Ārea sub-

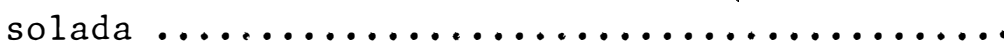

33 - Umidade volumétrica em função do tempo de drenagem, para a profundidade de $60 \mathrm{~cm}$, nas parcelas 1,2 e 3 da Terra Roxa Estruturada - Ārea subsolada

34 - Umidade volumétrica em função do tempo de drenagem, para a profundidade de $75 \mathrm{~cm}$, nas parcelas 1,2 e 3 da Terra Roxa Estruturada - Ārea subsolada $\ldots \ldots \ldots \ldots \ldots \ldots \ldots \ldots \ldots \ldots \ldots$

35 - Umidade volumétrica em função do tempo de drena- 
gem, para a profundidade de $90 \mathrm{~cm}$, nas parcelas 1,2 e 3 da Terra Roxa Estruturada - Ārea subsolada

36 - Umidade volumétrica em função do tempo de drenagem, para a profundidade de $105 \mathrm{~cm}$, nas parcelas 1,2 e 3 da Terra Roxa Estruturada - Ārea subsolada

37 - Umidade volumétrica em função do tempo de drenagem, para a profundidade de $150 \mathrm{~cm}$, nas parcelas 1,2 e 3 da Terra Roxa Estruturada - Ārea subsolada $\ldots \ldots \ldots \ldots \ldots \ldots \ldots \ldots \ldots \ldots \ldots \ldots$

38 - Umidade volumétrica em função do tempo de drenagem, para a profundidade de $195 \mathrm{~cm}$, nas parcelas 1,2 e 3 da Terra Roxa Estruturada - Ārea subsolada

39 - Relação entre $\gamma$ e $\alpha$ para todas as profundidades dos solos estudados 
LISTA DE TABELAS

Tabela

Página

1 - Algumas características físicas do perfil do so10 em estudo..$\ldots \ldots \ldots \ldots \ldots \ldots \ldots \ldots \ldots \ldots$

2 - Algumas características químicas do perfil do so-

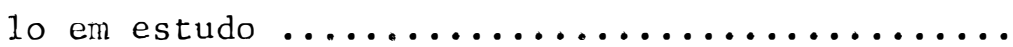

3 - Granulometria e densidadedas camadas estudadas do perfil do solo Latossolo Vermelho Amarelo ....

4 - Umidade volumétrica nas diversas tensões e profundidades, para o Latossolo Vermelho Amarelo ..

5 - Valores de potencial matricial no solo Latossolo Vermelho Amarelo, nos diversos tempos e profundidades, obtidos a partir de tensiônetros instalados no campo $\ldots \ldots \ldots \ldots \ldots \ldots \ldots \ldots \ldots$

6 - Umidade volumétrica nas diversas tensões e profundidades, do Solo Terra Roxa Estruturada

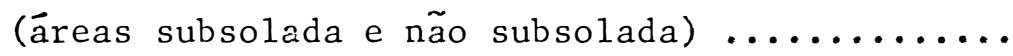

7 - Equações representativas das curvas características da água no solo, para as diversas profundidades, do Latossolo Vermelho Amarelo

8 - Equações representativas das curvas características da água no solo, para as diversas profun- 
didades, para a Terra Roxa Estruturada (äreas não subsolada e subsolada) $\ldots . . \ldots \ldots \ldots \ldots \ldots \ldots$

9 - Potencial matricial nos diversos tempos, obtidos da leitura dos tensiômetros instalados às diversas profundidades na Terra Roxa Estruturada - $\bar{a}-$ rea não subsolada - Parcela $1 \ldots \ldots \ldots \ldots \ldots$

10 - Potencial matricial nos diversos tempos, obtidos da leitura dos tensiômetros instalados às diversas profundidades na Terra Roxa Estruturada - ārea não subsolada - Parcela $2 \ldots \ldots \ldots \ldots \ldots \ldots$

11 - Potencial matricial nos diversos tempos, obtidos da leitura dos tensiômetros instalados às diversas profundidades na Terra Roxa Estruturada - $\bar{a}-$ rea não subsolada - Parcela $3 \ldots \ldots \ldots \ldots \ldots$

12 - Potencial matricial nos diversos tempos, obtidos da leitura dos tensiômetros instalados às diversas profundidades na Terra Roxa Estruturada - $\bar{a}-$ rea subsolada - Parcela $1 \ldots \ldots \ldots \ldots \ldots \ldots \ldots$

13 - Potencial matricial nos diversos tempos, obtidos da leitura dos tensiômetros instalados às diversas profundidades na Terra Roxa Estruturada - $\bar{a}-$ rea subsolada - Parcela $2 \ldots \ldots \ldots \ldots \ldots \ldots$ 
da leitura dos tensiômetros instalados às diversas profundidades na Terra Roxa Estruturada - ā-

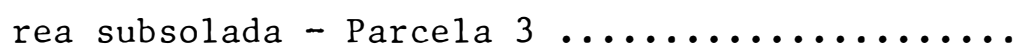

15 - Umidade volumétrica para os diversos tempos e profundidades, no Latossolo Vermelho Amarelo ...

16 - Valores de umidade para os diversos tempos e profundidades, na Terra Roxa Estruturada - ärea não subsolada - Parcela 1

17 - Umidade volumétrica paraos diversos tempos e profundidades, no Solo Terra Roxa Estruturada-ärea

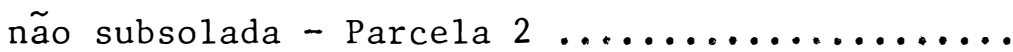

18 - Umidade volumétrica para os diversos tempos e profundidades, no Solo Terra Roxa Estruturada - ärea não subsolada - Parcela $3 \ldots \ldots \ldots \ldots \ldots \ldots$

19 - Umidade volumétrica para os diversos tempos e profundidades, no Solo Terra Roxa Estruturada - ārea subsolada - Parcela 1

20 - Valores de umidade para os diversos tempose profundidades, na Terra Roxa Estruturada - ārea subsolada - Parcela 2

21 - Valores de umidade para os diversos tempos e profundidades, na Terra Roxa Estruturada - área subsolada - Parcela $3 \ldots \ldots \ldots \ldots \ldots \ldots \ldots \ldots$ 
22 - Equações de regressão, com seus respectivos coeficientes de correlação, para as diversas profundidades, obtidas através do ajuste dos dados apresentados na Tabela 15 à eq. (21). Solo La-

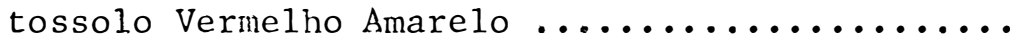

23 - Equações de regressão, com seus respectivos coeficientes, para as diversas profundidades, obtidas através do ajuste dos dados apresentados nas Tabelas 19, 20 e 21 à eq. (21). Solo Terra Roxa Estruturada - ärea não subsolada ........... 100

24 - Equações de regressão e seus respectivos coeficientes, para as diversas profundidades, obtidas atravēs do ajuste dos dados apresentados nas Tabelas 16, 17 e 18 à eq. (21) Solo Terra Roxa

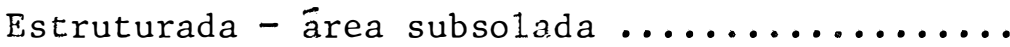

25 - Coeficientes $\gamma$ e $\alpha$ obtidos, respectivamente, a partir das eq. (21) e (5), pela regressão de $\theta$ versus $\ln$ t e $\ln \psi_{\mathrm{m}}$ versus $\Theta$, para a Terra Roxa Estruturada (áreas não subsolada e subsolada) e para o Latossolo Vermelho Amarelo ........... 106 
RESUMO

PAULETTO, E.A. Determinação da condutividade hidráulica de solos a partir da curva de retenção de água. 133 p. (Doutorado - Escola Superior de Agricultura "Luiz de Queiroz" da Universidade de São Paulo). Professor Orientador: Paulo Leonel Libardi.

A partir da suposição de que a condutividade hidráulica (K) e a difusividade da ägua (D) se relacionam de maneira exponencial coma umidade volumétrica $(\Theta)$ do solo, formulou - se a hipótese de traba1ho, de que há uma relação entre os coeficientes angulares $\alpha$ e $\gamma$ das relações $\ln \mathrm{D}$ versus $\Theta$ e $\ln \mathrm{K}$ versus $\Theta$, respectivamente. Como se sabe pela teoria do movimento da água em meios porosos, a razão entre $\mathrm{D}$ e $\mathrm{K}$ é igual à tangente à curva de retenção (potencial matricial $\psi_{\mathrm{m}}$ vs $\left.\theta\right)$. A partirdessefatoe das duas suposições acima citadas, pode-se chegar a uma equação $\psi_{m}(\Theta)$, na qual um dos parâmetros existente $\bar{e} B=\alpha-\gamma$. Para comprovar a hipótese de trabalho determinaram-se os valores de $\gamma$ a campo, pelo método daumidade de LIBARDI et alii (Soil Sci. Soc. Am. J., 44:3-7, 1980) de dois solos distintos, um deles classificado como Terra Roxa Estruturada (Paleudalf öxico) e o outro como Latossolo Vermelho Amarelo (Haplustox), ambos localizados no campus de Piracicaba da Universidade de 
São Paulo. No total, determinaram-se 63 valores de $\gamma$ correspondentes a diversas profundidades, em diferentes parcelas. Elaboraram-se tambēm curvas de retenção para essas profundidades, com amostras de solo com estrutura indeformada, para obtenção de B. Com isso, obtiveram-se os pares de valores de $\alpha$ e $\gamma$ e, consequentemente, a relação entre ambos. Essa relação foi linear e única para os dois solos e mostrando ser única tambëm para outros tipos de solo. De posse dessa relação universal, a obtenção da condutividade hidräulica em função da umidade do solo, a partir da curva de retenção é imediata. A conclusão, portanto, do presente trabalho, é de que, com base em fundamento teörico, desenvolveu-se um novo método de determinação da condutividade hidräulica em função da umidade, a partir da curva de retenção de água, elaborada com amostras de solo com estrutura indeformada. 


\section{SUMMARY}

PAULETTO, E.A. Soil hydraulic conductivity determination from soil-water retention curve. 133 p. (Ph,D. thesis - Escola Superior de Agricultura "Luiz de Queirnz", University of São Paulo). Adviser Professor: Paulo Leonel Libardi.

Assuming that hydraulic conductivity (K) and water diffusivity (D) are exponentially related to volumetric soil-water content ( $(\theta)$, a working hypothesis was set forth as follows: there is relationship between the slopes $\alpha$ and $\gamma$ of $\ln D$ versus $\theta$ and $\ln K$ versus $\Theta$ relations, respectively. As it is known from water movement theory in porous media, the $\mathrm{D} / \mathrm{K}$ ratio is equal to the tangent to the water retention curve, $\psi_{\mathrm{m}}=\psi_{\mathrm{m}}(\Theta)$, where $\psi_{\mathrm{m}}=$ matric potential. From this ratio and the two above assumptions, an equation of $\psi_{\mathrm{m}}$ versus $\theta$ can be derived, one parameter of which is $B=\alpha-\gamma$. In order to text the hypothesis of this work, $63 \gamma$ values were determined under field conditions in different plots and depths of two different soils (Oxic Paleudalf and Haplustox) by LIBARDI et alii (1980, Soil Sci. Soc. Am. J. 44: 3-7) $\Theta$-method. Both soils are located at the Piracicaba campus of the University of São Paulo (USP), Piracicaba (SP), Brazil. Soil-water retention curves, using undisturbed soil samples, were also worked out in order to obtain B. Thus, the 
relationship between $\alpha$ and $\gamma$ could be obtained, i.e., a straight line, the same for both soils and showing to be the same for other kinds of soils. With this universal relationship between $\alpha$ and $\gamma$, the obtainment of the hydraulic conductivity as a function of the soil-water content is immediate. The conclusion, therefore, of the present work is that a new method, with theoretical basis, was developed to determine the $k(\Theta)$ function, from the water retention curve worked out with undisturbed soil samples. 


\section{INTRODUÇÃO}

A ägua é um dos componentes mais importantes no processo da produção agrícola. Assim, corrigidas as deficiências nutricionais do solo, tem sido a substância que com maior frequência determina os níveis de rendimento das culturas.

o solo funciona como o reservatório de onde a planta retira, atravēs de seu sistema radicular, a água e também nutrientes para o seu crescimento e desenvolvimento. Características do solo, comogranulometria, estrutura e tipo de material são importantes para caracterizar seu armazenamento e movimento no solo. Modificações nessas características poderão acarretar diferenças na quantidade de água disponível às plantas.

0 movimento da água no sistema solo-planta envolve processos como infiltração, redistribuição, drenagem e absorção pela planta. Neste contexto, a condutividade hidráulica ocupa papel de destaque, pois reflete a capacidade do solo em conduzir água. Á medida que o solo seca, sua condutivídade hidráulica decresce, dificultando assim a extração de água pêlanta.

A primeira equação que possibilitou a quantificação do fluxo de água em meios porosos saturados foi apresentada por DARCY (1856). Em meios porosos não saturados, a primeira modificação da Equação de Darcy foi feita por BUCKINGHAM (1907), envolvendo o 
conhecimento de que a condutividade hidrāulica é função da ārea do espaço poroso do solo ñão ocupado por ar, tornando-se dependente, portanto, do conteúdo de água ou do potencial matricial do meio. A equação diferencial geral, entretanto, que descreve o movimento da āgua em meios porosos foi apresentada por RICHARDS (1931), e è simplesmente a equação oriunda da substituição da equação de Darcy na equação da continuidade.

Tanto para meios porosos saturados como não saturados, a maior dificuldade na quantificação do fluxo da água reside na determinação da condutividade hidrāulica. Esta tem sido realizada em grande escala em condições de laboratório, utilizando amostras com estrutura deformada ou indeformada, assim como sob condições de campo.

Vārios pesquisadores têm desenvolvido métodos de campo a partir da equação de Richards com condições de contorno definidas. Estes métodos, entretanto, envolvem experimentos de campo um tanto trabalhosos e demorados. Um dos procedimentos de relativa facilidade de execução para a determinação da condutividade (K) como função da umidade $(\Theta)$ do solo, ou simplesmente função $K(\Theta)$, $\overrightarrow{~ o ~}$ apresentado por HILLEL et alii (1972), baseado na técnica do perfil instantâneo, definida sob condições de contorno que exigem que o perfil de solo após saturado tenha sua superfície coberta com uma capa de plástico para evitar evaporação e o movimento da água seja sempre vertical descendente. Utilizando estas mesmas condições de contorno, LIBARDI et alii (1980) desenvolveram métodos simples para a determinação da função $K(\Theta)$. Mais ou menos na mesma época, VAN GENUCHTEN et alii (1980) apresentam um método da determinação desta função a 
partir apenas da curva característica de retenção da água no solo. 0 objetivo do presente trabalho é apresentar um método novo de determinação da função $K(\Theta)$ a partir apenas dos dados da curva de retenção com fundamento teórico e que exige, para sua aplicação não mais que regressões lineares simples. 


\section{REVISÃO DE LITERATURA}

0 conhecimento do movimento da água no perfil de um solo é de fundamental importância para a resolução de problemas envolvendo irrigação, drenagem, armazenamento e transporte de ägua e nutrientes, bem como o controle da infiltração e escoamento superficial.

DARCY (1856), efetuando experiências de infiltração em colunas de areia, foi o primeiro a estabelecer uma equação que descrevesse o fluxo da água em meios porosos saturados.

A maioria dos solosem condições naturais, porém, se apresentam normalmente sob condiçōes de não saturação. Nessas condições, a ārea efetiva do fluxo fica reduzida e este se torna, portanto, dependente do conteūdo de āgua do solo. BUCKINGHAM (1907) foi o primeiro a considerar esses aspectos, mostrando a importância da umidade no movimento da água e estabeleceu a relação funcional entre a umidade e o potencial matricial da água no solo, conhecida como curva característica de retenção da āgua. Com isto, Buckingham estendeu a equação de Darcy para situações de não saturação, mostrando que, em solos não saturados, o fluxo de água também era proporcional a um gradiente de potencial hidráulico, mas que a constante de proporcionalidade era função da umidade do solo e o potencial hidráulico a soma do potencial gravitacional e potencial matricial. O caso em que o solo se encontra saturado (ex- 
periência de Darcy) é um caso particular no qual a constante de proporcionalidade tem seu valor máximo e o potencial matricial deixa de existir, atuando em seu lugar o potencial de pressão. Esta constante de proporcionalidade entre o fluxo e gradiente na equação de Darcy denomina-se condutividade hidräulica.

A equação de Darcy, entretanto, é válida apenas para fluxo em regime estacionário. Para condições transientes, há necessidade de se considerar a equação da continuidade que, combinada com a de Darcy, fornece a equação diferencial geral que rege o movimento da água no solo, conhecida como equação de Richards (RICHARDS, 1931).

O próprio RICHARDS (1931) foi o primeiro pesquisador a apresentar um método de determinação da condutividade hidráulica em condições de fluxo estacionário. Este autor utilizou uma pequena coluna de solo entre duas placas de cerâmica e manteve um gradiente de potencial constante entre elas por meio de colunas deägua. Quando o regime estacionário era atingido, a condutividade hidráulica era facilmente estimada por meio da equação de Darcy.

Depois do trabalho de RICHARDS (1931), muitos outros apareceram, os quais buscavam determinar a condutividade hidráulica em colunas de solo, como os de CHILDS \& COLLIS-GEORGE (1950), RICHARDS \& WEEKS (1953), GARDNER $(1956,1962)$, MILLER \& ELRICH (1958), KUNZE \& KIRKHAM (1962), DOERING (1965), JACKSON et alii. (1963), WATSON (1966), SWARTZENDRUBER (1966), LALIBERTE \& COREY (1967), VACHAUD (1967), REICHARDT et alii. (1975), ALEMI et alii. (1976), CAVÁCANTE et alii (1978), e outros que jä foram detalhadamente anallsados por LIBARDJ. (1978).

Também em parte analisados por LIBARDI (1978), mas que merecem ser aqui reanalisados e atualizados, são os métodos de 
campo de medida desta propriedade hidráulica dos solos.

Sob condições de campo, a metodologia que se tem utilizado é conhecida como 'método do"perfil instantâneo". Neste método, quando se integra a equação de Richards com relação à distância, obtém-se que a diferença entre os fluxos nas distâncias correspondentes aos limites de integração equivale à integral das variações de umidade, com o tempo, na camada de solo considerada. Se a variação da umidade do solo com a profundidade e com o tempo for conhecida, esta integral pode ser avaliada e se um dos fluxos for também. conhecido, o outro pode ser estimado. Por outro lado, se as variações do potencial hidráulico com o tempo e a distância também forem conhecidas, o gradiente de potencial para um dado tempoe posição também pode ser avaliado. Dividindo-se o fluxo num dado tempo e posição pelo gradiente de potencial no mesmo tempo e posição, obtém-se a condutividade hidráulica para a umidade encontrada naquela posição (LIBARDI, 1978).

Segundo KLUTE (1972), esta técnica do"perfil instantâneo"para a determinação da condutividade hidrāulica do solo em função da umidade,foi primeiramente utilizada, sob condiçōes de campo, por RICHARDS et aliij. (1956) que, após saturarem um perfil de so1o, permitiram que este sofresse evaporação e drenagem. A partir de medidas simultâneas do potencial matricial, medido através de tensiômetros instalados a diversas profundidades, e da umidade do solo medida gravimetricamente, esses autores estimaram o gradiente de potencial e o fluxo de drenagem (ou evaporação) procurando, ao longo do perfil, as posiçōes nas quais o fluxo se tornava nulo. "OGATA \& RICHARDS (1957) modificaram este procedimento cobrindo a superfície do solo com plástico, permitindo assim que apenas o fluxo de drenagem ocor- 
resse. NIELSEN et alii. (1964) introduziram, no procedimento de 0GATA \& RICHARDS (1957), a tëcnica da sonda de nêutrons para medida da umidade do solo. Esta técnica tem sido muito utilizada em condições de campo, podendo-se citar os trabalhos de ROSE et alii. (1965), HILLEL et alii. (1972), VAN BAVEL et alii. (1968), CHO et alii (1976,1977), REICHARDT \& LIBARDI (1974), GROHMANN et alii (1976), SAUNDERS et alii. (1978), LIBARDI et alii. (1980), PREVEDELLO et alii (1981), LOOXMORE et alii. (1981), destacando-se o trabalho de HILLEL et alii. (1972), pelo fato de apresentar um roteiro simples e completo do método do "perfil instantâneo" sob condições de campo.

A partir do método de HILLEL et alii. (1972), muitos pesquisadores se preocuparam em tornar ainda mais simples a metodologia de determinação da condutividade hidrāulica. Uma das simplificações do mëtodo do "perfil instantâneo" è a de se considerar o gradiente do potencial hidrâulico como sendo unitário, ou seja, a ägua drenaria quase que na mesma razão em todas as profundidades. BLACK et alii. (1969) foram os primeiros a introduzir esta hipótese com a finalidade de derivar uma equação de fluxo a uma dada profundidade do solo. A equação foi aplicada com sucesso para um soloarenoso e uniforme, em um lisímetro, na predição da variação do armazenamento da água. DAVIDSON et alii. (1969) aplicaram o mesmo raciocínio para diversos solos, variando o conteüdo de ägua e o potencial de pressão do perfil durante a drenagem. A concordância entre os valores de drenagem experimental e teórico foi muito boa nos solos uniformes, deixando a desejar, entretanto, nos solos onde ocorre desuniformidade do perfil.

Outros pesquisadores, tambëm considerando o gradien- 
te hidráulico como sendo unitário, obtiveram métodos simplificados de determinação da condutividade hidráulica em função da umidade do solo no campo. NIELSEN et alii. (1973) apresentaram um método simplificado que permite determinar a condutividade hidráulica durante o período de distribuição da água no perfil do solo e obtiveram resultados satisfatōrios. Uma limitação, entretanto, deste método è que a condutividade hidráulica é determinada somente dentro da faixa de umidade medida no campo durante o período de drenagem do solo após seu umedecimento. CHONG et alii (1981) expandiram o método de NIELSEN et alii. (1973), permitindo que a condutividade hidráulica fosse estimada para uma faixa de umidade maior do que a medida no campo. Para a obtenção desta extensão, os autores desenvolveram expressões matemáticas baseadas nas suposições de RICHARDS et alii. (1956) e GARDNER et alii. (1970) em que o teor de água e o potencial hidräulico no perfil do solo, durante o processo de distribuição, diminuem com o tempo de uma maneira exponencial. A aplicabilidade desse método foi testada em oxissolos do Havaii. Os autores verificaram que, para estes solos, o método proposto apresentou boa concordância quando comparado com outros métodos simplificados, como os de LIBARDI et alii (1980). A consideração de gradiente unitārio na determinação da condutividade hidráulica, também foi objeto de estudo por CHONG et alii (1981). Verificaram, para os solos estudados, que os valores do gradiente variaram de 0,3, para os períodos iniciais de drenagem, a 2,0 após vārios dias do início do período de drenagem. Comparando os valores da condutividade hidrāulica, calculados considerando os gradientes hidrāulicos iguais a 0,33 e 2,0, com os valores obtidos considerando o gradiente unitário, verificaram que o valor da condutividade hidráulica, quando se 
considera o gradiente como sendo unitário, é 1/3 do valor da condutividade hidrāulica obtida quando se considera o gradiente igual a 0,33 e duas vezes maior quando se considera o gradiente igual a 2,0. Os autores concluiram dizendo que, para medidas rotineiras em solos bem drenados, este método pode ser utilizado mesmo quando a suposição do gradiente unitário não seja plenamente satisfeita.

LIBARDI et alii (1980; considerando também o gradiente como sendo unitário e a condutividade hidráulica como sendo uma função exponencial da umidade, desenvolveram dois métodos simplificados, denominados: método da umidade e método do fluxo, onde apenas medjdas de umidade do solo ao longo do perfil, em função do tempo de distribuição, são necessārias para estimar a condutividade hidrāulica em função da umidade do solo.

SISSON et alii. (1980), combase no método de Lax(1972), citado por esses autores, obtiveram também dois métodos simplificados (método da armazenagem de Lax e método da umidade de Lax) para predizer a drenagem após a infiltração.

AHUJA et alii. (1980), preocupados em simplificar ao máximo a estimativa da condutividade hidráulica e da difusividade, apresentaram um modelo que, partindo de medidas do potencial matricial juntamente com uma determinação da umidade do so1o durante o período de drenagem, permite estimar estas propriedades hĩdricas.

Vários pesquisadores testaram esses métodos coma finalidade de verificar sua aplicabilidade. LUXMOORE et alii. (1981) compararam os métodos apresentados por LIBARDI et alii (1980) com o método de ROSE et alii (1965) em um bloco de solo de $2 \mathrm{~m}$ de largura, $2 \mathrm{~m}$ de comprimento e $3 \mathrm{~m}$ de profundidade, no qual foram instalaåos mi- 
cro-tensiômetros munidos de manômetros de āgua a vārias profundidades para a medida do potencial matricial e tubos de alumínio para acesso da sonda de nêutrons para a medida da umidade do solo. Esses pesquisadores verificaram que houve maiores diferenças na condutividade hidráulica entre repetições do que entre os próprios métodos e que o método do fluxo de LIBARDI et alii. (1980) foi o que apresentou resultados mais concordantes com o de ROSE et alii. (1965). SCHUH et alii (1984) compararam os métodos propostos por LIBARDI et alii (1980) e o método desenvolvido por AHUJA et alii. (1980) com a técnica do"perfil instantâneo"' em cinco locais diferentes com diferentes tipos de solo. Esses autores verificaram que o método de AHUJA et alii. (1980) apresentou bons resultados, tanto para solos arenosos como para solos argilosos, bem como para perfis estratificados, o mesmo não ocorrendo, entretanto, com os métodos de LIBARDI et alii. (1980) que apresentaram bons resultados somente em solos homogêneos. Os autores verificaram, também, que a estimativa do valor do $K_{0}$ (condutividade hidrāulica saturada) para o método de LIBARDI et alii (1980) foi frequentemente inadequada, sugerindo que esta medida seja feita no campo.

Uma avaliação dos métodos simplificados apresentados por LIBARDI et alii (1980) e SISSON et alii (1981) foi feita também por JONES \& WAGENET (1984) em um solo não salino de textura média. A comparação entre os métodos foi feita através da média e do desvio padrão dos parâmetros $\mathrm{K}_{0}$ e $\gamma$ pertinentes a cada método, determinados em 100 locais diferentes dentro de uma ārea de $5000 \mathrm{~m}^{2}$, às profundidades de $30 \mathrm{~cm}, 45 \mathrm{~cm}, 60 \mathrm{~cm}, 75 \mathrm{~cm}, 90 \mathrm{~cm}, 105 \mathrm{~cm}$ e $120 \mathrm{~cm}$. Através da anālise dos resultados, os autores apresentaram as seguintes conclusões: os valores médios de $k_{0}$ e $\gamma$ determinados pelo método de Lax, foram sempre meno- 
res do que os dos outros métodos; o valor médio de $\mathrm{K}_{0}$ obtido pelo método CGA, apresentado no trabalho de LIBARDI et alii (1980), foi sempre maior do que os dos outros métodos; o método da umidade de Libardi e o método da umidade de Lax foram equivalentes, e os valores da variância do parâmetro $\gamma$ abaixo da profundidade de $90 \mathrm{~cm}$, quando determinado pelo método da umidade de Libardi e pelo da umidade de Lax, e os valores da variância do parâmetro $\mathrm{K}_{0}$ abaixo de 105 cm, quando determinado pelo método da armazenagem de Lax, mostraramse extremamente grandes em comparação com os dos outros métodos e profundidades .

Por causa da dificuldade encontrada na medida da condutividade hidráulica, muitos pesquisadores têm procurado calculála a partir de outras propriedades do meio poroso, que são de mais fäcil determinação. Assim, pesquisadores como CHILDS \& COLLIS-GEORGE (1950), MARSHALL (1958), MLLLINGTON \& QUTRK (1959, 1960), MUALEM (1976), ANDERSON \& BOUMA (1973) desenvolveram equações matemáticas para calcular a condutividade hidráulica não saturada a partir da distribuição de tamanho de poros. Posteriormente, outros estudiosos do assunto tentaram aplicar. a essas equaçōes dados experimentais, sendo que NIELSEN et alii (1960) efetuaram comparações entre o método de CHILDS \& COLLIS-GEORGE (1950) e o de MARSHAL (1958), em quatro solos, mostrando que os resultados do primeiro foram me1hores do que os do segundo.

A textura do solo também tem sido utilizada para avaliar a condutividade hidráulica. PERSINGER \& YAHMER (1970) encontraram correlação positiva entre a taxa de percolação e o teor de areia do solo, enquanto que DERR et alii (1969) não encontraram correlação positiva com a fração areia, mas sim com a fração silte. JAYNES \& 
TYLER (1984), entretanto, encontraram correlações altamente significativas entre a condutividade hidráulica e a \% de areia, \% de silte, densidade global e porosidade do solo. Estes autores derivaram também uma equação de estimativa da condutividade hidráulica baseada no conteüdo de areia, que descreve $83 \%$ da variação dessa propriedade. Esta equação, porém, não foi adequada para solos de textura fina.

A curva caracteristica da água no solo também tem sido muito utilizada para a estimativa da condutividade hidráulica em função da umidade do solo, como ressaltam os trabalhos de GREEN \& COREY (1971), MARSHALL (1958), WIND (1966), MILLINGTON \& QUIRK (1959), CAMPBELL (1974), van Genuchten (1979), citado por DAlKE \& KRUSKA(1983), TALSMA (1985), entre outros.

CAMPBELL (1974) apresentou um método de determinação da condutividade hidrāulica não saturada a partir da curva de retenção. Os resultados obtidos, utilizando cinco solos de diferentes granulometrias foram tão bons quanto os calculados pelo método de MILLINGTON \& QUIRK (1959). Por sua vez, TALSMA (1985) testou a validade do método de CAMPBELL (1974) em laboratório, utilizando colunas de solo uniformemente preparadas, com cinco solos de texturas diversas, e no campo utilizando 9 solos, também de diferentes texturas. Para quatro solos, cujas determinações foram feitas no laboratório, houve boa concordância entre os dados obtidos experimentalmente e os calculados através das curvas de retenção. Um solo apenas, com predominância da fração areia fina, apresentou concordância razoável na faixa de altos teores de água. Das 9 determinações feitas no campo, apenas quatro apresentaram boa concordância entre os dados experimentais e os obtidos pelo modelo proposto por CAMPBELL (1974), dois apresentaram concordância razoável para altos teores de 
ảgua e três não apresentaram concordância. Estes três solos eram constituídos, predominantemente, da fração argila.

Destaca-se ultimamente o trabalho de VAN GENUCHTEN (1980), que apresenta uma forma analítica de determinação da condutividade hidräulica relativa $\left(\mathrm{K}_{\mathrm{K}}=\mathrm{K} / \mathrm{K}_{0}\right)$ atravēs dos modelos apresentados por BURDINE (1953) e MUALEM (1976), partindo do conhecimento da curva de retenção da água do solo. Através de um programa de otimização de funções não lineares pelo método dos quadrados mînimos, os parâmetros das equações propostas por este autor são estimados e utilizados para determinar a relação entre o potencial matricial e a umidade $\left[\psi_{\mathrm{m}}(\Theta)\right]$, e entre a condutividade hidrāulica e a umidade $[\mathrm{K}(\Theta)]$ ou a condutividade hidráụlica e o potencial matricial $\left[\mathrm{K}\left(\psi_{\mathrm{m}}\right)\right]$. Convém ressaltar, entretanto, que a utilização da técnica de otimização de funções não lineares pelo método dos quadrados mînimos exige que seja dado um valor inicial aos parâmetros para a obtenção do ajuste final. A magnitude do valor inicial dado a esses parâmetros e o número de îterações, leva à obtenção de diferentes valores finais destes parâmetros, que poderão influir na obtenção das relações $\psi_{\mathrm{m}}(\Theta)$, $\mathrm{K}(\Theta)$ ou $\mathrm{K}\left(\psi_{\mathrm{m}}\right)$.

DANE \& KRUSKA (1983) fizeram um estudo da influência dos parâmetros a e n, que aparecemnas equações de VAN GENUCHTEN (1980) na determinação das relações $\psi_{m}(\Theta)$ e $K(\Theta)$ em um solo hipotético e em um solo de textura média através da técnica de superfície de resposta (HIcks, 1964 , citado por DANE \& KRUSKA, 1983), onde se procura obter o minimo de superfície de resposta para diferentes combinações de $\alpha$ e n. Comparando as curvas $\psi_{\mathrm{m}}(\Theta)$ e $\mathrm{K}(\Theta)$, obtidas através dos parâmetros a e n estimados,que levaram à obtenção do menor e maior valor de superfície de resposta, com os valores verdadeiros, os autores verificaram, para 
o solo hipotético, uma boa concordância entre os dados medidos e os estimados. Observaram, entretanto, que as curvas $\psi_{m}(\Theta)$ são mais sensíveis às mudanças desses parâmetros do que as curvas $K(\Theta)$. Para o solo de textura média, porém, os dados medidos e estimados das curvas $\psi_{\mathrm{m}}(\Theta)$ apresentaram um bom ajuste e os das curvas $K(\Theta)$, entretanto, apresentaram diferenças de uma ordemde grandeza. Esta diferença, segundo os autores, foi atribuída a uma superestimativa da condutividade hidráulica saturada que foi assumida como sendo a taxa de infiltração final durante a inundação.

STEPHENS \& REHFERDT (1.985) também fizeram um estudo para verificar a influência dos parâmetros das equações de VAN GENUCHTEN (1980) na determinação da condutividade hidráulica. Através da regressão não linear pelo método dos quadrados mínimos, eles estudaram: a influência dos parâmetros $\Theta_{r}$ (umidade residual, ou seja, umidade equivalente ao ponto de murchamento permanente) e do parâmetro $\Theta_{\mathrm{S}}$ (umidade de saturação), o efeito do nümero de pontos experimentais da curva de retenção e a convergência de $\alpha$, n e $\Theta_{r}$ a partir de diferentes valores iniciais nas curvas $\psi_{\mathrm{m}}(\Theta)$ e $\mathrm{K}_{\mathrm{r}}\left(\psi_{\mathrm{m}}\right)$. Com relação ao parâmetro $\Theta_{r}$, os autores verificaram que diferentes valores desses parâmetros $(0,01 ; 0,03 ; 0,05$ e 0,1$)$ levaramà obtenção de diferentes ajustes das curvas $\psi_{m}(\Theta)$, e que o melhor ajuste foi obtido quando o valor de $\theta_{\mathrm{r}}$ variou entre 0,05 e 0,1 . As curvas $\mathrm{K}_{\mathrm{r}}\left(\psi_{\mathrm{m}}\right)$, obtidas através das curvas $\psi_{\mathrm{m}}(\Theta)$ ajustadas para os diferentes valores de $\Theta_{\mathrm{r}}$, mostraram diferenças menores do que $50 \%$ apenas para tensões menoreș do que $50 \mathrm{~cm}$ de coluna de água. Para uma tensão de $100 \mathrm{~cm}$ de coluna de āgua, por exemplo, a condutividade hidräulica relativa apresentou variações ao redor de duas ordens de grandeza. A inclinação das curvas $K_{x}\left(\psi_{m}\right)$ diminuiu com a diminuição do valor de $\theta_{r}$. Como 
ressaltam os autores, a inclinação da curva $\mathrm{K}_{\mathrm{r}}\left(\psi_{\mathrm{m}}\right)$ depende,quase que exclusivamente, do parâmetro n que é obtido pelo ajuste dos dados experimentais da curva $\psi_{\mathfrak{m}}(\Theta)$, parâmetro este que tem maior peso no ajuste destes dados e, consequentemente, na curva $\mathrm{K}_{\mathrm{r}}\left(\psi_{\mathrm{m}}\right)$. Um aumento no valor de $\Theta_{\mathrm{r}}$ provoca um grande aumento no valor estimado de $\mathrm{n}$, enquanto que o parâmetro $\alpha$ sofre um aumento relativamente menor.Com relação ao parâmetro $\Theta_{S}$, os autores verificaram que as curvas $\psi_{m}(\Theta)$ obtidas para diferentes valores de $\Theta_{\mathrm{s}}\left(0,332 ; 0,362 \mathrm{e} 0,402 \mathrm{~cm}^{3}\right.$. $\mathrm{cm}^{-3}$ ) são muito semelhantes para valores de umidade menores do que $0,300 \mathrm{~cm}^{3} \cdot \mathrm{cm}^{-3}$, apresentando diferenças considerāveis, entretanto, para valores maiores do que $0,300 \mathrm{~cm}^{3} \cdot \mathrm{cm}^{-3}$. As curvas $\mathrm{K}_{\mathrm{r}}\left(\psi_{\mathrm{m}}\right)$, obtidas a partir dessas curvas, apresentam diferenças maiores do que uma ordem de grandeza para tensões maiores do que $90 \mathrm{~cm}$ de tensão. Isto sugere que mudanças nos valores de $\Theta_{\mathrm{S}}$ provocam mudanças maiores na região mais seca das curvas $\mathrm{K}_{\mathrm{r}}\left(\psi_{\mathrm{m}}\right)$, embora nesta região não tenha havido diferença no ajuste dos dados da curva $\psi_{m}(\Theta)$. Como no caso do parâmetro $\Theta_{r}$, o parâmetro $\Theta_{S}$ também influi indiretamente nas curvas $\mathrm{K}_{\mathrm{r}}\left(\psi_{\mathrm{m}}\right)$, pois um aumento nos valores de $\Theta_{\mathrm{s}}$ provoca uma maior diminuição dos valores do parâmetro $n$ do que de $\alpha$ no ajuste das curvas $\psi_{m}(\Theta)$. Com relação ao efeito do nümero de pontos experimentais no ajuste das curvas $\psi_{\mathrm{m}}(\Theta)$ e, consequentemente, no ajuste das curvas $\mathrm{K}_{\mathrm{r}}\left(\psi_{\mathrm{m}}\right)$, os autores verificaram que a diminuição do número de pontos de 9 para 7, eliminando os pontos correspondentes às tensões maiores (109 e $150 \mathrm{~cm}$ de coluna de água), levou à obtenção de um bom ajuste das curvas $\psi_{\mathrm{m}}(\Theta)$ para baixas tensões. Para altas tensões, entretanto, o ajuste não foi perfeito, verificando-se inclusive que o valor de $\Theta_{\mathrm{r}}$ aproximou-se do valor zero com a diminuição do nümero de pontos, distanciando-se consideravelmente do valor real. Em 
consequência disto, houve uma superestimativa dos valores da condutividade hidrāulica relativa nesta região mais seca da curva de retenção, embora os valores de umidade tenham sido subestimados.

No mesmo trabalho, STEPHENS \& REHFELDT (1985)fizeram também uma comparação da condutividade hidräulica relativa $\left(\mathrm{K}_{\mathrm{r}}\right)$ calculada pelos métodos apresentados por VAN GENUCHTEN (1980) derivados dos modelos apresentados por MUALEM (1976) e BURDINE (1953). As diferenças entre os valores de $\mathrm{K}_{\mathrm{r}}$ calculados pelos dois métodos obtidos por estes modelos foram pequenas, com tendência a aumentar com a diminuição da umidade. Para uma tensão de $125 \mathrm{~cm} \mathrm{H}_{2} \mathrm{O}$, por exemplo, o valor de $\mathrm{K}_{\mathrm{r}}$ calculado pelo modelo derivado do de Mualem é cerca de três vezes maior do que o valor calculado pelo modelo derivado do de Burdine. Comparando os valores de $\mathrm{K}_{\mathrm{r}}$ estimados por estes modelos com os obtidos pelo método do "perfil instantâneo", observou-se uma superestimativa dos valores de $\mathrm{K}_{\mathrm{r}}$ obtidos por estes modelos para tensões maiores do que $80 \mathrm{~cm}$ de tensão, devido, segundo os autores, à baixa estimativa dos valores do parâmetro $\Theta_{\mathrm{r}}$. Portanto, embora um bom ajuste dos dados da curva $\psi_{m}(\theta)$ possa ser obtido, isto não garante uma boa estimativa das curvas $\mathrm{K}_{\mathrm{r}}\left(\psi_{\mathrm{m}}\right)$, principalmente na faixa de umidade em condições de campo.

Com o intuito de facilitar o ajuste da curva $\psi_{\mathrm{m}}(\Theta)$ às equações de VAN GENUCHTEN (1980), SIRIDOROPOULOS \& YANNOPOULOS (1984) apresentaram um algoritmo que permite estimar, com maior precisão,os parâmetros destas equações para estimativa da função condutividade. Os valores dos parâmetros estimados por este algoritmo são usados como valores iniciais para o ajuste das equações através da otimização de funções não lineares pelo método dos quadrados mínimos, diminuindo assim o número de iterações necessārias para a 
obtenção do ajuste final dos parâmetros das equações.

DANE (1980), comparando os métodos propostos por VAN GENUCHTEN (1980) com os de LIBARDI et alii (1980) em solo arenoso, obtiveram boa concordância entre os métodos. 0 autor ressaltou tambémque os métodos de LIBARDI et alii (1980) podem ser preferidos quando se deseja apenas a relação condutividade hidráulica em função da umidade, por $\vec{m}$, se o interesse for saber ambas as relações $\psi_{m}(\Theta)$ e $K(\Theta)$, o método de VAN GENUCHTEN (1980) deve ser o escolhido.

Em trabalho semelhante ao de DANE (1980), FIELD et alii. (1984) também compararam o método proposto por VAN GENUCHTEN (1980) com os modelos propostos por JACKSON (1972). Verificaram que esses modelos apresentaram bons resultados quando foram utilizados os dados de retenção de ägua obtidos no campo, o mesmo não acontecendo quando foram utilizadas as curvas características da água do solo obtida no laboratório, refletindo a dificuldade de se obter amostras de solo não perturbadas representativas.

Mais recentemente, VAN GENUCHTEN e NIELSEN (1985) fizeram uma revisão dos modelos mais utilizados para o ajuste dos dados experimentais das curvas de retenção, visando a determinação mais precisa da condutividade hidráulica do solo. Esses autores verificaram que o modelo de determinação da condutividade hidráulica relativa através da curva de retenção apresentado por VAN GENUCHTEN et alii (1980), derivado do modelo apresentado por MUALEM (1976), foi o que apresentou a maior validade para a maioriados solos analisados (95\% dos casos). Verificaram também que para o modelo derivado do de Mualem, o valor do parâmetro n das equações deve estar entre 1 e 2 e para o modelo derivado do de BURDINE deve ser sempre maior que 2. Valores de $n$ menores do que 1 , entre- 
tanto, levam a uma situação fisicamente irreal, pois, neste caso, a inclinação do ajuste da curva de retenção perto da saturação tende para o infinito. Esta situação foi verificada em apenas $5 \%$ dos casos quando se utilizou o método de VAN GENUCHTÉn et alii (1980) derivado do modelo de MUAJEM (1976).

Esta revisão mostra, portanto, que a tendência atual devido, principalmente, ao problema da variabilidade espacial de propriedades do solo, entre elas a condutividade hidráulica, parece estar voltada para métodos que sejam de fácil determinação, e que reflitam as condições de campo sem, entretanto, haver necessidade de que a determinação seja feita diretamente no campo. Nesse sentido, uma condutividade relativa, de fácil determinação, reveste-se de importância indiscutível para a aplicação da técnica das variáveis regionalizadas (NIELSEN et alii, 1983; VIEIRA et alii, 1983), um dos assuntos mais atuais na ciência do solo. 
3. BASE TEÓRICA PARA A HIPÓTESE FORMULADA

Com o intuito de se poder obter a condutividade hidrāulica dos solos, especificamente uma condutividade hidráulica relativa (relação entre a condutividade numa dada umidade e aquela de saturação), assumiu-se, no presente trabalho, que:

1) A condutividade varia de maneira exponencial com a umidade, segundo a equação:

$K(\Theta)=K_{0} e^{\gamma\left(\Theta-\Theta_{0}\right)}$

onde $K_{0}$ e $\Theta_{0}$ representam valores de $K$ e $\Theta$ na condição de solo saturado.

2) A difusividade da água no solo tambēm apresenta uma relação exponencial com a umidade do solo, isto é:

$D(\Theta)=D_{0} e^{\alpha\left(\Theta-\Theta_{0}\right)}$

onde igualmente, $D_{0}$ e $\Theta_{0}$ representam valores de $D$ e $\Theta$ na condição de solo saturado.

Sabe-se que, para uma dada camada de solo homogêneo, a difusividade se relaciona com a condutividade segundo a expressão: 
$D(\theta)=K(\theta) \frac{d \psi_{m}}{d \theta}$

onde $\psi_{\mathrm{m}}$ representa o potencial matricial à umidade $\Theta$ e $\mathrm{d} \psi_{\mathrm{m}} / \mathrm{d} \Theta$, a tangente à curva $\psi_{m}$ versus $\Theta$. (curva característica de retenção de ägua no solo).

Rearranjando a eq. (3) e nela substituindo as suposições (1) e (2), obtém-se:

$$
\frac{d \psi_{m}}{d \Theta}=\frac{D_{0}}{K_{0}} e^{(\alpha-\gamma)\left(\Theta-\Theta_{0}\right)}
$$

A integração da eq. (4) de $\psi_{\mathrm{m}}=\psi_{\mathrm{m}}$ a $\psi_{\mathrm{m}}=0$ e de $\theta=$ $\Theta$ e $\Theta=\Theta_{0}$ resulta numa equação para a curva de retenção que tem a seguinte forma:

$$
\psi_{m}=A\left[e^{B\left(\Theta-\Theta_{0}\right)}-1\right]
$$

onde

$$
A=\frac{D_{0}}{K_{0}(\alpha-\gamma)}
$$

e

$$
B=\alpha-\gamma
$$

A hipötese fundamental do presente trabalho é a de que, se a eq. (5) representa adequadamente os dados experimentais, o conhecimento de uma relação entre $\alpha$ e $\gamma$ permitiria obter diretamente, a partir apenas da curva característica, o valor da condutividade hidráulica relativa para as diversas umidades do solo. 
Nesse sentido, o que se tem que obter são os valores de $\alpha$ e $\gamma$ e daî a relação entre ambos.

A partir do ajuste da eq. (5) aos dados experimentais, o que se obtém é o valor de $\alpha-\gamma$ (valor B da eq. 5). Para comprovar a hipötese de trabalho hä necessidade de se obter o valor de um deles ( $\alpha$ ou $\gamma$ ) por um outro método e então investigar a existência de uma dada relação entre ambos. Para tanto, será obtido o valor de $\gamma$ pelo método da umidade de LIBARDI et alii (1980), resumidamente descrito no item 4.4.2.

Com a finalidade de tornaro método que se propõe o mais simples possĩvel, o cálculo do parâmetro B da eq. (5) será feito atravēs da regressão linear entre $1 n \psi_{\mathrm{m}}$ versus $\Theta$, desprezando o número 1 que aparece na equação. Desse modo, o parâmetro B é automaticamente o valor do coeficiente angular da curva $\ln \psi_{\mathrm{m}}$ versus $\theta$. Esta simplificação da eq. (5), para facilitar a obtenção de $B$, fundamenta-se no fato de que tal equação, paravalores relativamente baixos de umidade, possui de fato um comportamento linear e o número 1 nela presente pode ser desprezado face ao alto valor do fator $e^{B\left(\Theta-\Theta_{0}\right)}$, uma vez que o valor $B$ é sempre um número negativo.

Conhecendomse, portanto, o parâmetro B da maneira acima descrita, e $\gamma$ pelo método de LIBARDI et alii (1980), obtém-se facilmente $\alpha$ pela soma de $B$ com $\gamma$ e, consequentemente, a relação entre $\alpha$ e $\gamma$. 
4. MATERIAL E METODO

\subsection{Descrição geral da área}

\subsubsection{Local}

o experimento foi conduzido, sob condições de campo, na ārea experimental do Departamento de Física e Meteorologiada Escola Superior de Agricultura "Luiz de Queiroz", em Piracicaba, SP, cujas coordenadas geogräficas são $20^{\circ} 42^{\prime} 30^{\prime \prime}$ de latitude sul, $47^{\circ} 38^{\prime}$ 00" de longitude oeste, a $580 \mathrm{~m}$ de altitude. As āreas pontilhadas da Figura 1 mostram o local onde foi instalado o presente experimento, sendo a ärea A a que recebeu tratamento de subsolagem, e a ārea B apenas o convencional.

\subsubsection{Clima}

Dados meteorológicos coletados na Estação Meteorológica instalada próxima ao experimento, pertencente ao Departamento de Física e Meteorologia da ESALQ/USP (Figura 1) mostram, em termos médios anuais, que a precipitação pluvial é de $1247,1 \mathrm{~mm}$, ocorrendo, a maior parte, no verão (de novembro a fevereiro), principalmente como chuvas de alta intensidade e curta duração; a temperatura do ar é de $20,8^{\circ} \mathrm{C}$, sendo a mínima da ordem de $10^{\circ} \mathrm{C}$ em julho, e a máxima da ordem de $30^{\circ} \mathrm{C}$ em janeiro; a umidade relativa do ar 


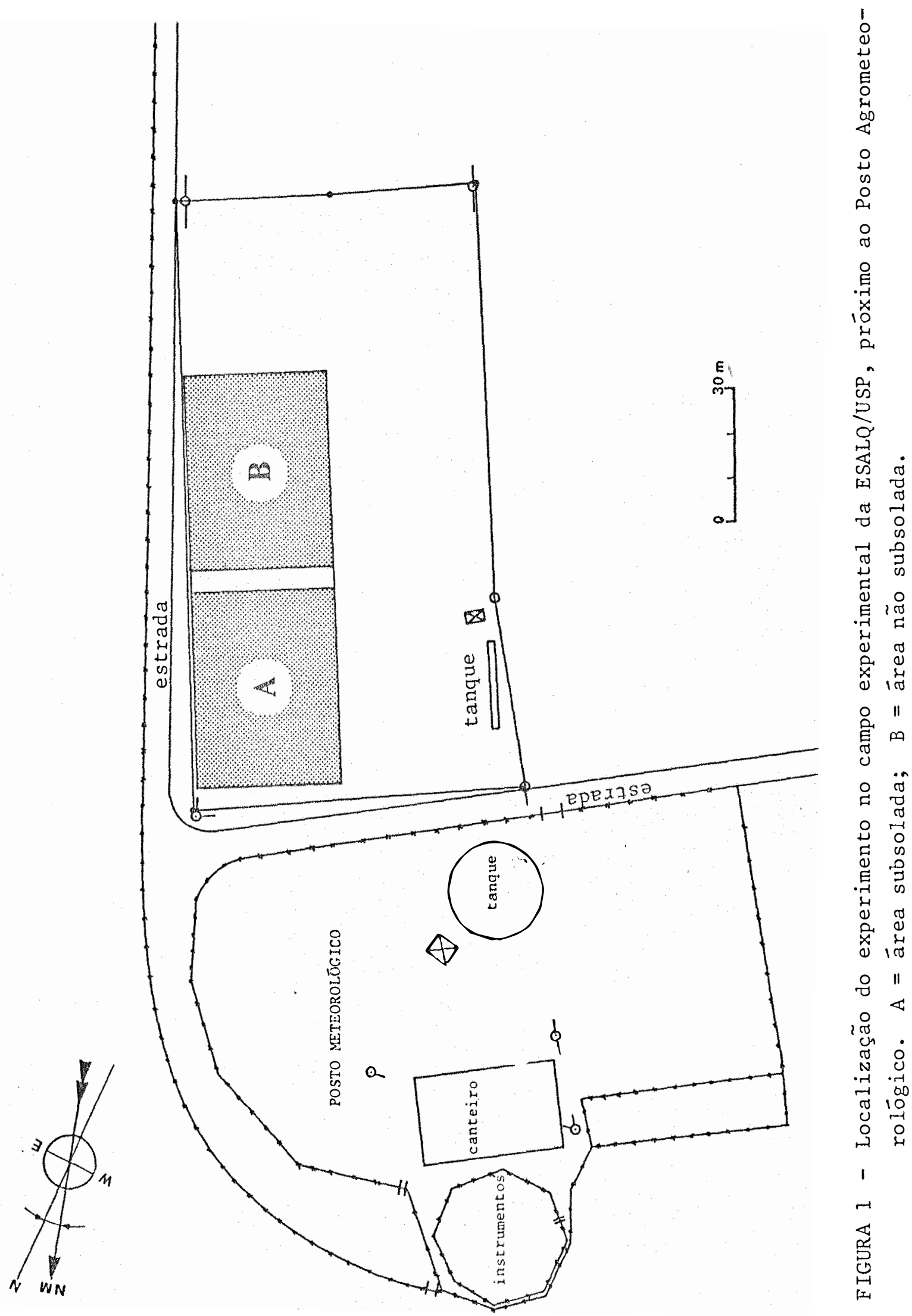


é de 69\%; a velocidade do vento é de $2,5 \mathrm{~m} \cdot \mathrm{seg}^{-1}$ e o período de brilho solar é de $6 \mathrm{~h} \cdot \mathrm{dia}^{-1}$ (CERVELLINI et alii, 1973).

o clima da região é do tipo mesotérmico Cwa, pela classificação climātica de Koppen, ou seja, subtropical úmido, com estiagem no inverno, com temperatura média do mês mais frio superior a $18^{\circ} \mathrm{C}$ e a do mês mais quente superior a $22^{\circ} \mathrm{C}$, tambēm denominado de tropical de altitude por CAMARGO et alii (1974).

\subsubsection{Solo}

0 solo no qual foi instalado o experimento foi descrito e classificado por RANZANI et alii (1966) como uma Terra Roxa Estruturada série "Luiz de Queiroz", e pela classificação americana (U.S.D.A., 1975) como um Paleudalf óxico.

A Terra Roxa Estruturada apresenta como material de origem rochas eruptivas bāsicas e cobre aproximadamente $10 \%$ da ārea do Estado de São Paulo. Apresenta, tambēm, um perfil homogêneo e muito profundo, com o lençol freático a vários metros abaixo da superfície.

Este mesmo tipo de solo, mas de outro local,apresenta, segundo Moniz \& Jackson (1967), citados por LIBARDI (1984), do ponto de vista mineråógico: $15,3 \%$ de óxidos de ferro; $48 \%$ de cao1inita; $10,7 \%$ de mica + vermiculita; 4,3\% de gibsita e $31,7 \%$ de material amorfo.

A caracterização morfológica deste solo, descrito em trincheira aberta na ārea não subsolada, apresenta:

$\mathrm{Ap}_{1} 0-7 \mathrm{~cm}$, vermelho acinzentado (10R4/2, úmido); argila; estrutura modificada pelo uso agrícola, composta por blocos 
compactados de tamanho variável; muito firme, plästico e pegajoso; carvões pequenos esparsos; transição gradual/difusa, plana.

$\mathrm{Ap}_{2}$ 7-18 cm; bruno-avermelhado (2,5 YR 4/4, úmido); muito argiloso; estrutura modificada pelo uso agrícola composta por blocos compactados de tamanho variável; muito firme, 'muito plástico e muito pegajoso; carvões pequenos esparsos; transição gradual/difusa, plana.

$\mathrm{Ap}_{3} 18-27 \mathrm{~cm}$; vermelho-acinzentado ( $10 \mathrm{R} \mathrm{4/3,} \mathrm{úmilo);} \mathrm{muito} \mathrm{argiloso;}$ estrutura modificada pelo uso agrícola composta por blocos compactados de tamanho variävel; muito firme, muito plástico e muito pegajoso; carvões pequenos esparsos; transição gradual/difusa, plana.

Bt $27-45 \mathrm{~cm}$; vermelho-acinzentado (10R 4/3, úmido); muito argiloso; forte, pequeno a médio, blocos subangulares; cerosidade moderada a forte, abundante; muito firme, muito plástico e muj.to pegajoso; carvões pequenos esparsos; transição gradual/difusa, plana.

$\mathrm{Bt}_{2}$ 45-68 cm; vermelho-acinzentado (1.0R 4/4, úmido); muito argiloso; forte; pequeno a médio, blocos subangulares; cerosidade forte e abundante; muito firme, muito plástico e muito pegajoso; transição gradual/difusa, ondulada. $\mathrm{Bt}_{3} 68-105 \mathrm{~cm}$; vermelho-escuro-acinzentado (10R 3/4, úmido); muito argiloso; moderado, pequeno, blocos subangulares/granular; cerosidade fraca e pouca; firme, muito plástico e muito pegajoso; transição gradual/difusa, ondulada. 
$\mathrm{Bw}_{1}$ 105-160 cm; vermelho-escuro (10R 3/6, ümido); muito argiloso; macro-estrutura maciça, muito porosa, quebrando-se facilmente com o contato das mãos ou martelo; micro-estrutura forte, pequena a muito pequena, granular; friāvel, muito plástico e muito pegajoso; transição clara e plana.

$\mathrm{Bw}_{2}$ 160-200 $\mathrm{cm}^{+}$; vermelho-escuro (10R 3/6, ümido); muito argiloso; macro estrutura maciça, muito porosa; micro-estrutura forte muito pequena, granular; muito friāvel, muito plástico e muito pegajoso; transição clara e. plana.

Observações.

1) Os horizontes $A p_{1},{A p_{2}}_{2}$ e $A p_{3}$ apresentam apenas variações quanto $\bar{a} \operatorname{cor}$.

2) Raízes: muitas, médias e finas no Ap; comuns e finas no $\mathrm{Bt}_{1}$; raras e muito finas nos demais horizontes.

3) Porosidade: são encontrados poros muito pequenos, comuns nos horizontes Ap e Bt e poros pequenos médios, abundantes nos demais horizontes.

Para a caracterização física e química do solo, foram abertas, antes da instalação do experimento, duas trincheiras, uma na ārea subsolada e a outra na ārea não subsolada, de onde foram retiradas amostras com estrutura deformada e indeformada das profundidades de $15 \mathrm{~cm}, 30 \mathrm{~cm}, 45 \mathrm{~cm}, 60 \mathrm{~cm}, 75 \mathrm{~cm}, 90 \mathrm{~cm}, 105 \mathrm{~cm}, 150 \mathrm{~cm}$ e $195 \mathrm{~cm}$.

Em cada profundidade, foram feitas as seguintes determinaçöes:

a) densidade global pelo método do anel volumétrico, utilizando ci- 
lindros de alumínio de aproximadamente $50 \mathrm{~cm}^{3}$, com uma das bordas cortantes (KIEHL, 1979).

b) densidade das partículas pelo método do picnômetro com água (KIEHL, 1979).

c) anālise granulométrica pelo método da pipeta, segundo procedimento desenvolvido por PAULETTO (1978). A distribuição das partículas foi feita de acordo corl o sistema do Departamento de Agricultura dos Estados Unidos da América do Norte (BRADY, 1979) e a classificação textural segundo LEMOS \& SANTOS (1982) .

d) análise química feita no laboratório de rotina do Departamento de Solos, Geologia e Fertilizantes da ESALQ/USP, seguindo métodos analiticos descritos por CATANI \& JACINTHO (1974).

As Tabelas 1 e 2 mostram os resultados das análises destas características físicas e químicas do solo no perfil, respectivamente. 


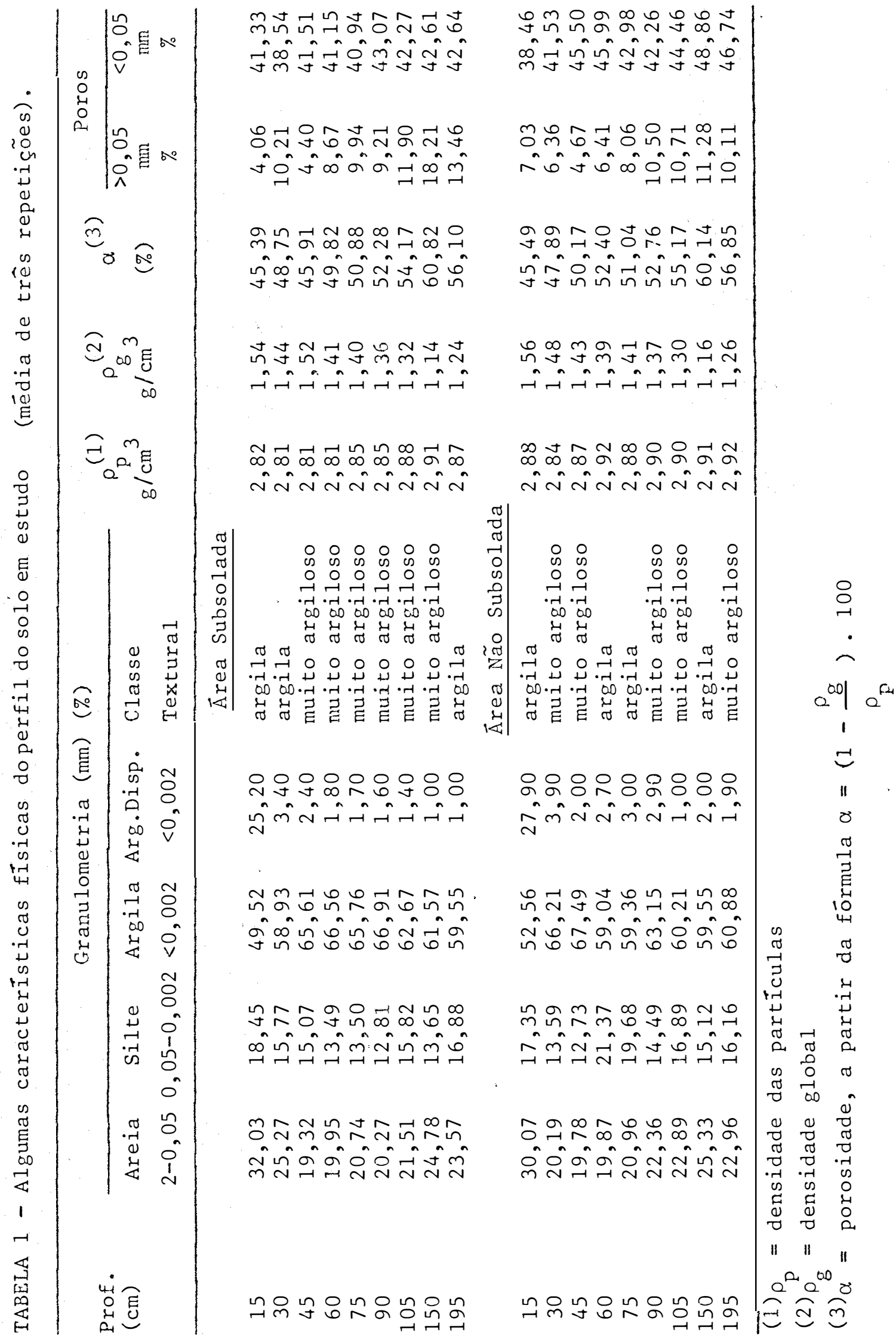




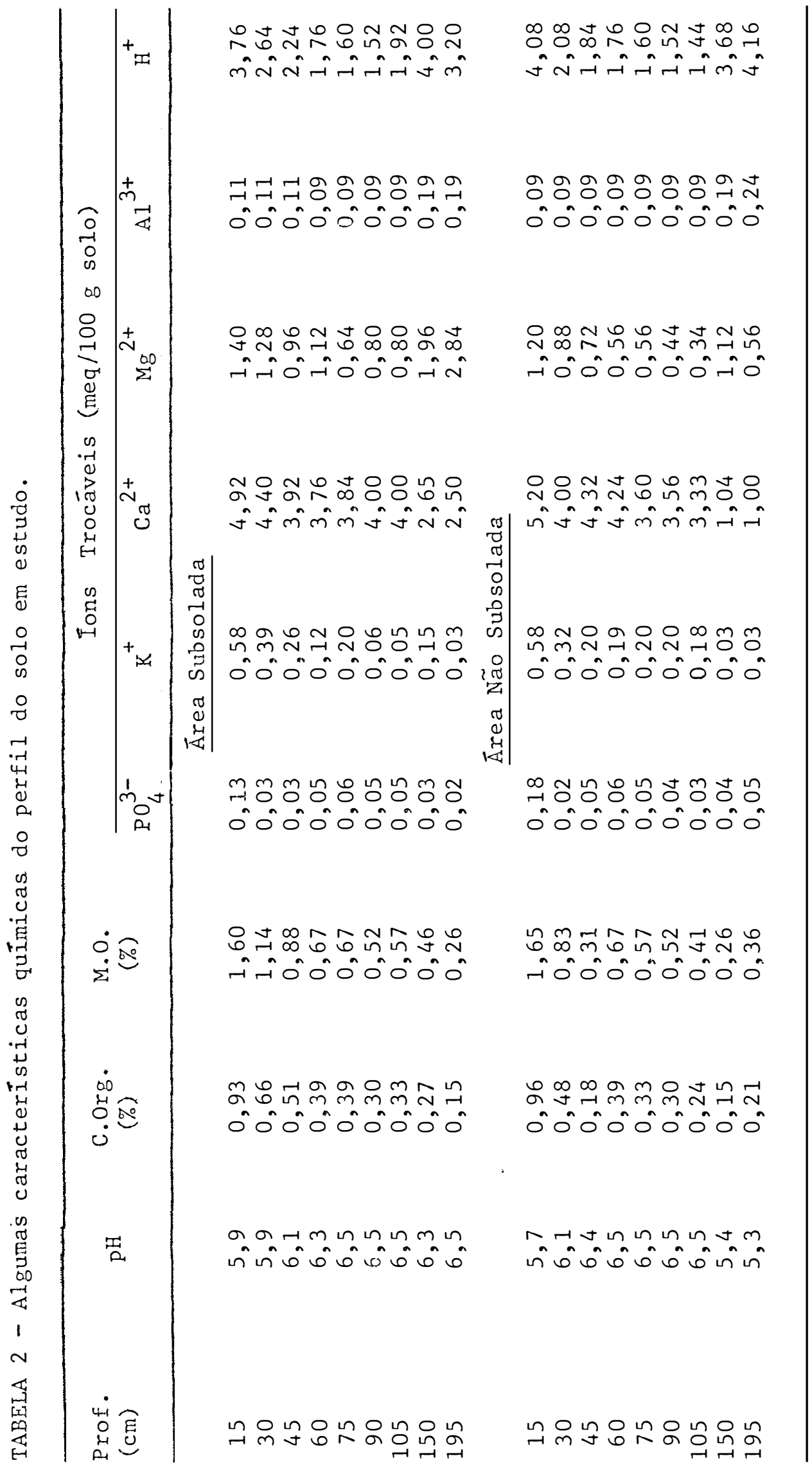




\subsection{Delineamento experimental.}

0 experimento foi instalado em duas áreas contíguas de $33 \times 44 \mathrm{~m}$, sendo que uma delas, além das prāticas normais de preparo do solo, foi antes subsolada.

A subsolagem foi feita em 07/12/83, com arado subsolador de duas hastes, distanciadas $35 \mathrm{~cm}$ entre si, tendo $60 \mathrm{~cm}$ de comprimento. 0 arado subsolador foi regulado para garantir uma subsolagem de $50 \mathrm{~cm}$ de profundidade, tendo sido feitas duas passadas no sentido do declive e duas no sentido perpendicular ao declive. A seguir, toda a ārea experimental, inclusive a ārea subsolada, recebeu uma aração e uma gradagem, uma semana antes da semeadura. Na vêspera da semeadura, entretanto, foi passada a enxada rotativa para garantir melhor uniformidade do terreno e melhor emergência das plantas. A cultura implantada foi o milho (Zea mays L.), cultivar AGROCERES 401, cuja semeadura foi feita no dia 07/02/84.

\subsection{Curvas de retenção da água no solo.}

As curvas de retenção de āgua no solo foram elaboradas por secamento, em amostras de solo com estrutura indeformada. As amostras foram retiradas de trincheiras abertas nas āreas subsolada e. não subsolada, com auxílio de um cilindro de volume conhecido, no dia 10 de janeiro de 1984,31 dias após a subsolagem. O cilindro era introduzido no solo por simples pressão, numa das faces do perfil. Oconjunto solo-cilindro com excesso de solo era retirado com auxílio de 
uma faca, envolto em papel-alumínio e levado ao laboratório. No laboratório, as amostras eram aparadas e na extremidade não cortante do cilindro colavirse um lenço de papel, para evitar possiveis perdas de terra e garantir um bom contato das amostras com a placa porosa dos aparelhos de medida de pressão. As amostras de solo assim preparadas, eram colocadas em cima da placa porosa e o conjunto saturado por um período de 24 horas. Este procedimento se repetiu sempre que era estabelecido o equilíbrio entre a água retida na amostra e a tensão aplicada, tendo-se o cuidado, entretanto, de antes, pesar a amostra. 0 fenômeno de histerese não foi considerado.

A água das amostras foi submetida às tensões de : $1 \mathrm{~cm}$, $10 \mathrm{~cm}, 60 \mathrm{~cm}, 102 \mathrm{~cm}, 340 \mathrm{~cm}, 1020 \mathrm{~cm}, 3060 \mathrm{~cm}, 50100 \mathrm{~cm}$ e $15300 \mathrm{~cm}$ de coluna de água. Para as tensões de 1,10 e $60 \mathrm{~cm}$ de coluna de água foram utilizados funis de placa porosa (Funil de Buchner), de média porosidade, da Schott Mainz, Jena Er Glass, e para as demais tensões, câmaras de pressão de Richards, da Soil Moisture Equipment Co.

\subsection{Condutividade hidräulica do solo}

A determinação da condutividade hidráulica das diversas camadas do solo foi feita atravẻs do método da umidade de LIBARDI et alii (1980), com algumas modificações, as quais serão mostradas a seguir. Esta determinação foi feita logo após a colheita da cultura de milho $(11 / 06 / 84)$.

Para obtenção das condições de contorno exigidas pe1o método, selecionaran-se seis parcelas de $2,5 \times 5,0 \mathrm{~m}$, 
3 na ārea subsolada e 3 na não subsolada (Figura 2). As parcelas foram confinadas com uma estrutura de madeira. As pequenas trincheiras que aparecem a $3 \mathrm{~m}$ de cada parcela foram abertas até uma profundidade de $1 \mathrm{~m}$, a fim de que as capas plásticas a serem utilizadas para cobrir as parcelas fossem enterradas até essa profundidade. Essa capa plástica foi utilizada para evitar que uma possïvel chuva durante o experimento de determinação da condutividade hidrāulica pudesse penetrar na parcela, visto que o terreno apresenta uma declividade de $6 \%$ aproximadamente no sentido sudoeste nordeste (Figura 1). No interior de cada uma das parcelas foram instalados 9 tensiômetros, às profundidades de $15 \mathrm{~cm}, 30 \mathrm{~cm}, 45 \mathrm{~cm}, 60$ $\mathrm{cm}, 75 \mathrm{~cm}, 90 \mathrm{~cm}, 105 \mathrm{~cm}, 150 \mathrm{~cm} \mathrm{e} 195 \mathrm{~cm}$, distribuídos conforme o esquema da Figura 3.

Os tensiômetros, em cada parcela, foram instalados em linha e distanciados de $20 \mathrm{~cm}$. Para facilidade de leitura, os manômetros de mercürio dos tensiômetros foram colocados numa estrutura ünica de madeira.

Esses equipamentos, cujos detalhes são descritos a seguir, foram construídos na Seção de Física de Solos do CENA/USP.

\subsubsection{Tensiômetros}

Todo o material utilizado para a construção dos tensiômetros utilizados no experimento foi adquirido da indústria nacional. Os materiais são os seguintes: tubo de PVC rígido, com diâmetro externo e interno de $21 \mathrm{~mm}$ e $15 \mathrm{~mm}$, respectivamente, e de comprimento variável de acordo com a profundidade de instalação; câpsulas porosas de $5 \mathrm{~cm}$ de comprimento e diâmetro externo igual ao 


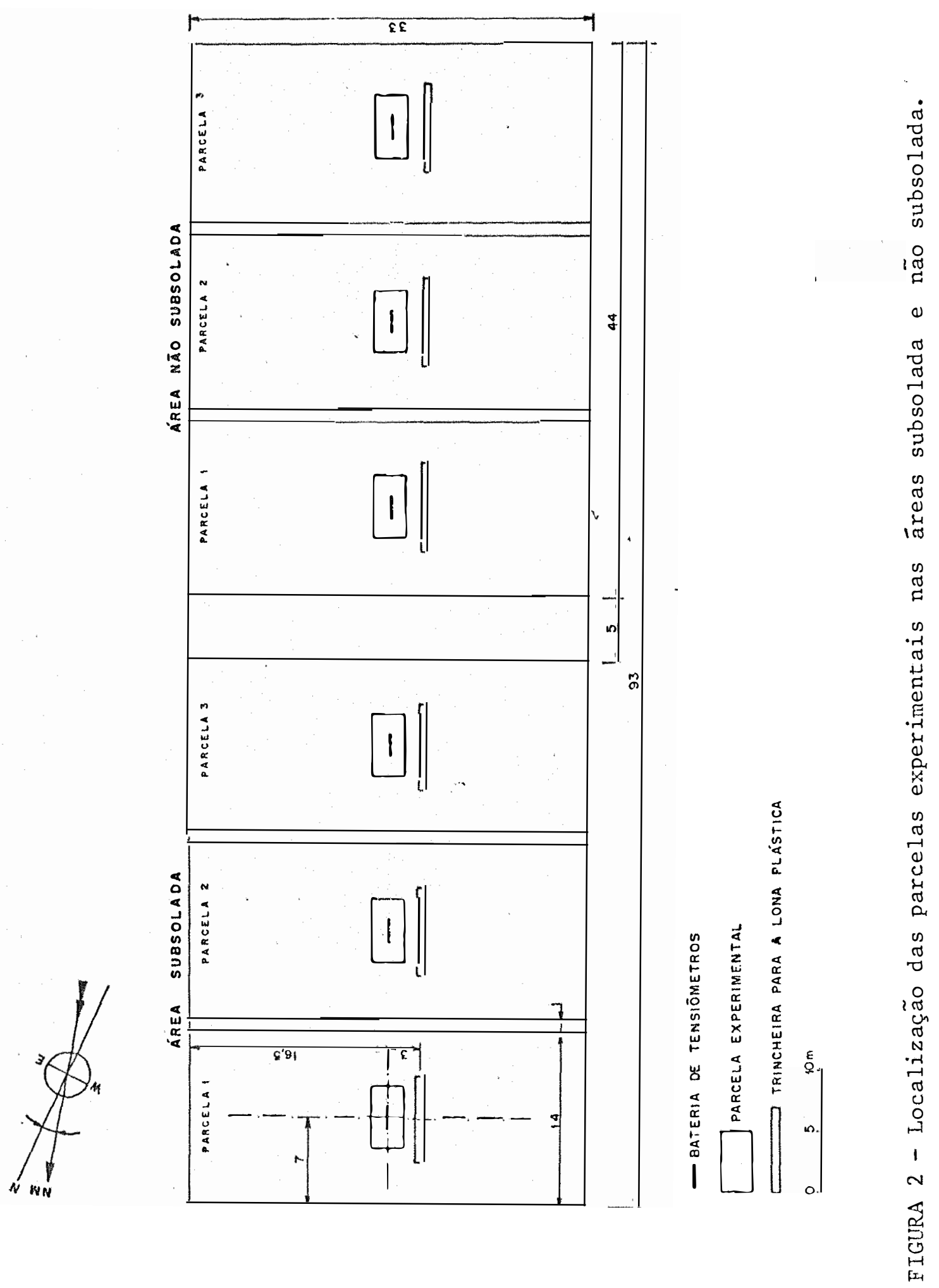



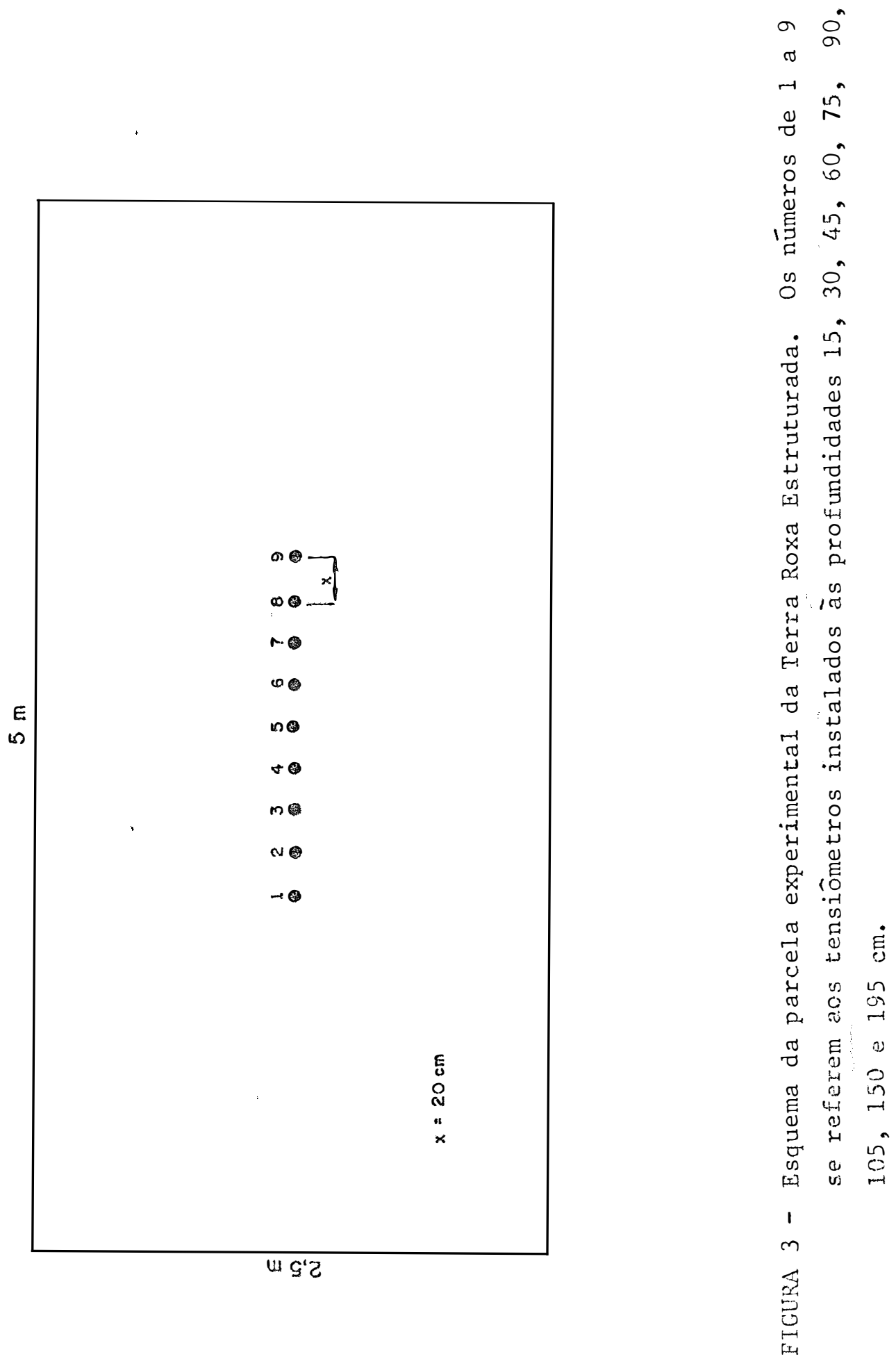
do tubo de PVC, com um gargalo de $1 \mathrm{~cm}$ de comprimento e diâmetro externo um pouco menor que o diâmetro interno do tubo de PVC, para permitir um perfeito encaixe entre eles; tubos de nylon flexível de $2 \mathrm{~mm}$ de diâmetro interno e 3,2 mm de diâmetro externo; placas de acrílico de $20 \mathrm{~cm}$ por $7 \mathrm{~cm}$ e espessura de $2 \mathrm{~cm}$, com 9 orifícios de diâmetro de $1,4 \mathrm{~cm}$ e $5 \mathrm{~cm}$ de profundidade, para receber o mercúrio; suporte de madeira de $20 \mathrm{~cm}$ de largura, $200 \mathrm{~cm}$ de altura e 2,5 cm de espessura, para receber as cubetas (placa de acrílico) e os tubos de nylon; rolhas de borracha e "caps" de PVC rosqueáveis ao tubo de PVC; cola "Araldite" de ação lenta para as junções cápsula-PVC e PVC-tubo de nylon.

A fim de poder demonstrar a fórmula para o câlculo do potencial matricial com este tipo de tensiômetro, é apresentado na Figura 4 o esquema de um deles, instalado no solo, mostrando a maneira como foi construído e todos os materiais acima discriminados.

Para instalação dos tensiômetros, foram abertos orifícios no solo com a ajuda de um trado helicoidal, de diâmetro igual ao do tensiômetro. Antes da introdução do tensiômetro, o orifício era alargado um pouco com um trado do tipo pistão, de diâmetro um pouco maior ao da cápsula porosa. Este trado era sempre introduzido até uma profundidade $5 \mathrm{~cm}$ menor do que a profundidade que seria alcançada pela ponta da cápsula do tensiômetro, a fim de que quando este fosse introduzido no orifício, pudesse ser obtido um contato perfeito entre a cápsula e o solo, na profundidade desejada.

Com base no esquema mostrado na Figura 4, pode - se demonstrar que: 


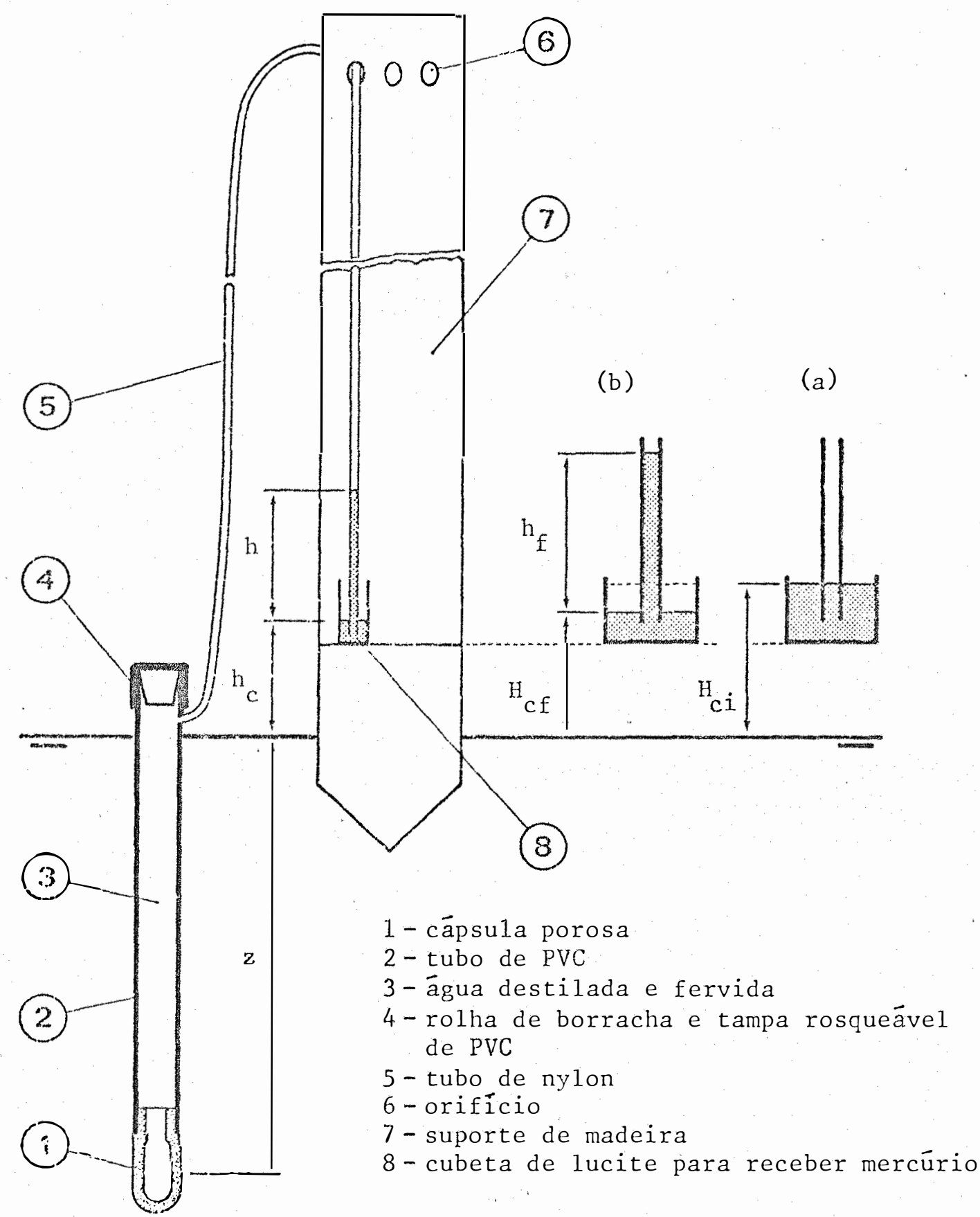

FIGURA 4 - Esquema de um tensiômetro instalado no campo. $\mathrm{h}=$ altura do mercúrio; $\mathrm{h}_{\mathrm{C}}=$ distância do nível de mercúrio na cubeta à superfície do soloe $z$ =profundidade; $a$ e b = detalhe da cubeta de mercúrio em condições de solo saturado e não saturado, respectivamente, onde $\mathrm{H}_{\text {ci }}$ e $\mathrm{H}_{\text {ef }}=$ distância inicial e final do nível de mercūrióa superfície do solo, respectivamente. 
$\psi_{\mathrm{m}}=-12,6 \mathrm{~h}+\mathrm{H}_{\mathrm{c}}+\mathrm{z}$

onde: $\psi_{\mathrm{m}}=$ potencial matricial, em $\mathrm{cm}$ de coluna de ägua

$\mathrm{h}=$ altura de mercúrio, em $\mathrm{cm}$, medida com régua

$\mathrm{H}_{\mathrm{c}}=$ distância, em cm, da superfície do solo à interface mercúrio-ar

$z=$ distância do meio da cápsula à superfície do solo em cm.

No caso deste experimento, a eq. (8) foi um pouco mais elaborada, a fim de considerar uma altura de cuba $\mathrm{H}_{\mathrm{c}} \mathrm{fixa}$, uma vez que esta varia à medida que a leitura h varia. Para que isso possa ser feito, há que se levar em conta o diâmetro da cubeta de mercūrio e o diâmetro interno do tubo de nylon. Assim, uma vez instalados os tensiômetros e colocado o mercúrio em suas cubetas correspondentes, demarcou-se a posição da interface mercūrio-ar na cubeta de cada um deles, de tal maneira que a distância a partir dessa demarcação, (feita antes que houvesse qualquer tensão) até a superfície do solo ficou sendo uma ${ }_{C}$ fixa, independentementedos valores de h (eq. 8). Para melhor ilustrar e facilitar o entendimento, apresenta-se, na Figura 4, duas situações do manômetro de mercúrio: a inicial (a), na qual não há leitura, e uma outra situação final (b), na qual o manômetro estā mostrando uma leitura qualquer $h_{f} \cdot \bar{E}$ na situação inicial que se definiu a altura $\mathrm{H}_{c i}(i=i n i c i a l)$ da expressão (8). Reportando-se, assim, à Figura 4, percebe-se que o abaixamento do nível de mercúrio na cubeta de $\mathrm{H}_{\mathrm{ci}}$ para $\mathrm{H}_{\mathrm{cf}}$ $(\mathrm{f}=\mathrm{final})$, corresponde à leitura final $\mathrm{h}_{\mathrm{f}}$. Nestas condições, o volume de mercūrio que desaparece da cubeta ( $\Delta V)$ é igual àquele que vai para o tubo de nylon $(\Delta v)$. Portanto, pode-se estabelecer: 


$$
\Delta V=\pi \frac{D^{2}}{4}\left(H_{c i}-H_{c f}\right)
$$

e

$$
\Delta v=\pi \frac{d^{2}}{4} \cdot h_{f}
$$

onde: $\mathrm{D}=$ diâmetro da cubeta $(\mathrm{cm})$

$\mathrm{d}=$ diâmetro interno do tubo de nylon $(\mathrm{cm})$.

$$
\text { Como } \Delta V=\Delta v \text {, è claro que }
$$

$$
\pi \frac{\mathrm{D}^{2}}{4}\left(\mathrm{H}_{\mathrm{Ci}}-\mathrm{H}_{\mathrm{Cf}}\right)=\pi \frac{\mathrm{d}^{2}}{4} \cdot \mathrm{h}_{\mathrm{f}}
$$

e, então:

$$
\left.H_{c f}=H_{c i}-\frac{d}{D}\right)^{2} \cdot h_{f}
$$

Esta expressão representa, portanto, a altura real do nível de mercúrio da cubeta à superfície do solo, quando está havendo uma determinada leitura $h_{f}$ de mercúrio. E evidente que, em comparação com a eq. (8), $\mathrm{h}_{f}=\mathrm{h}$. e $\mathrm{H}_{c i}=\mathrm{H}_{\mathrm{C}}$. Consequentemente, a substituição da expressão (9) na eq. (8) dará a förmula mais exata para o cálculo do potencial matricial que leva em conta uma altura de cuba ( $\mathrm{H}_{\mathrm{C}}$ ) fixa:

$$
\psi_{\mathrm{m}}=-\left[12,6+\left(\frac{\mathrm{d}}{\mathrm{D}}\right)^{2}\right] \mathrm{h}+\mathrm{H}_{\mathrm{c}}+\mathrm{z}
$$


4.4.2. Procedimentos experimentais para obtenção da função $K(\Theta)$

As parcelas delimitadas com estrutura de madeira para a determinação da função $\mathrm{K}(\Theta)$, como mencionado anteriormente, depois de todos os tensiômetros terem sido instalados no seu interior, foram inundadas, bombeando água a partir de um reservatório próximo por meio de um conjunto moto-bomba da General Electric de $3 \mathrm{CV}, 60$ $\mathrm{Hz}$, através do qual mantinha-se sobre a superfície do solo, uma lâmina de água constante de $10 \mathrm{~cm}$.

A estrutura de madeira que mantinha esta carga hidräulica consistiu de tábuas de $2,5 \mathrm{~cm}$ de espessura e $30 \mathrm{~cm}$ de largura, $15 \mathrm{~cm}$ dos quais enterrados no solo.

O sistema de bombeamento de água foi mantido até que o perfil, estivesse saturado até $195 \mathrm{~cm}$ de profundidade, e que o fluxo de ägua se tornasse constante com o tempo. Esta condição foi verificada através das leituras dos tensiômetros os quais, uma vez não mais variando, indicavam que tal condição tinha sido alcançada, o que se verificou após aproximadamente 6 horas do início da inundação.

A seguir, obedecendo os procedimentos do método, foram retiradas as estruturas de madeira, cobrindo-se a superfície do solo com uma capa de plástico preto de $48 \mathrm{~m}^{2}$, para prevenir a perda de àgua através da superfície. Terminada a operação de cobertura, que consistiu em manter o plástico preso em suas extremidades e bem colado à superfície do solo, fez-se a primeira leitura dos tensiômetros. Este foi considerado o tempo zero de distribuição da āgua no perfil. A partir daí, foram feitas leituras diārias dos tensiômetros, sendo que, no primeiro dia,foram feitas três leituras. 
Quando se percebeu que praticamente a àgua não se distribuia, isto $\vec{e}$, as leituras não mais variavam com o tempo, deixou-se de ler os tensiômetros.

0 problema do valor de contorno que se ajusta a este procedimento experimental para o cálculo da função $K(\theta)$ è o seguinte:

$$
\begin{array}{ll}
\frac{\partial \Theta}{\partial t}=\frac{\partial}{\partial z}\left[K(\Theta) \frac{\partial \psi_{h}}{\partial z}\right] & z=0 \\
\Theta=\Theta(z), \quad t=0, & z=\infty \\
\Theta=\theta_{i}, & t>0, \quad z=0 \\
q=0, & t>0,
\end{array}
$$

A eq. (11) è a conhecida equação de Richards e as (12), (13) e (14) identificam as condições inicial e de contorno do método, nas quais:

$$
\begin{aligned}
\psi_{\mathrm{h}} & =\text { potencial hidrâulico } \\
\mathrm{t} & =\text { tempo de redistribuição } \\
z & =\text { coordenada vertical de posição igual à prof́undidade do solo } \\
\Theta & =\text { umidade volumétrica } \\
\Theta_{i} & =\text { umidade inicial do solo antes da inundação } \\
\mathrm{q} & =\text { densidade de Eluxo de água } \\
\mathrm{K} & =\text { condutividade hidrāulica }
\end{aligned}
$$

A integração da eq. (11), tendo em conta as condições iniciais e de contorno (12), (13) e (14), fornece:

$$
\int_{0}^{z} \frac{\partial \theta}{\partial t} d z=\left.k(\theta) \frac{\partial \psi}{\partial z}\right|_{z}
$$


0 método da umidade desenvolvido por LIBARDI et alii (1980) baseia-se na aferição a campo da relação:

$$
K(\Theta)=K_{0}^{\prime} e^{\gamma\left(\Theta-\Theta_{0}^{\prime}\right)}
$$

proposta por DAVIDSON et alii (1963), onde $K_{0}^{\prime}$ e $\Theta_{0}^{\prime}$ representam os valores da condutividade hidráulica e da umidade do solona condição em que a água está se movendo em regime estacionário (não variação da leitura dos tensiômetros), isto é, "saturação" sob condições de campo e $\gamma$ o coeficiente angular da equação de 1 inha reta $\ln \mathrm{K}(\Theta)\left(\Theta-\Theta_{0}^{0}\right)$; assume tambëm que $\partial \psi_{h} / \partial z=1$ (gradiente hidräulico unitärio). Assim, inserindo o segundo membro da eq.(16) na eq.(15), resulta:

$$
\int_{0}^{z} \frac{\partial \Theta}{\partial t} d z=K_{0}^{\prime} e^{\gamma\left(\Theta-\Theta_{0}^{\prime}\right)}
$$

Simplificando o primeiro membro da eq. (17) para

$$
z \cdot \frac{\partial \bar{\theta}}{\partial t}
$$

onde $\bar{\theta} \bar{e}$ a umidade média do perfil até a profundidade $z$, e assumindo que $\Theta$, em qualquer profundidade, se relaciona linearmente com $\bar{\theta}$, como segue

$$
\bar{\Theta}=a \Theta+
$$

a eq. (17) torna-se:

$$
-a \frac{\partial \Theta}{\partial t} z=K_{0}^{\prime} e^{\gamma\left(\theta-\theta_{0}^{\prime}\right)}
$$


a qual, integrada na profundidade $z$, de $t=0$ e $\theta=\Theta_{0}^{\prime}$ a $t=t$ e $\theta=\theta$, resulta:

$$
\theta=\theta_{0}^{\prime}-\frac{1}{\gamma} \ln (1+c t)
$$

onde

$$
c=\frac{\gamma \mathrm{K}_{0}^{\prime}}{\mathrm{az}}
$$

Em termos de umidade mëdia, atē a profundidade $z$, tendo em conta a eq. (19), a eq. (21) transforma-se em:

$$
\bar{\theta}=\bar{\theta}_{0}^{\prime}-\frac{1}{\gamma} \ln (1+c t),
$$

de tal maneira que

$$
a=\frac{\gamma}{\bar{\gamma}}
$$

que è uma maneira relativamente fäcil de calcular o coeficiente a. A regressão de $\Theta$ versus $\ln t$ pode ser usada para determinar $\gamma$ que, substituỉdo juntamente com $K_{0}^{\prime}$ e $\Theta_{0}^{\prime}$ na eq. (16), fornece a função $K(\Theta)$. $0 K_{0}^{\prime}$ pode ser determinado no campo ou estimado a partir da eq. (22) e eq. (24), e o $\theta_{0}^{\prime}$ medido no tempo zero de distrihuição. 


\section{RESULTADOS}

Para comprovar a hipōtese do presente trabalho (Capítulo 3), utilizou-se, além das 6 parcelas da Terra RoxaEstruturada, solo no qual a classe textural variou no perfil de argila a muito argilosa, um outro solo de textura média. As determinações foram feitas em 9 profundidades para ambos os solos. No casodesse solode textura média, os dados experimentais de anālise granulométrica, densidade global, curva de retenção e potencial matricial versus tempo de drenagem (para a obtenção da função $K(\theta)$ de acordo com os procedimentos experimentais descritos no item 4.4.2), encontram-se dispostos nas Tabelas 3, 4 e 5 e foram obtidos por LIBARDI (1978).

A Tabela 6 mostra os dados experimentais da curva de retenção das 9 profundidades das äreas subsolada e não subsolada da Terra Roxa Estruturada. De acordo com o desenvolvimento teórico apresentado no Capítulo 3, a Tabela 7 mostra as equações representativas das curvas de retenção do Latossolo Vermelho Amarelo, as quais foram obtidas pelo ajuste dos dados experimentais (Tabela 4) à eq. (5). Igualmente, para a Terra Roxa Estruturada, tais equações, obtidas pelo ajuste dos dados experimentais (Tabela 6) à eq. (5), são mostradas na Tabela 8.

Os dados experimentais das Tabelas 4 e 6 foram plotados em papel semi-log, a fim de melhor analisar como se dispunham com relação às equações das Tabelas 7 e 8. Essa disposição dos da- 
dos em gráficos para cada profundidade dos solos, juntamente com as curvas das equações representativas, pode ser vista nas Figuras 5 a 17.

Para a Terra Roxa Estruturada, os dados de potencial matricial versus tempo de drenagem (item 4.4.2), encontram-se nas Tabelas 9 a 14 .

A partir dos dados das Tabelas 5 e 9 a 14, e utilizando as respectivas equações de $\psi_{\mathrm{m}}$ versus $\Theta$ (Tabelas 7 e 8), calcularam-se os valores de umidade volumétrica $(\Theta)$ para cada tempo de drenagem em cada uma das profundidades do solo. Esses resultados assim obtidos, encontram-se nas Tabelas 15 a 21.

Utilizando a metodologia de LIBARDI et alii (1980) para a obtenção da função $K(\theta)$, fez-se o ajuste desses dados de umidade versus tempo, constantes nas Tabelas 15 a 21, à eq. (21) (item 4.4.2). As curvas representativas, assim como os dados experimentais, foram reunidos em grä́ficos que correspondem às Figuras 18 a 20. para o Latossolo Vermelho Amareló, Figuras 21 a 29 para as parcelas da Terra Roxa Estruturada não subsoladas, e Figuras 30 a 38 para as parcelas subsoladas da. Terra Roxa Estruturada.

As equações representativas das curvas mostradas nas Figuras 18 a 20 e respectivos coeficientes de regressão (r) encontram-se na Tabela 22; as das Figuras 21 a 29, na Tabela 23, e aquelas das Figuras 30 a 38 na Tabela 24.

Finalmente, tendo em vista a hipótese do presente trabalho, apresenta-se na Tabela 25 os valores de $\gamma$ obtidos da regressão dos dados de umidade versus tempo de drenagem (eq. 21) e de $\alpha$ obtidos a partir do ajuste das curvas de retenção (eq. 5), de acordo com o descrito no final do Capítulo 3. Esses dados foram 
plotados colocando-se na ordenada os valores de $\alpha$ e na abscissa os de $\gamma$, constituindo a Figura 39, na qual pode-se ver também a equação de regressão linear, juntamente com seu coeficiente de correlação (r). 


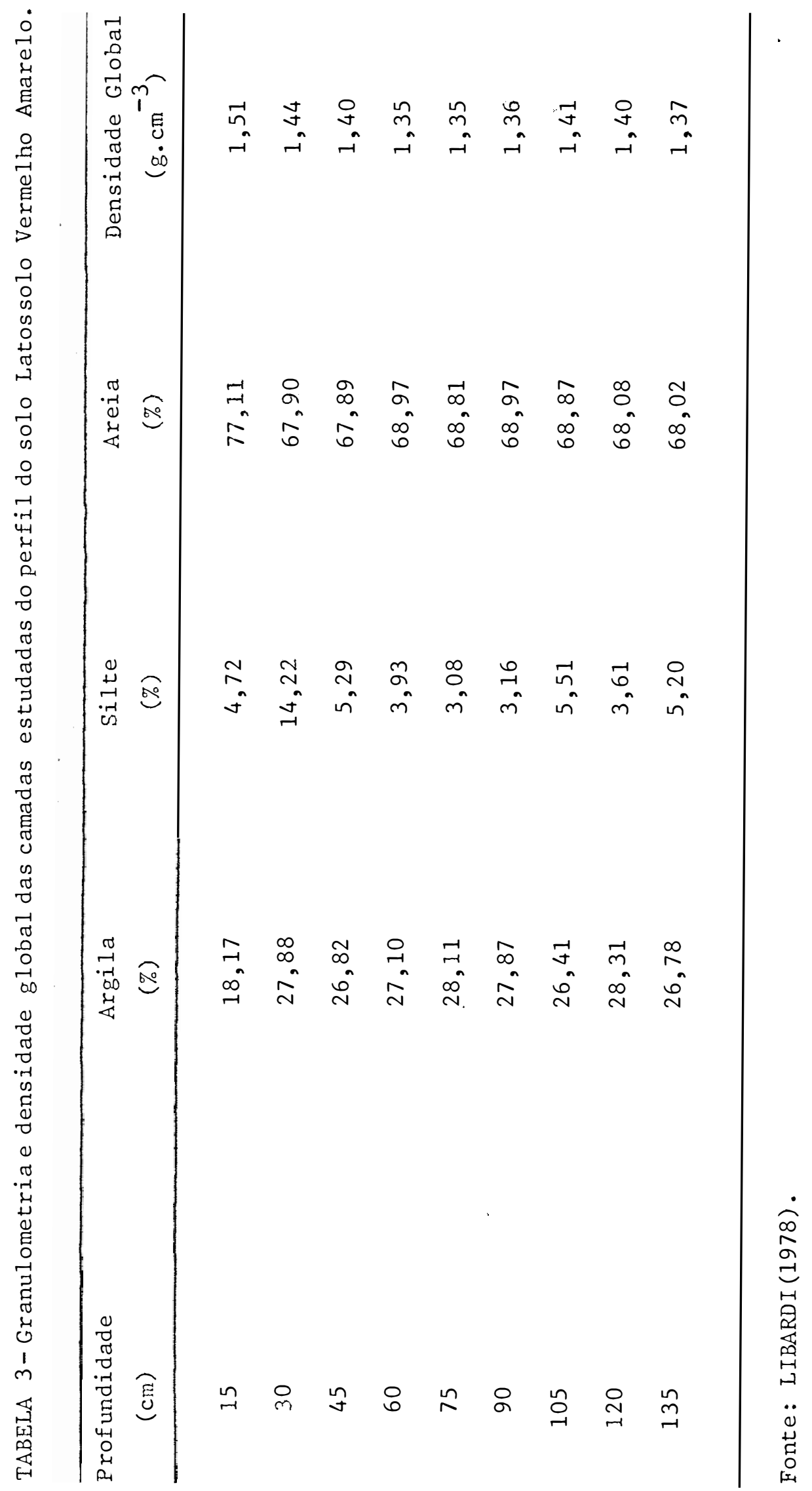




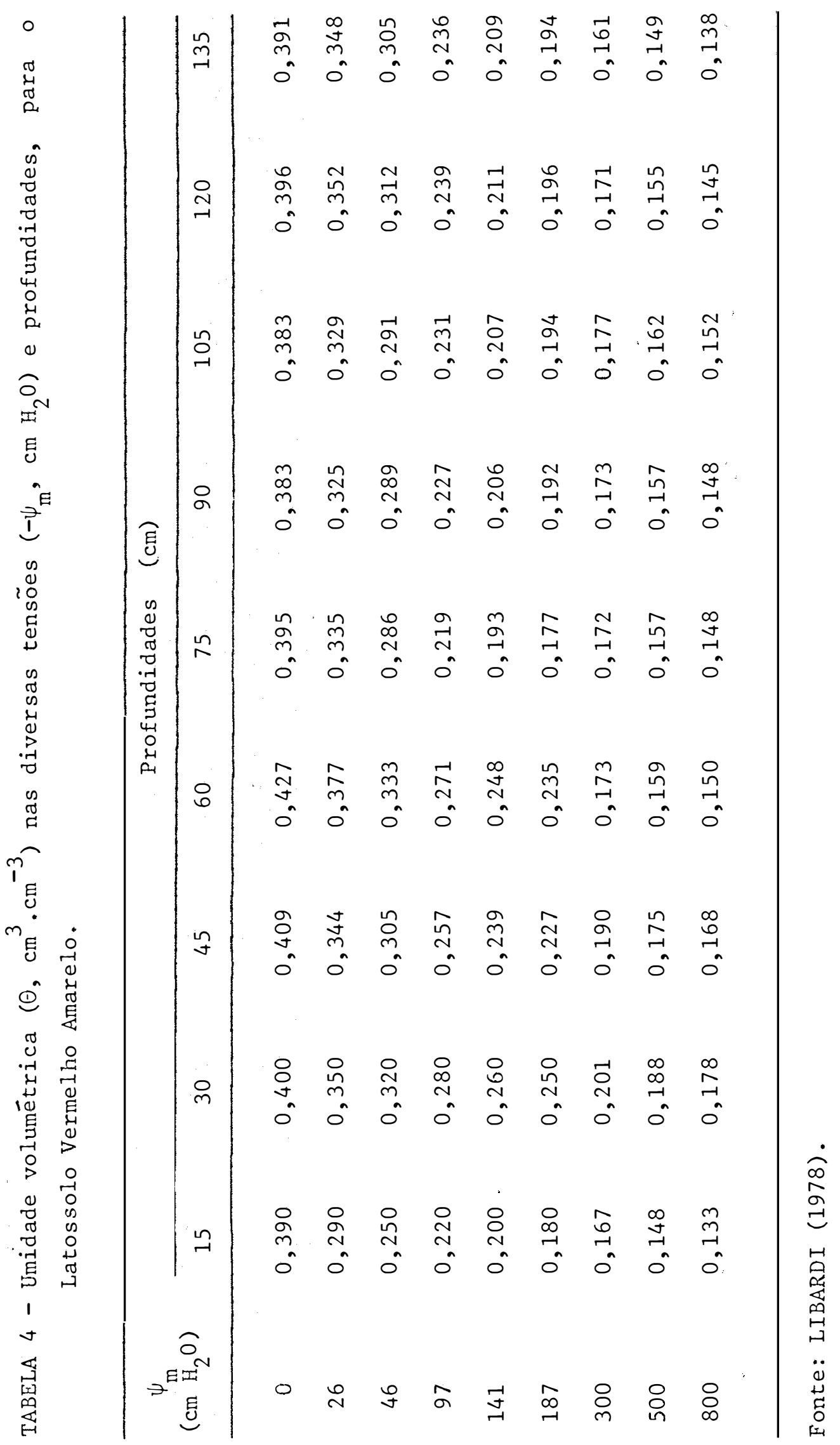




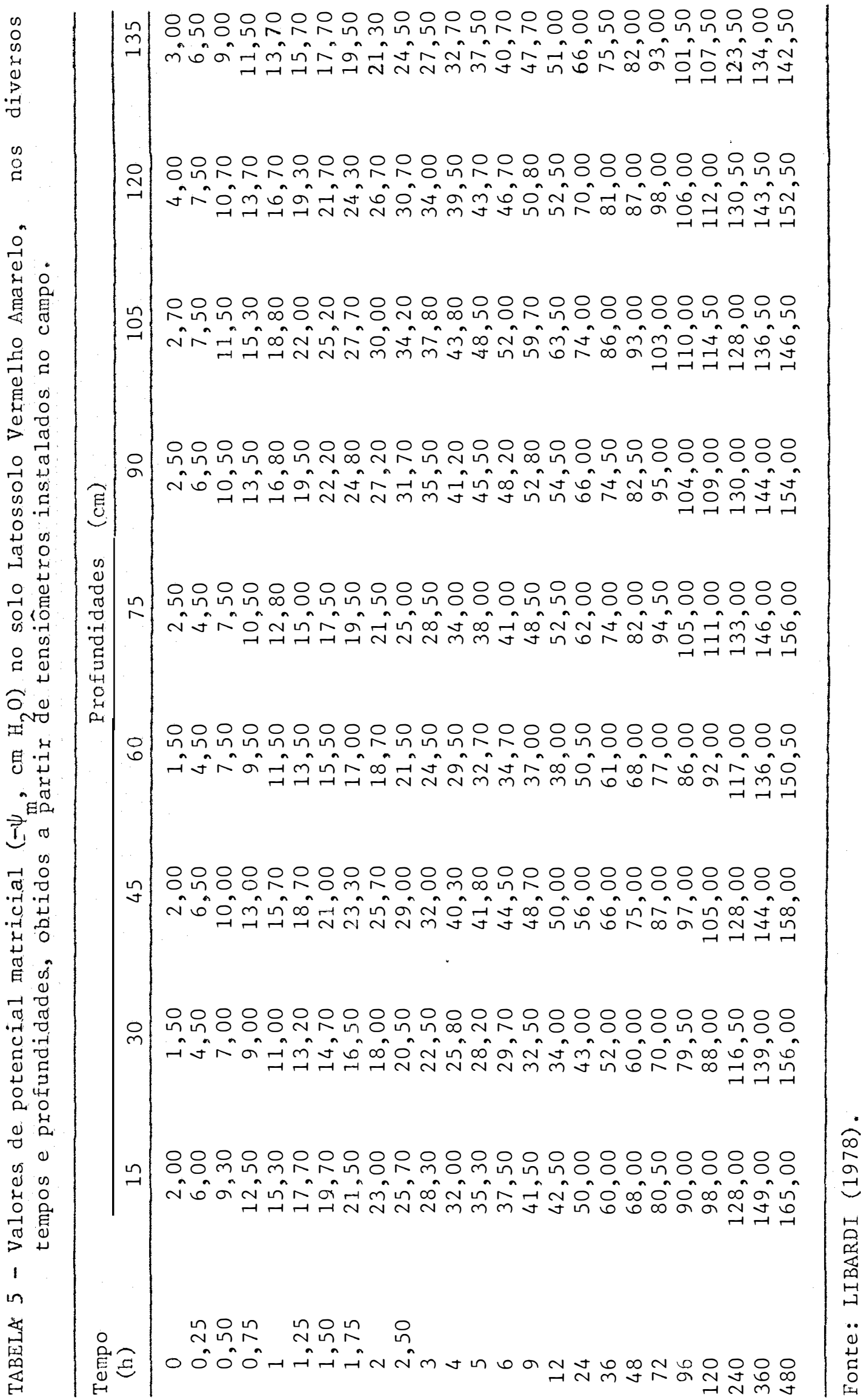




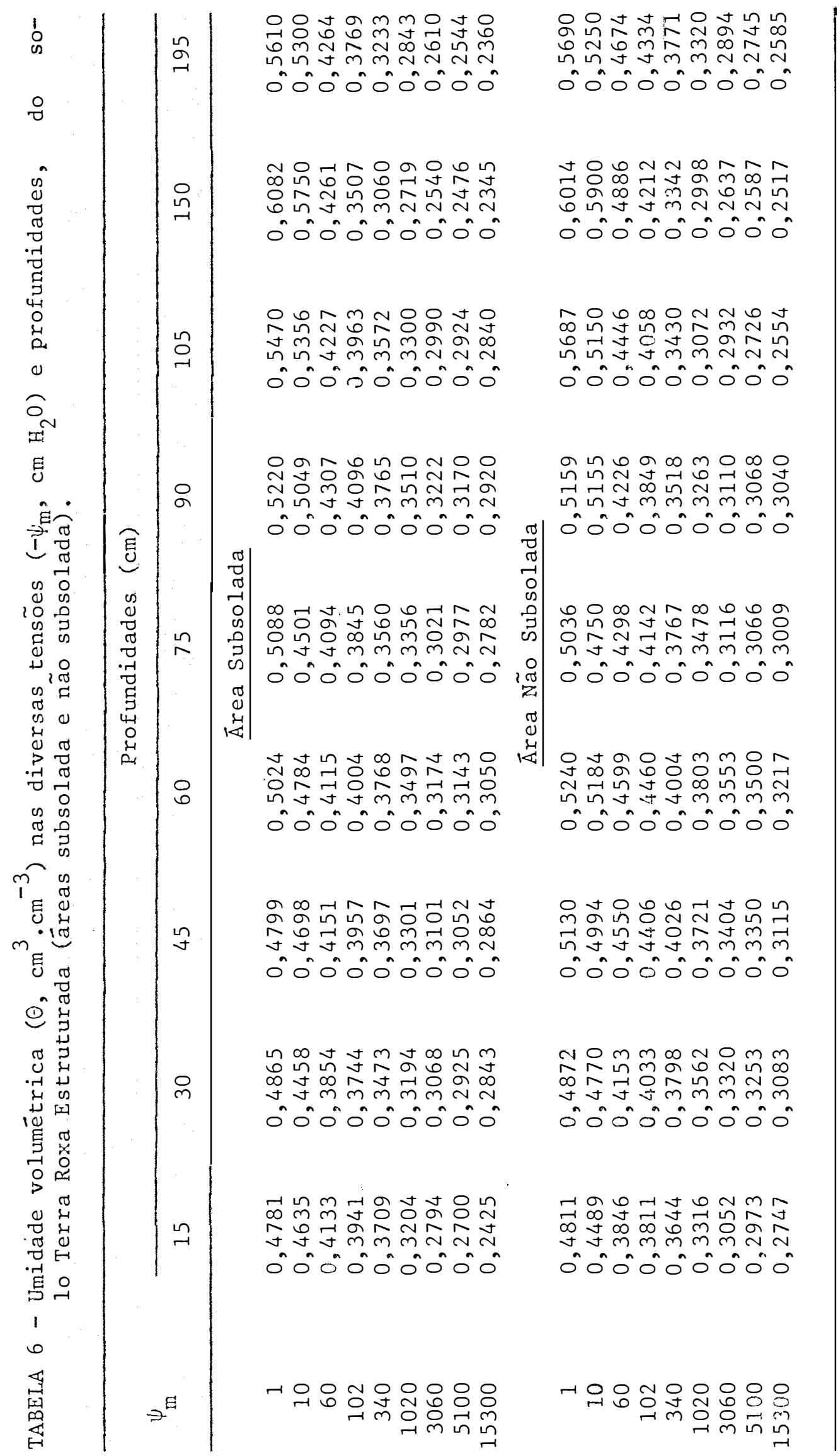


TABELA 7 - Equações representativas das curvas características da água no solo, para as diversas profundidades, do Latossolo Vermelho Amarelo.

\begin{tabular}{|c|c|c|c|}
\hline $\begin{array}{l}\text { Prof. } \\
(\mathrm{cm})\end{array}$ & . & Equações & $\begin{array}{l}\text { Coeficiente } \\
\text { de Correlação } \\
(\mathrm{r})\end{array}$ \\
\hline 15 & $\psi_{\mathrm{m}}=2,451320$ & $e^{-21,717665(\Theta-0,390)}-1$ & 0,991881 \\
\hline 30 & $\psi_{\mathrm{m}}=10,517051$ & $\mathrm{C}_{1}^{-18,931658(\theta-0,400)}-1$ & 0,990748 \\
\hline 45 & $\psi_{\mathrm{m}}=6,836282$ & {$\left[e^{-18,336775(\Theta-0,409)}-1\right.$} & 0,988232 \\
\hline 60 & $\psi_{\mathrm{m}}=12,190006$ & {$\left[e^{-13,904348(\Theta-0,427)}-1\right]$} & 0,987331 \\
\hline 75 & $\psi_{\mathrm{m}}=7,403593$ & {$\left[e^{-16,594248(\Theta-0,395)}-1\right]$} & 0,950265 \\
\hline 90 & $\psi_{\mathrm{m}}=7,669559$ & {$\left[e^{-17,925946(\Theta-0,383)}-1\right]$} & 0,976008 \\
\hline 105 & $\psi_{\mathrm{m}}=8,080117$ & {$\left[e^{-17,962960(0-0,383)}-1\right]$} & 0,973516 \\
\hline 120 & $\psi_{\mathrm{m}}=11,375920$ & {$\left[e^{-15,135061(\Theta-0,396)}-1\right]$} & 0,974755 \\
\hline 135 & $\psi_{\mathrm{m}}=11,538100$ & {$\left[e^{-15,042567(\Theta-0,391)}-1\right]$} & 0,978120 \\
\hline
\end{tabular}


TABELA 8 - Equaçōes representativas das curvas características da ägua no solo, nas diversas profundidades, para a Terra Roxa Estruturada (äreas não subsolada e subsolada).

\begin{tabular}{|c|c|c|c|c|}
\hline $\begin{array}{l}\text { Prof. } \\
(\mathrm{cm})\end{array}$ & & Equações & & $\begin{array}{c}\text { Coef. Cor. } \\
\text { (r) }\end{array}$ \\
\hline & Are & Não Subsolada & & \\
\hline 15 & $\psi_{\mathrm{m}}=1,691286$ & $e^{-43,141634(0-0,4811)}$ & $-1]$ & 0,992114 \\
\hline 30 & $\psi_{\mathrm{m}}^{\prime}=6,865948$ & $e^{-40,172701(\Theta-0,4872)}$ & $-1]$ & 0,977429 \\
\hline 45 & $\psi_{\mathrm{m}}=6,100459$ & $=e^{-37,481811(\Theta-0,5130)}$ & $-1]$ & 0,997629 \\
\hline 60 & $\psi_{\mathrm{m}}=5,838747$ & $e^{-37,355259(\Theta-0,5240)}$ & $-1]$ & 0,992623 \\
\hline 75 & $\psi_{\mathrm{m}}=3,226688$ & $e^{-38,084344(\Theta-0,5036)}$ & $-1]$ & 0,990017 \\
\hline 90 & $\psi_{\mathrm{m}}=4,366174$ & $e^{-31,708581(\Theta-0,5159)}$ & $-1]$ & 0,939481 \\
\hline 105 & $\psi_{\mathrm{m}}=1,760619$ & $e^{-26,536581(\Theta-0,5687)}$ & $-1]$ & 0,980319 \\
\hline 150 & $\psi_{\mathrm{m}}=5,074906$ & $e^{-19,228783(\Theta-0,6014)}$ & $-1]$ & 0,953860 \\
\hline 195 & $\psi_{\mathrm{m}}=3,376191$ & $e^{-25,235592(\theta-0,5690)}$ & $-1]$ & 0,995271 \\
\hline & & cea Subsolada & & \\
\hline 15 & $\psi_{\mathrm{m}}=9,604245$ & $e^{-31,159615(\Theta-0,4781)}$ & $-1]$ & 0,996242 \\
\hline 30 & $\psi_{m}=0,927573$ & $=e^{-44,519543(0-0,4865)}$ & $-1]$ & 0,984844 \\
\hline 45 & $\psi_{\mathrm{m}}=4,956934$ & $e^{-38,836990(\Theta-0,4799)}$ & $-1]$ & 0,991634 \\
\hline 60 & $\psi_{\mathrm{m}}=2,175186$ & $e^{-41,062466(\Theta-0,5024)}$ & $-1]$ & 0,984960 \\
\hline 75 & $\psi_{\mathrm{m}}=0,781731$ & $e^{-41,332859(\Theta-0,5088)}$ & $-1]$ & 0,995404 \\
\hline 90 & $\psi_{\mathrm{m}}=3,118390$ & $e^{-34,876414(\Theta-0,5220)}$ & $-1]$ & 0,987990 \\
\hline 105 & $\psi_{\mathrm{m}}=3,110827$ & $e^{-28,035421(\theta-0,5470)}$ & $-1]$ & 0,960493 \\
\hline 150 & $\psi_{\mathrm{m}}=2,244030$ & $e^{-19,779523(\Theta-0,6082)}$ & $-1]$ & 0,927058 \\
\hline 195 & $\psi_{\mathrm{m}}=2,569968$ & $e^{-23,626459(\Theta-0,5610)}$ & $-1]$ & 0,966817 \\
\hline
\end{tabular}




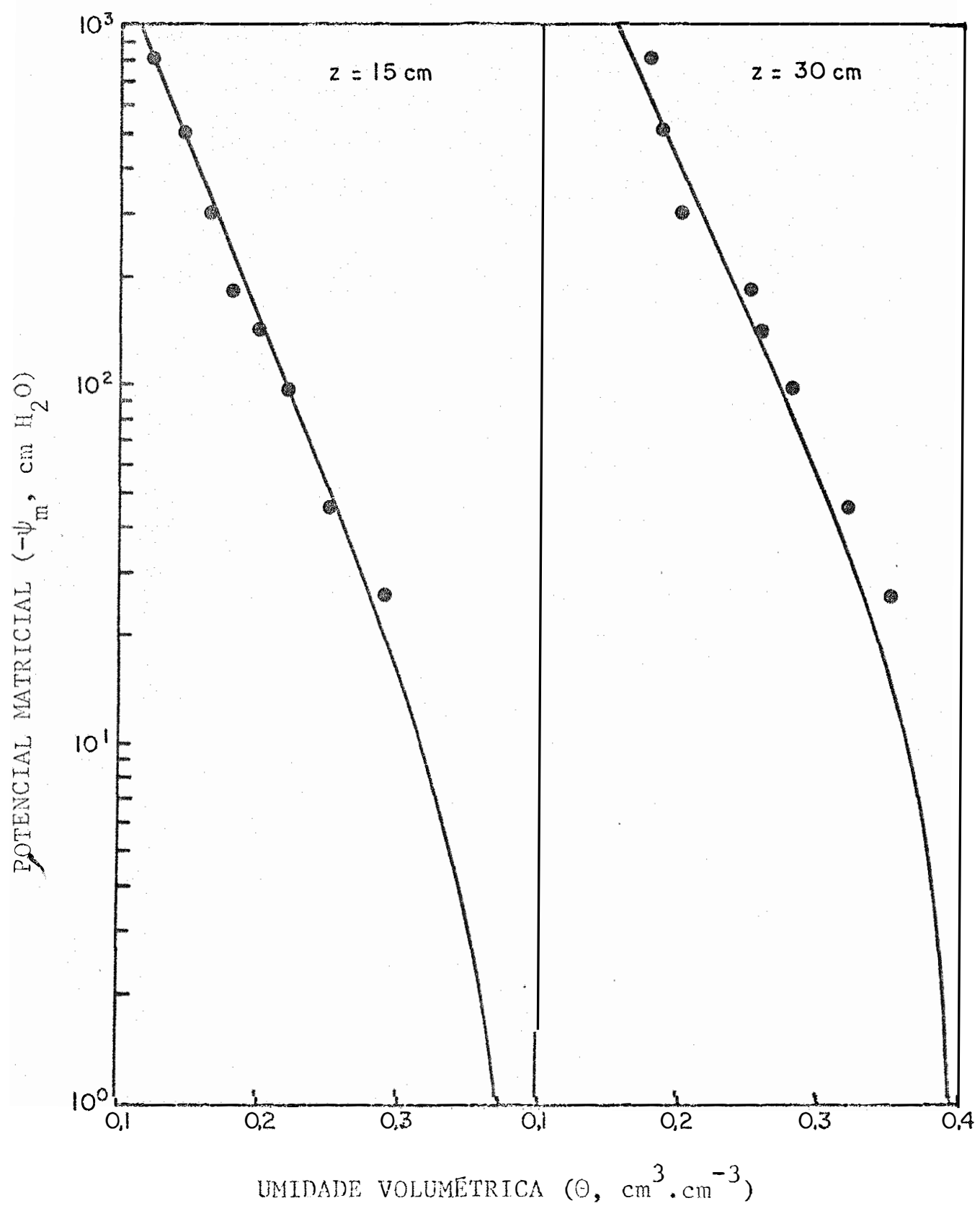

FIGURA 5 - Curvas de retenção da ägua no solo para as profundidades de 15 e $30 \mathrm{~cm}$ do Latossolo Vermelho Amarelo. Os pontos representam os dados experimentais e a linha a a equação (5). 


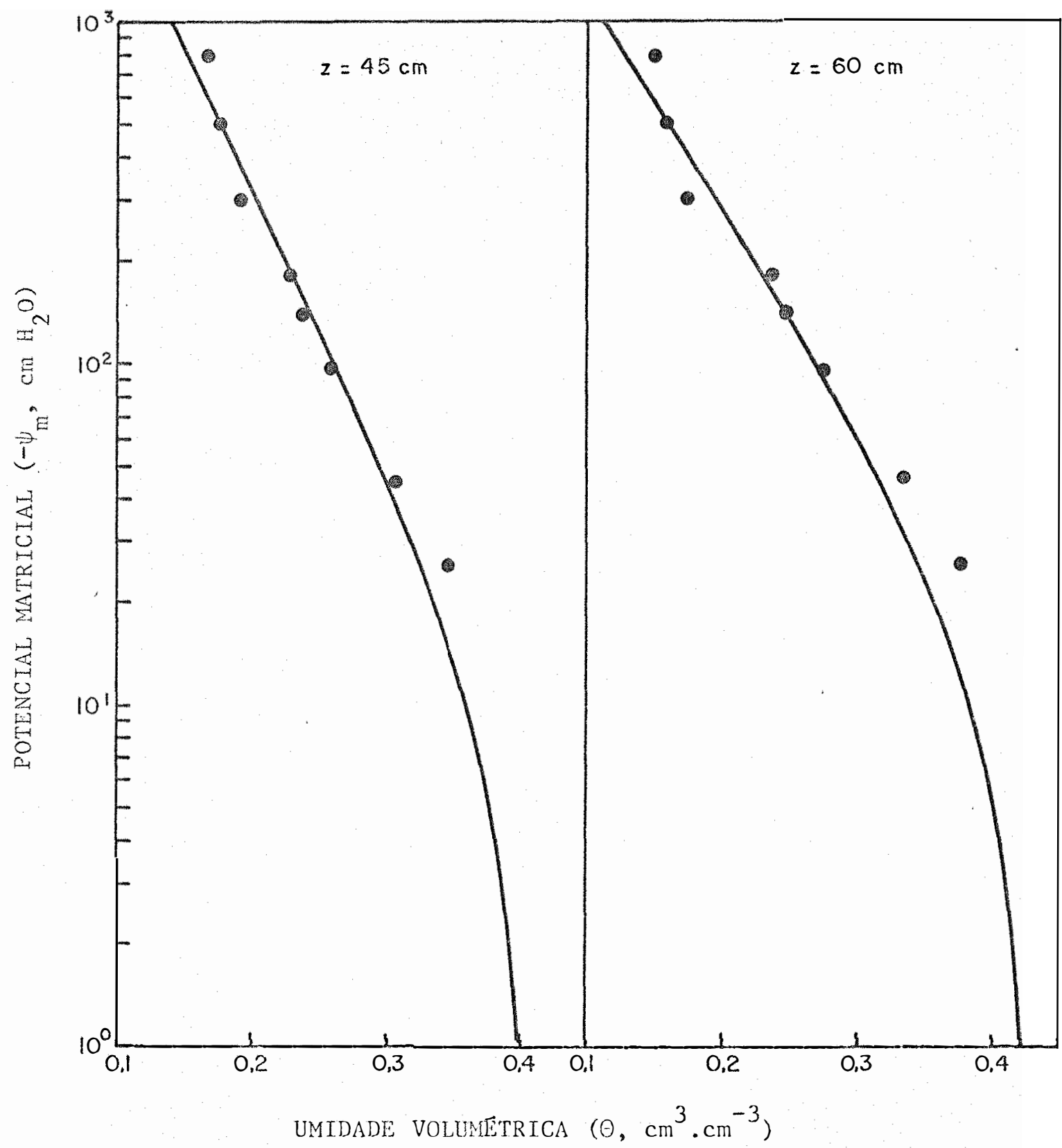

FIGURA 6 - Curvas de retenção da água no solo para as profundidades de 45 e $60 \mathrm{~cm}$ do Latossolo Vermelho Amarelo. Os pontos representam os dados experimentais e a linha a equação (5). 


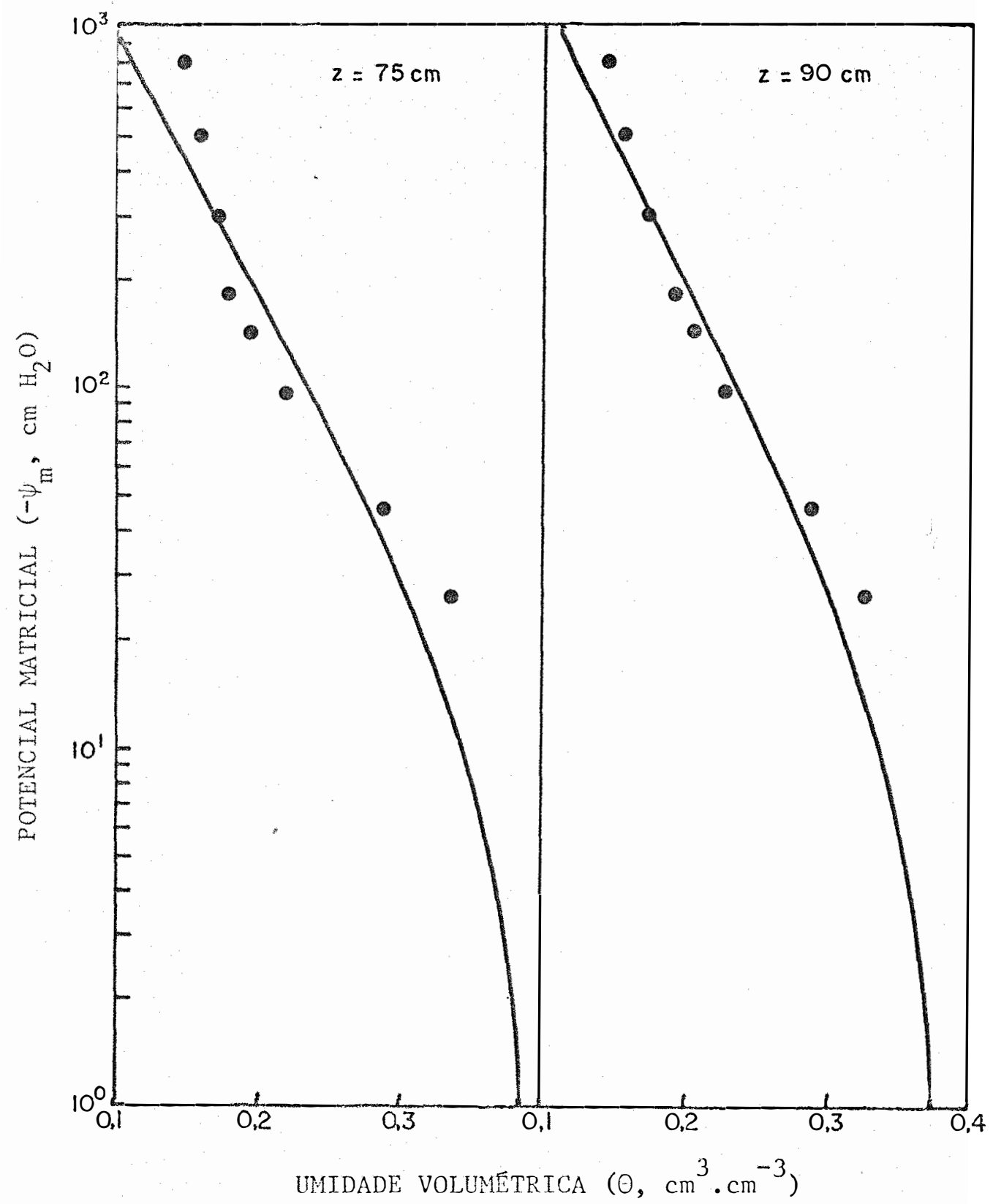

FIGURA 7 - Curvas de retenção da água no solo para as profundidades de 75 e $90 \mathrm{~cm}$ do Latossolo Vermelho Amarelo. Os pontos representam os dados experimentais e a linha a equação (5). 

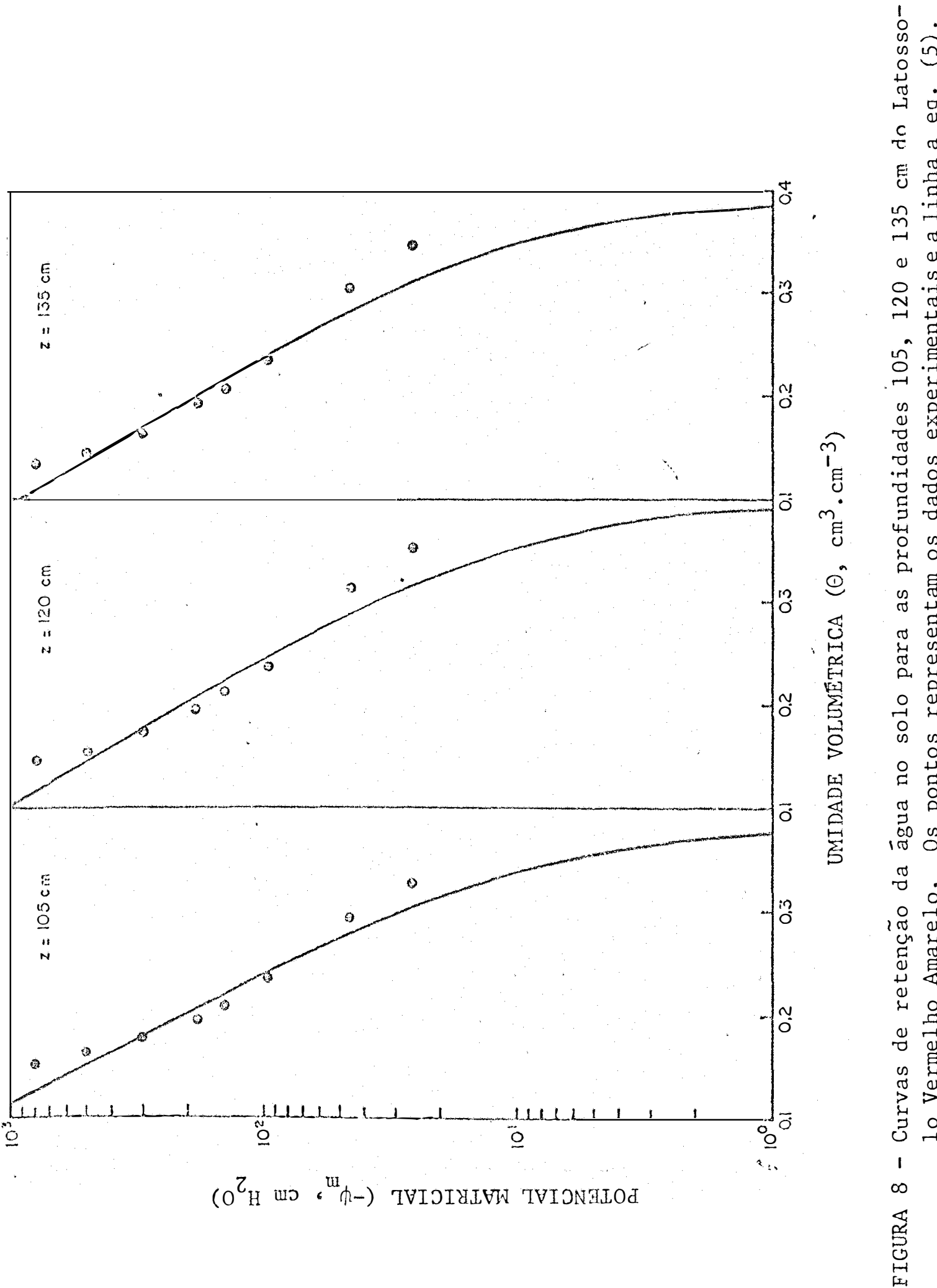


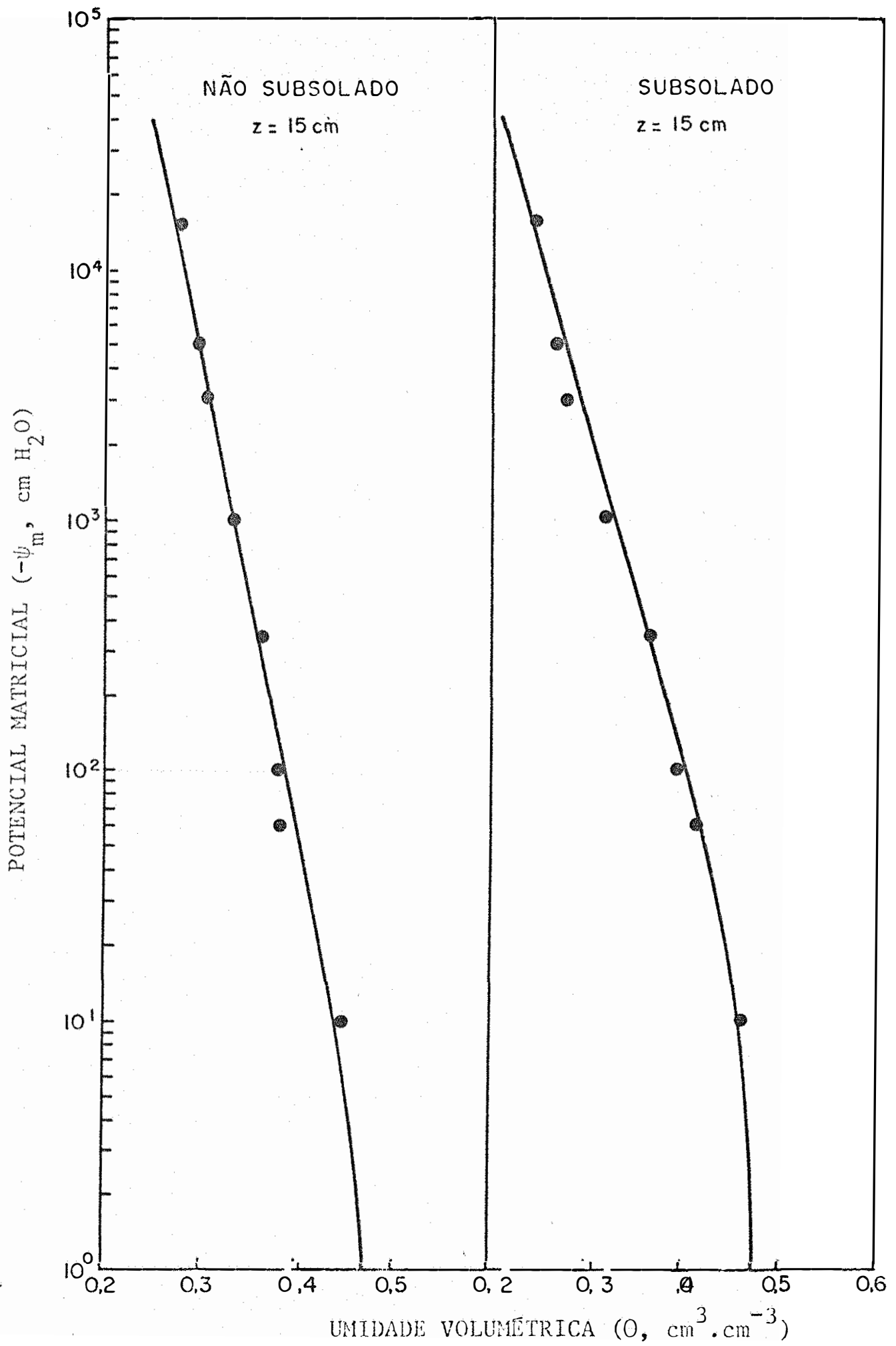

EIGURA 9 - Curvas de retenção da água no solo para a profundidade de $15 \mathrm{~cm}$ das áreas náo subsolada e subsolada da Terra Roxa Estruturada. Os pontos representam os dados experimentais e a linha a equa-

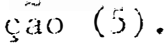




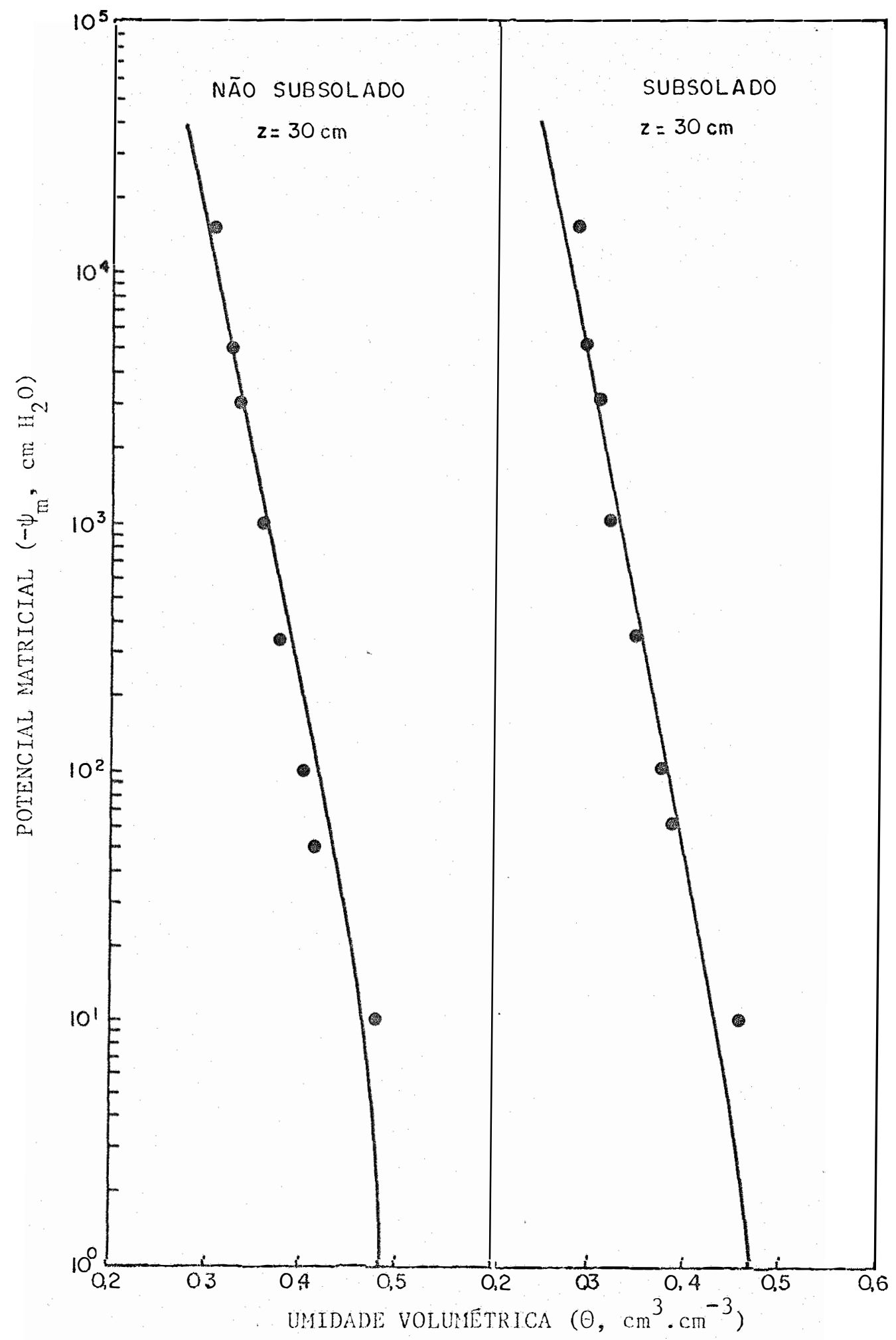

FICURA 10 - Curvas de retenção da árua no solo para a profundidade de 30 cm das áreas näo subsolada e subsolada da Terra Roxalistruturada. Os pontos representam os dados experimentais e a linha a equaçäo (5). 


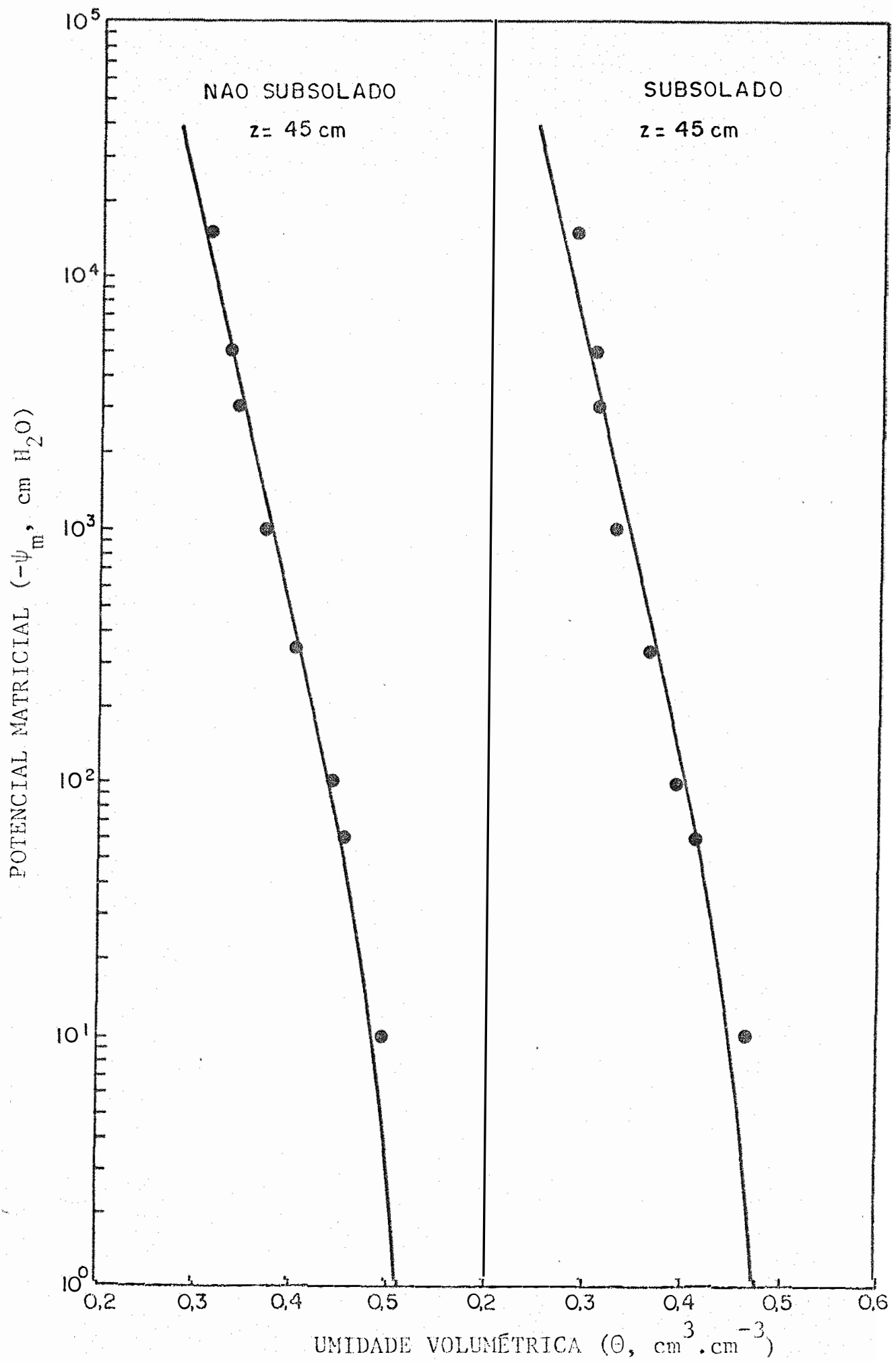

FicuRA 11 - Curvas de retenção da ägua no solo para a profundidade de 45 cin das áreas ná subsolada e subsolada da Terrakoxa Estruturada. Os pontos representam os dados experimentais e a linha a equaçán (5). 


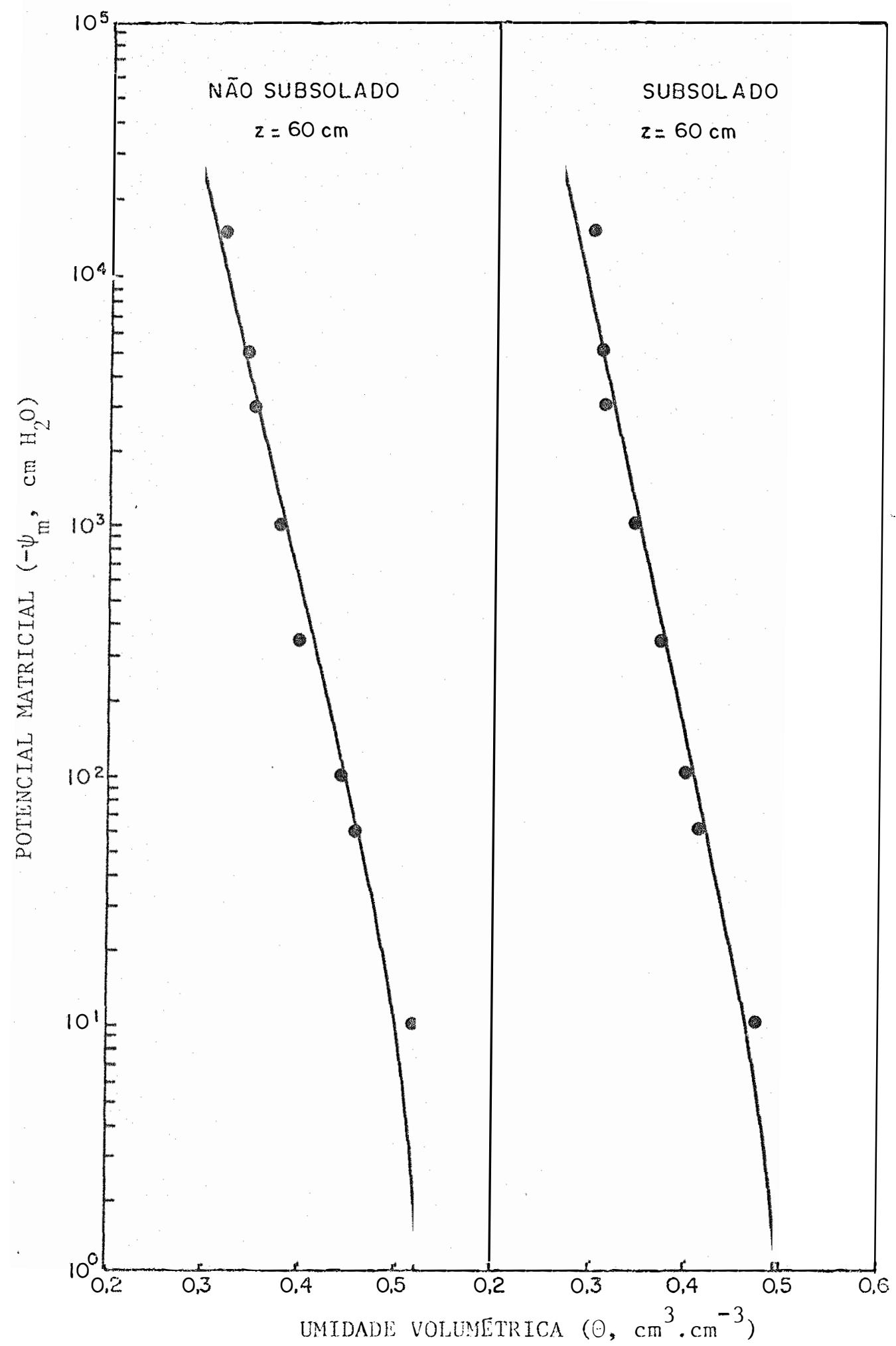

FIGURA 12 - Curvas de retenção da água no solo para a profundidade de $60 \mathrm{~cm}$ das áreas näo subsolada e subsolada da Terra Roxa Estruturada. Os pontos representan os dados experimentiaise a linha a equaçäo (5). 


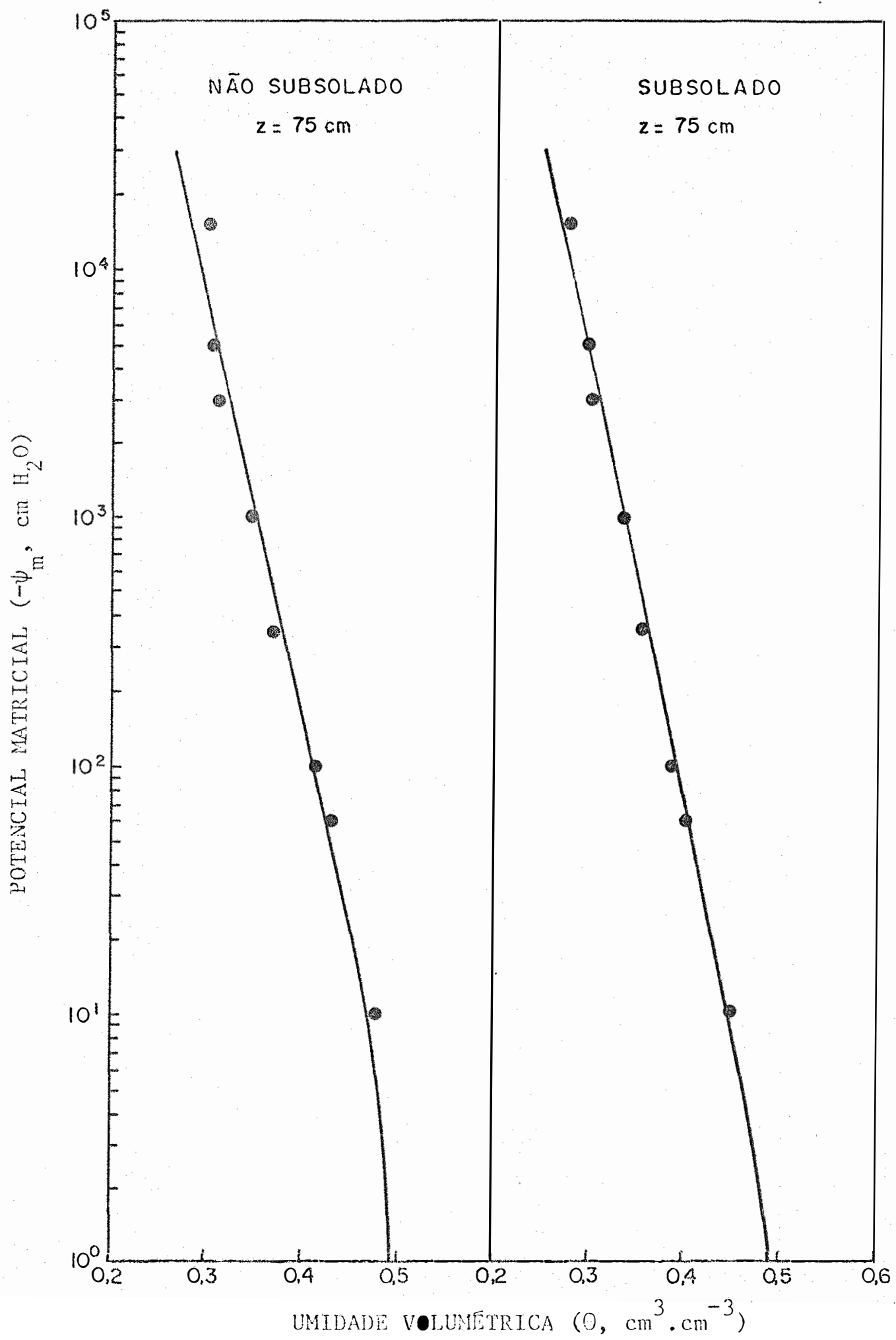

FIGURA 13 - Curvas de retenção da água no solo para a profundidade de $75 \mathrm{~cm}$ das äreas não subsolada e subsolada da Terra Roxa tostruturada. Os pontos representam os dados experimentaise a linha a equaçäo (5). 


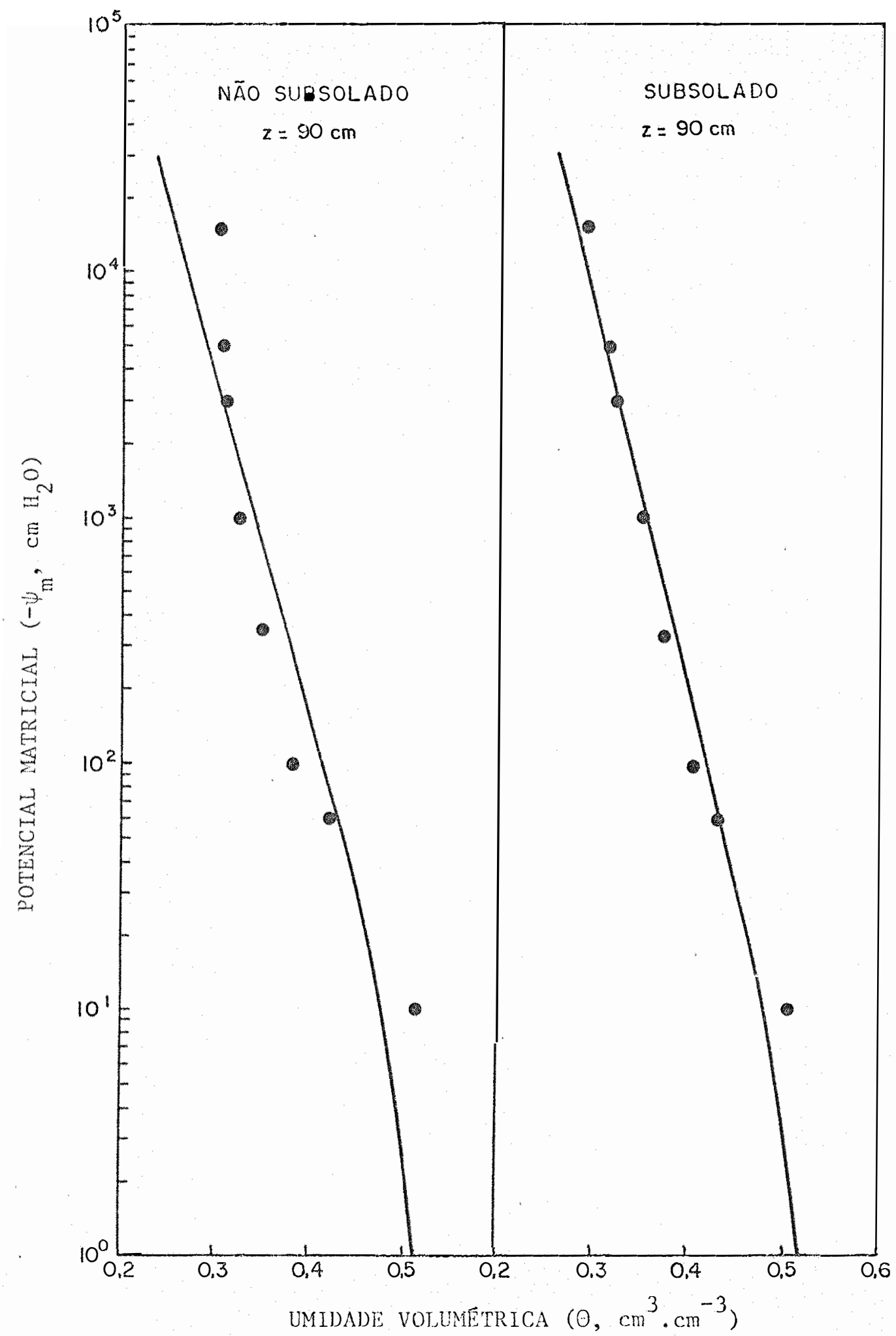

FIGURA 14 - Curvas de retenção da água no solo para a profundidade de $90 \mathrm{~cm}$ das áreas nãa subsolada e subsolada da Terra Roxa Estruturada. Os pontos representam os dados experimentais e a Iinha a equacáo (5). 


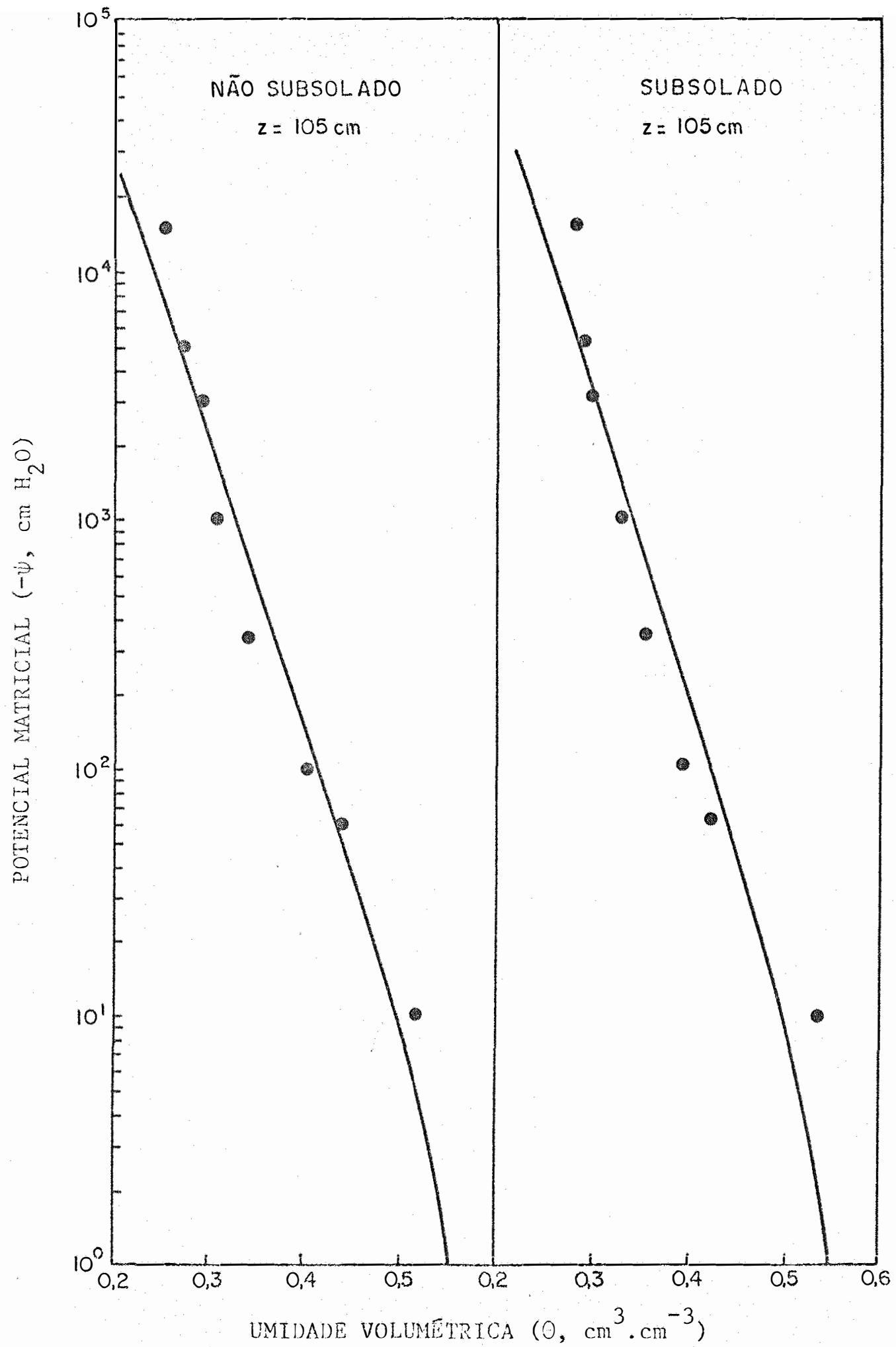

Elgura 15 - Curvas de retenção da água no solo para a profundidade de $105 \mathrm{~cm}$ das áreas năo subsolada e subsolada da. Terra Roxa Estruturada. Os pontos representam os dados experimentais e a Iinha a equaçăo (5). 


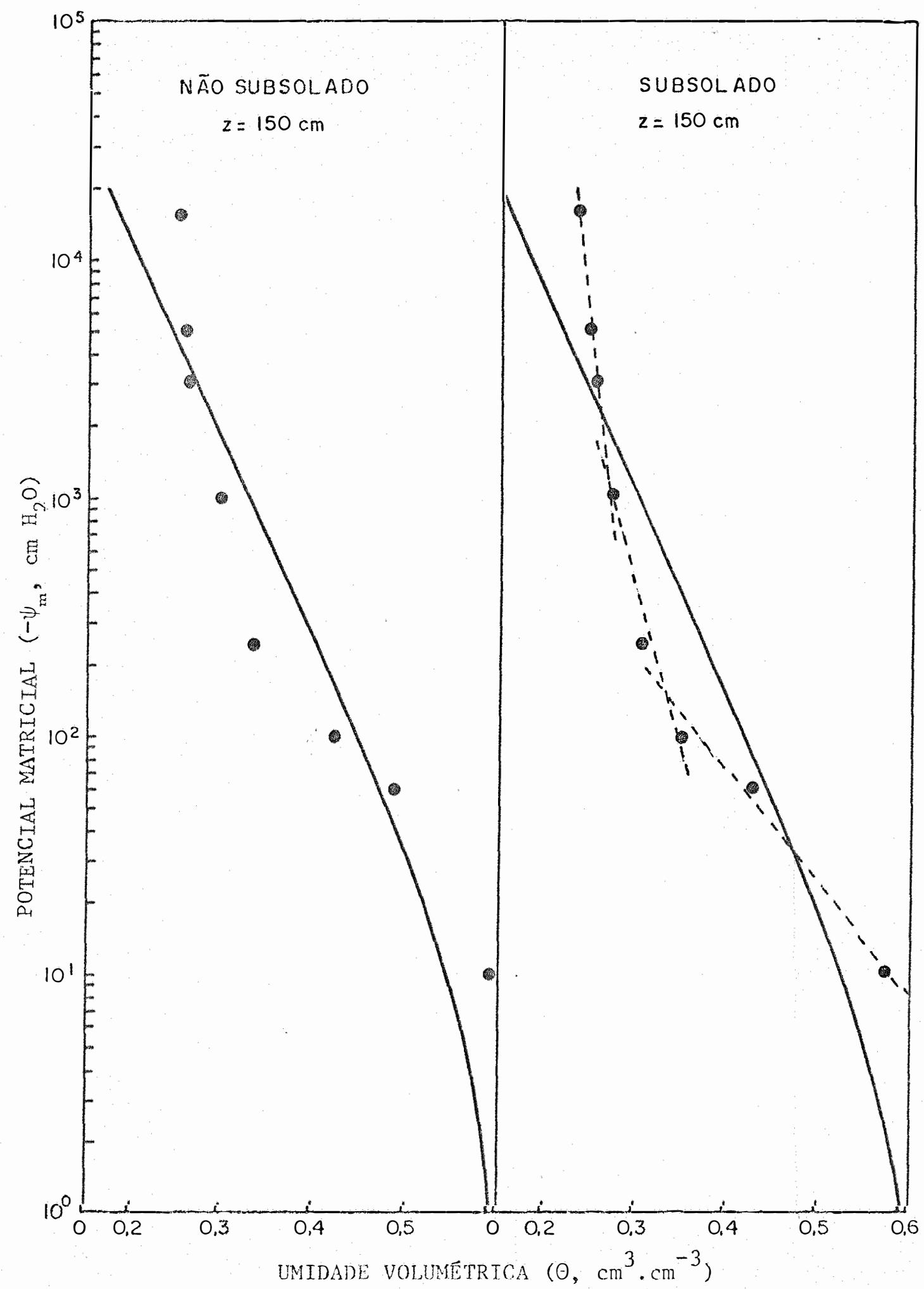

FIGURA 16 - Curvas de retenção da água no solo para a profundidade de $150 \mathrm{~cm}$ das äreas não subsolada e subsolada da Terra Roxa Estruturada. Os pontos representam os dados experimentais e a linha a equação (5). 


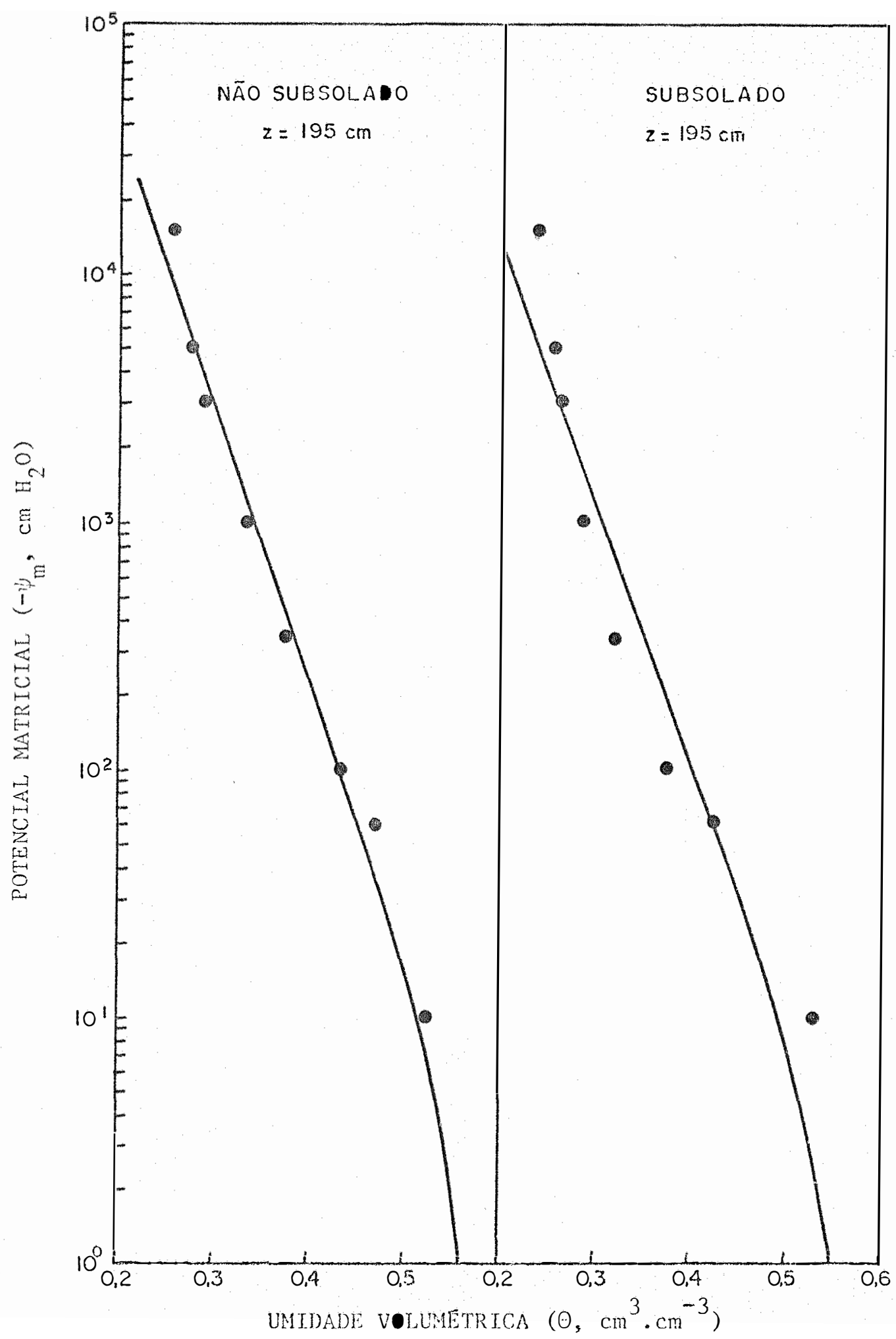

FIGURA 17 - Curvas de retenção da água no solo para a profundidade de $195 \mathrm{~cm}$ das äreas näo subsolada esubsolada da Terra Roxa Estruturada. Os pontos representam os dados experimentais e a linha a equacio (5). 


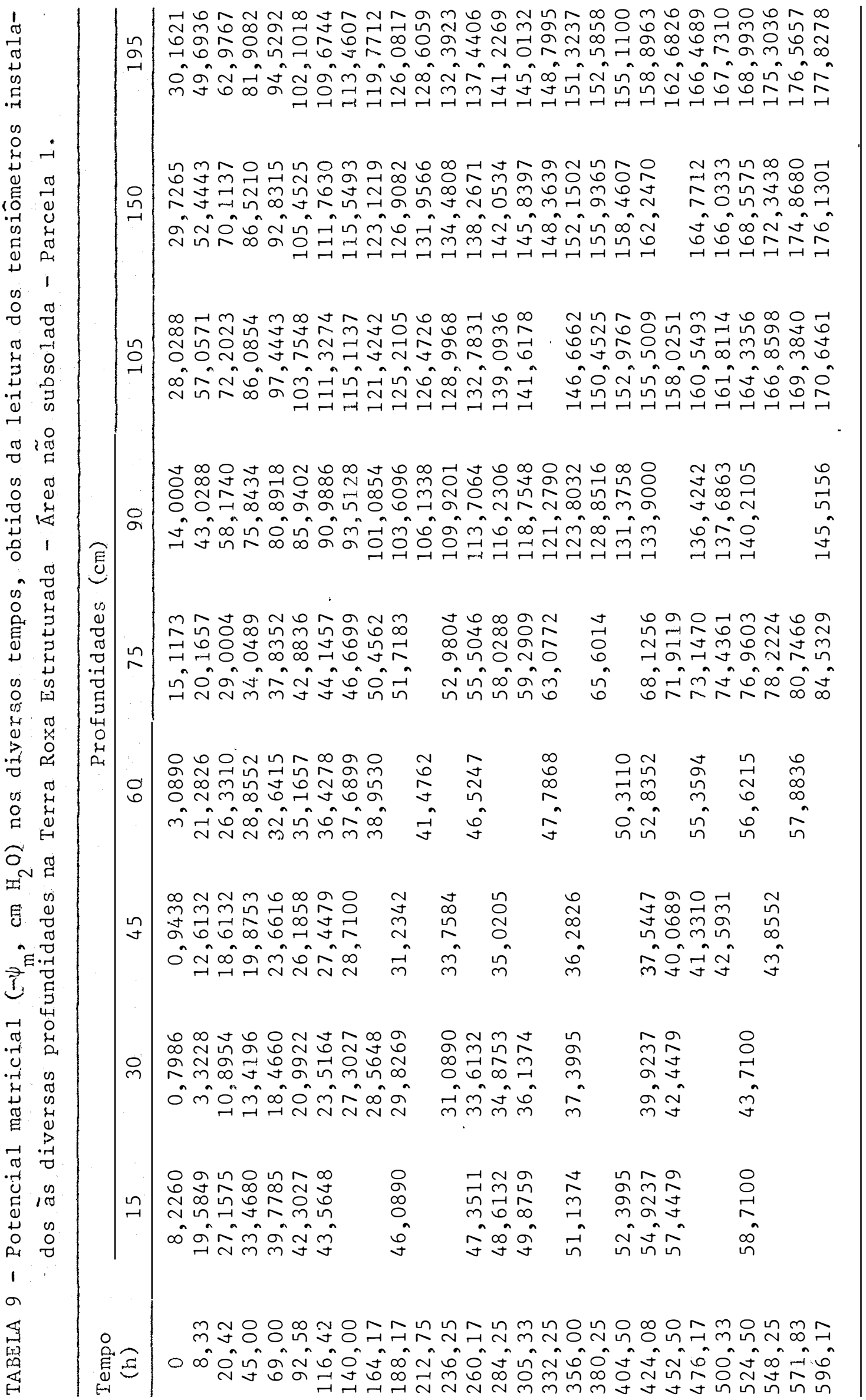




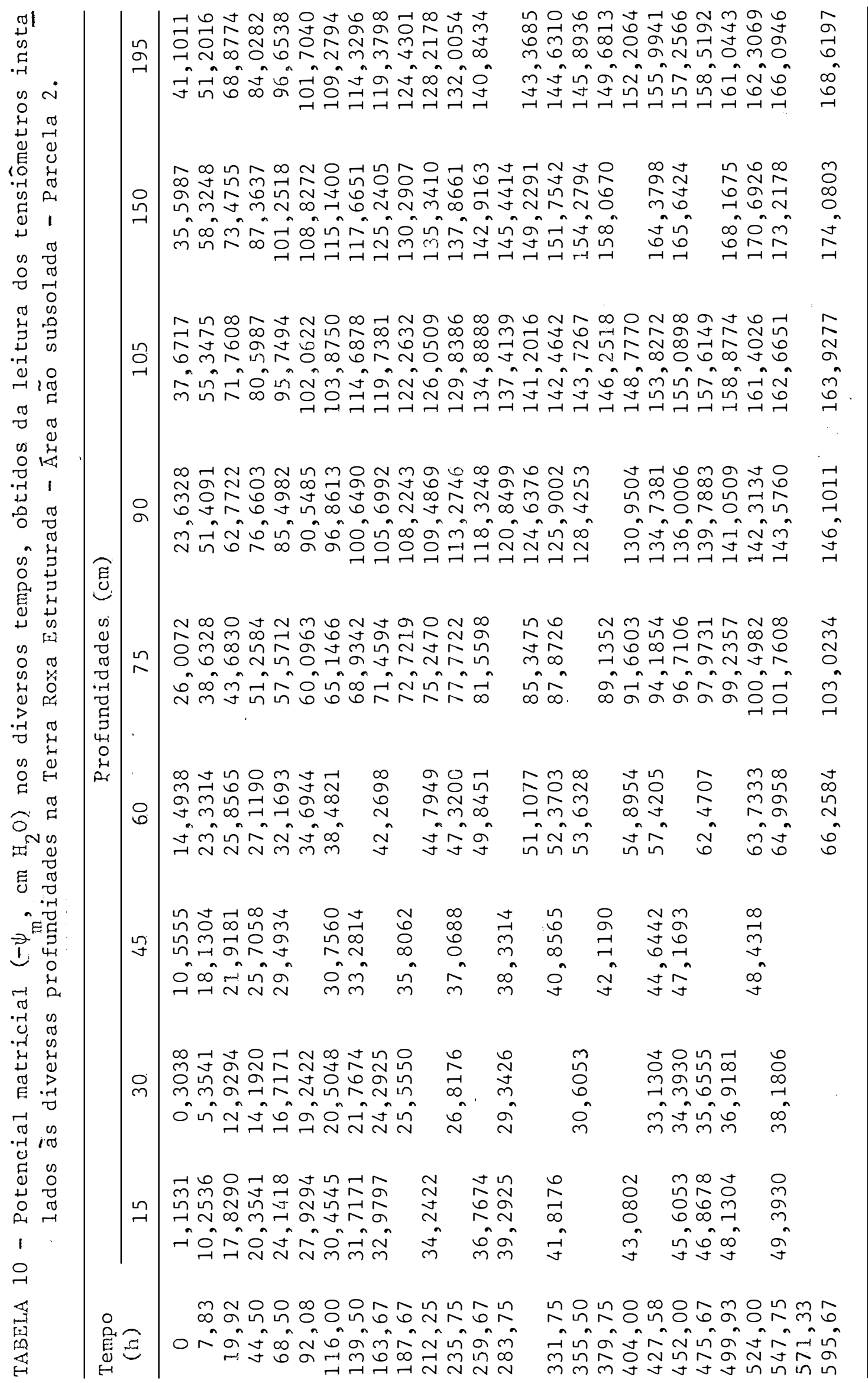


क ल

난

岂

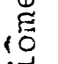

os

बै

क त

(2)

ठ

๘

光

c)

$\rightarrow ?$

ग

is

क 年

号

م

कें

D

岂

D

os

a)

.

$\nabla$

D

ช.

IN

E

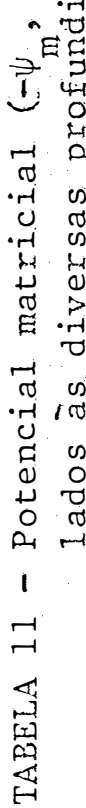

10

in

is

क क

Uु

G

岃 О

م.

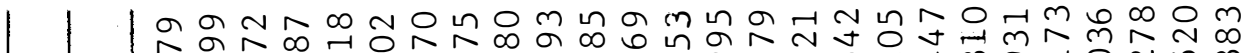

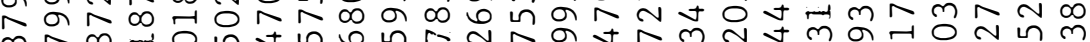

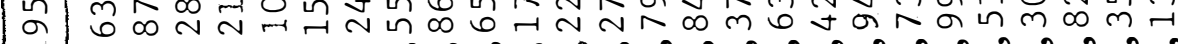

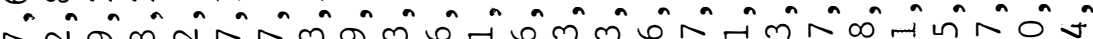

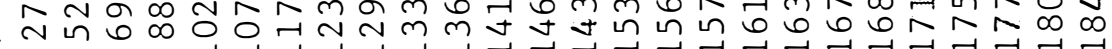

बิำ

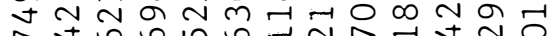

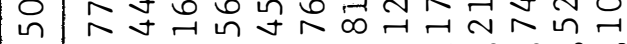

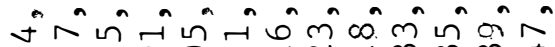

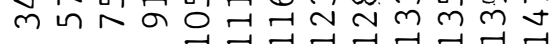

$m+4 \infty 0 \cdots+\infty$

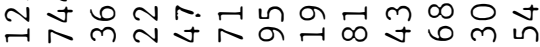
ज

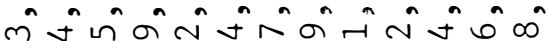

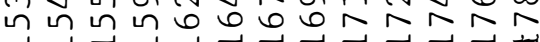

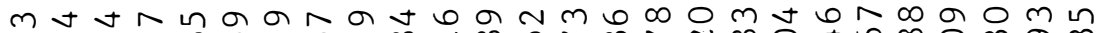

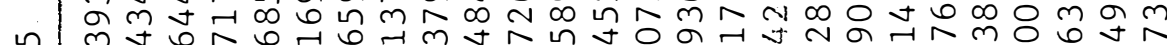

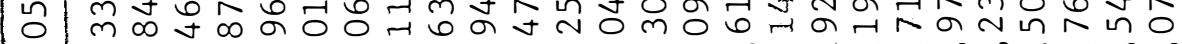

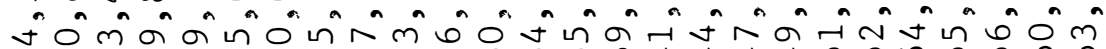
mं

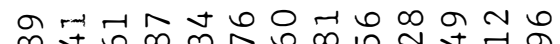

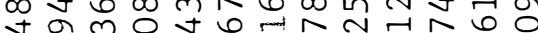

o

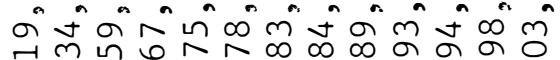

ำㅇำ

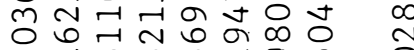
व $\sim m$ b 6 or

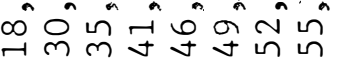
in

คำำ กิ

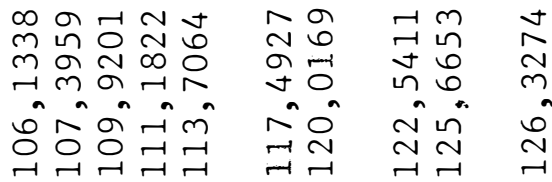

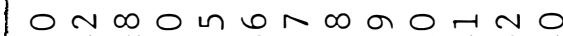
क ले ○ ค่ กิ่

ก m

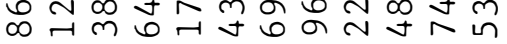

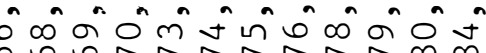
(1)

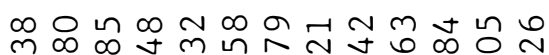

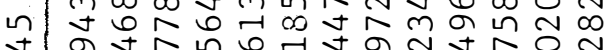

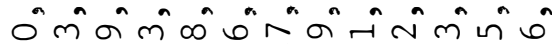

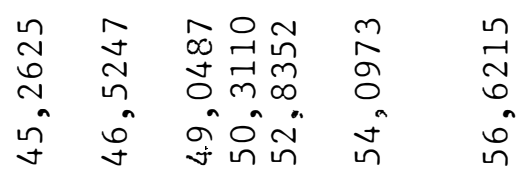

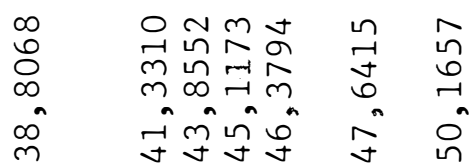

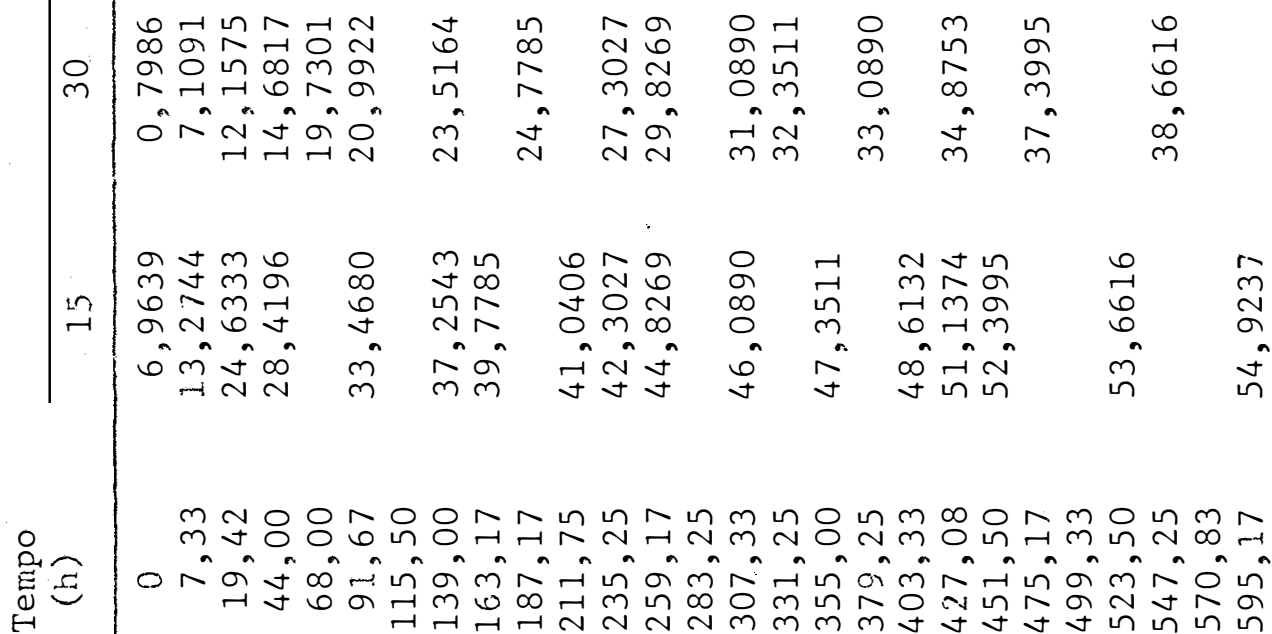

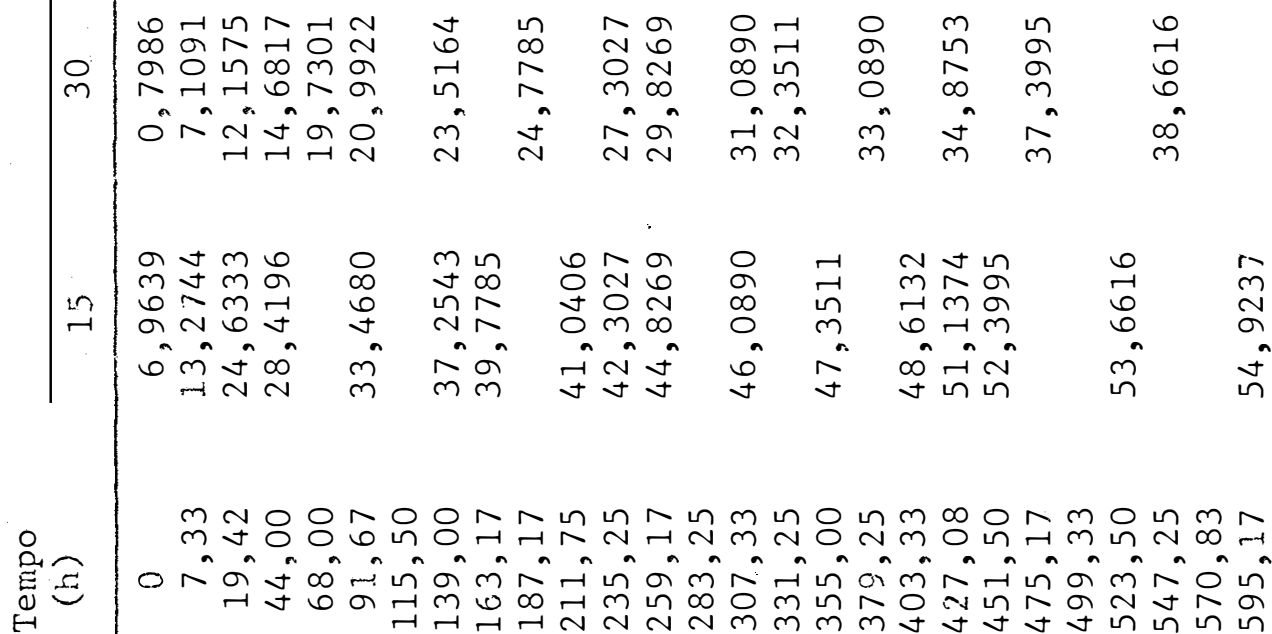




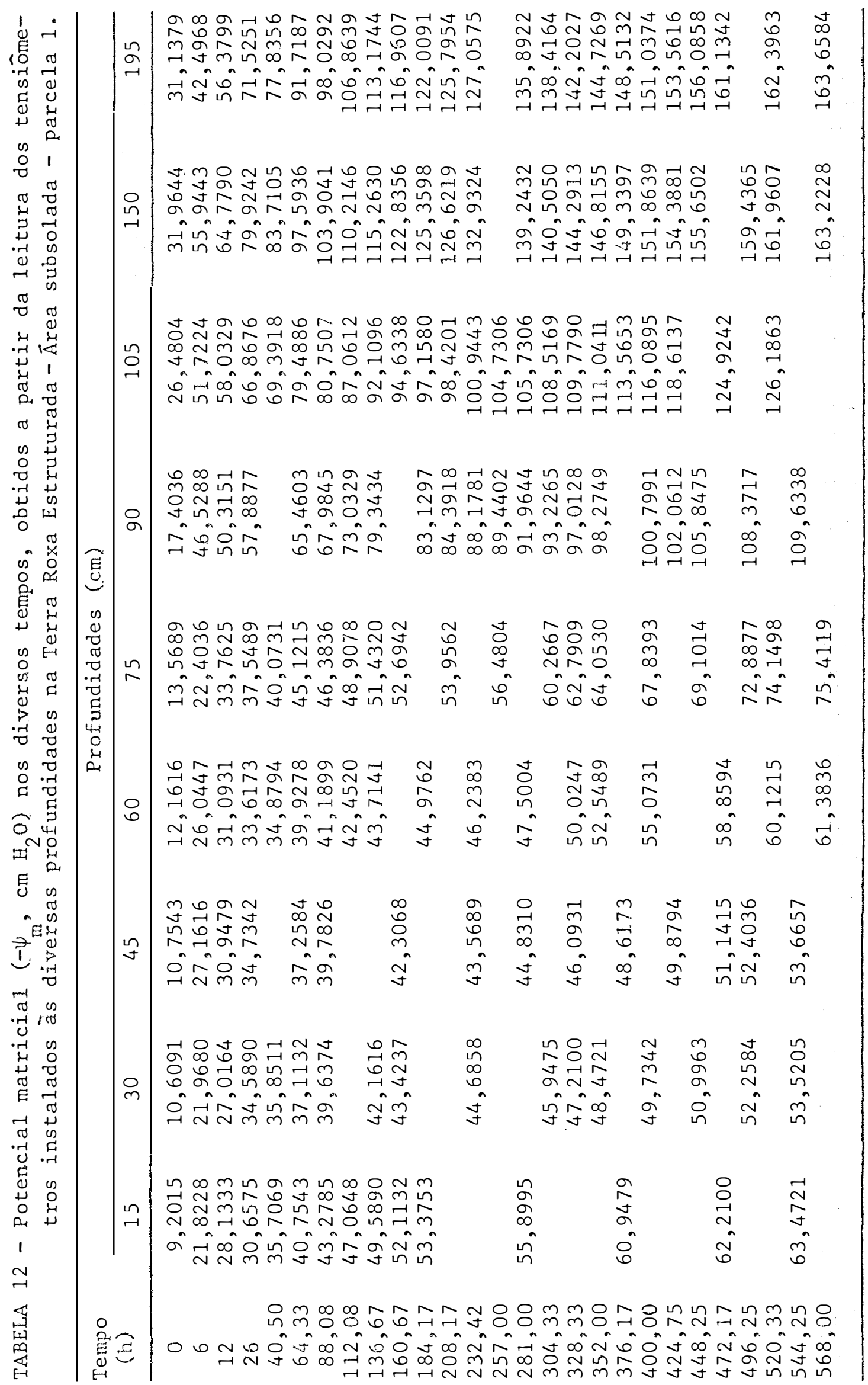




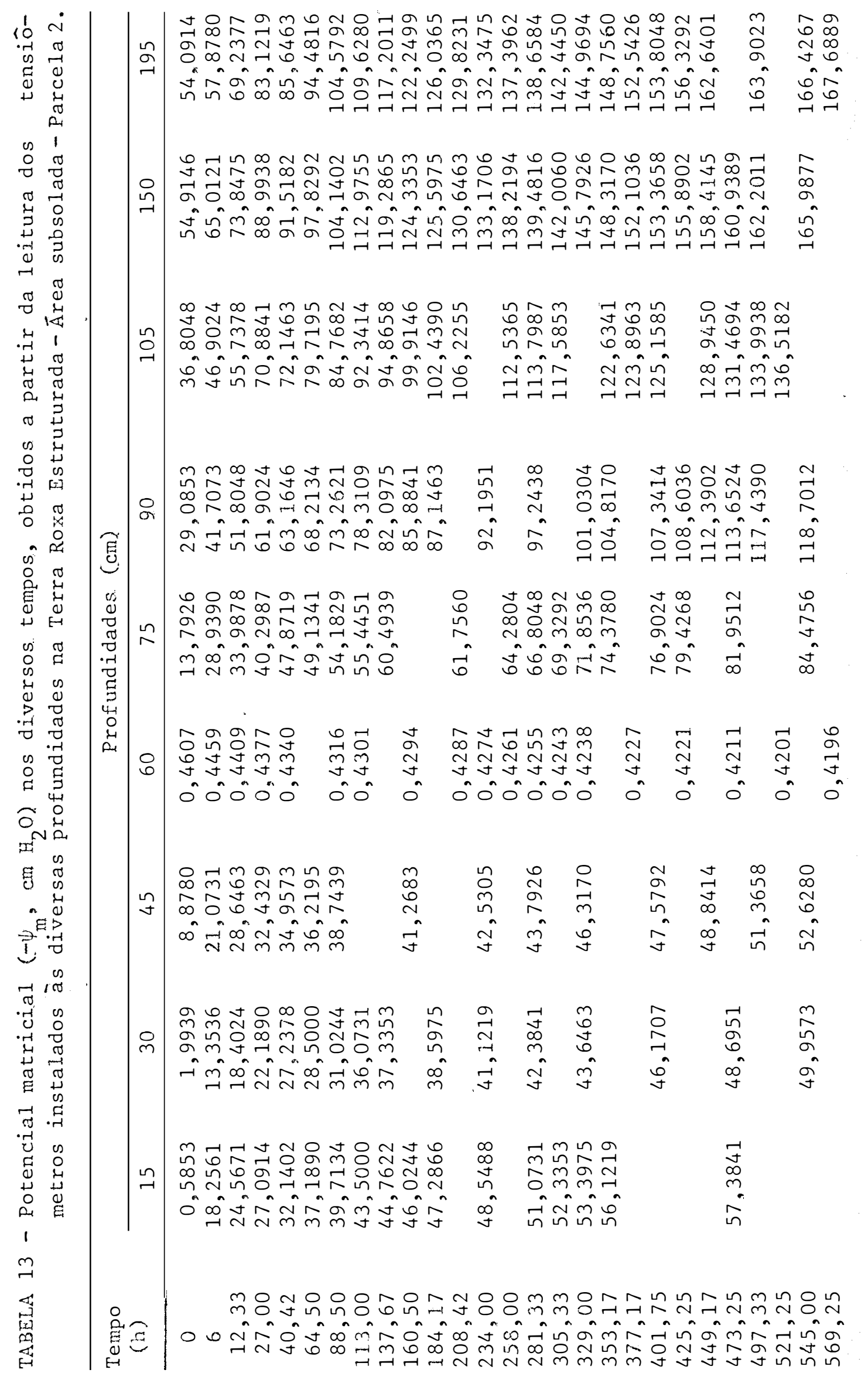




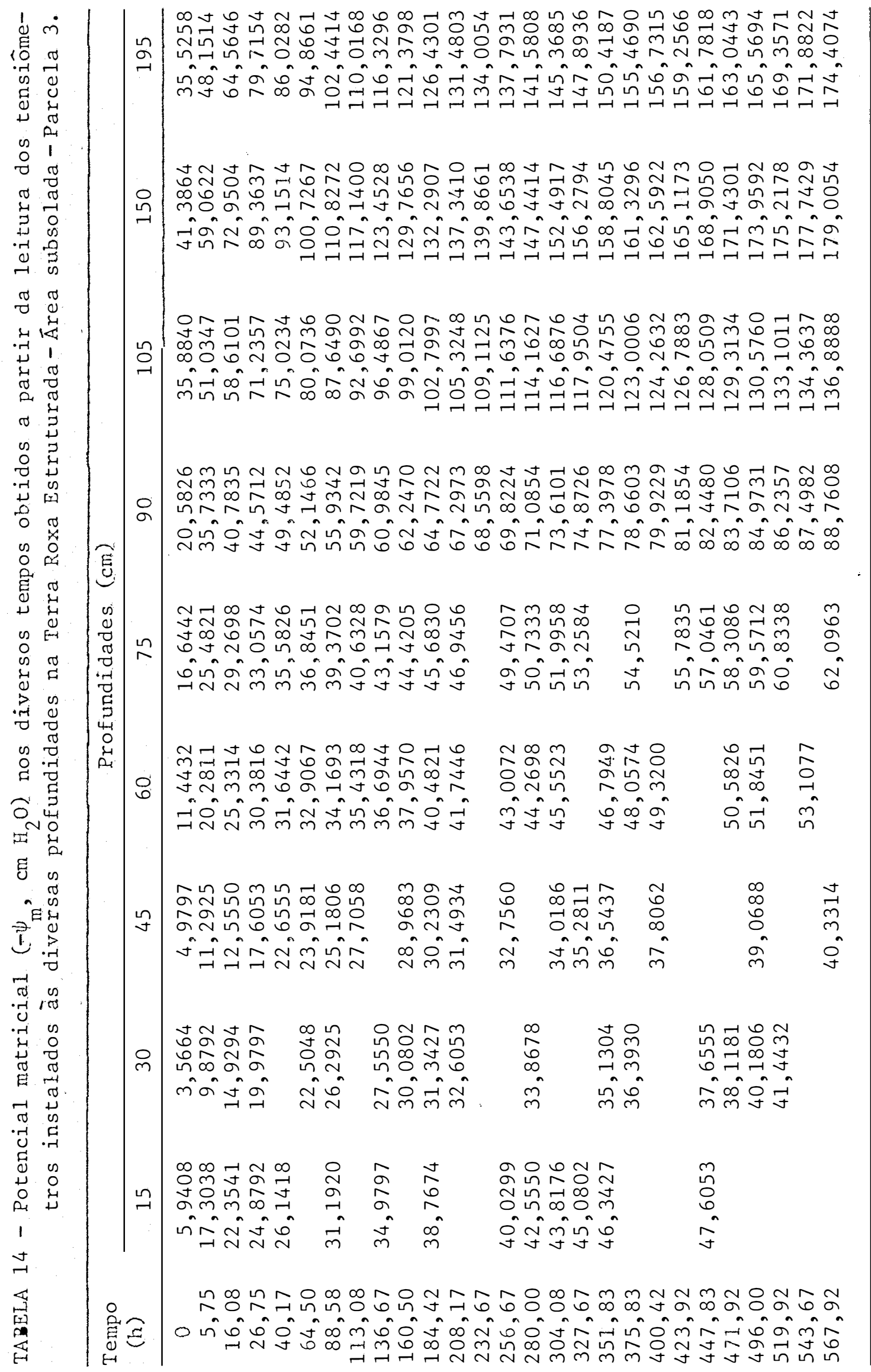




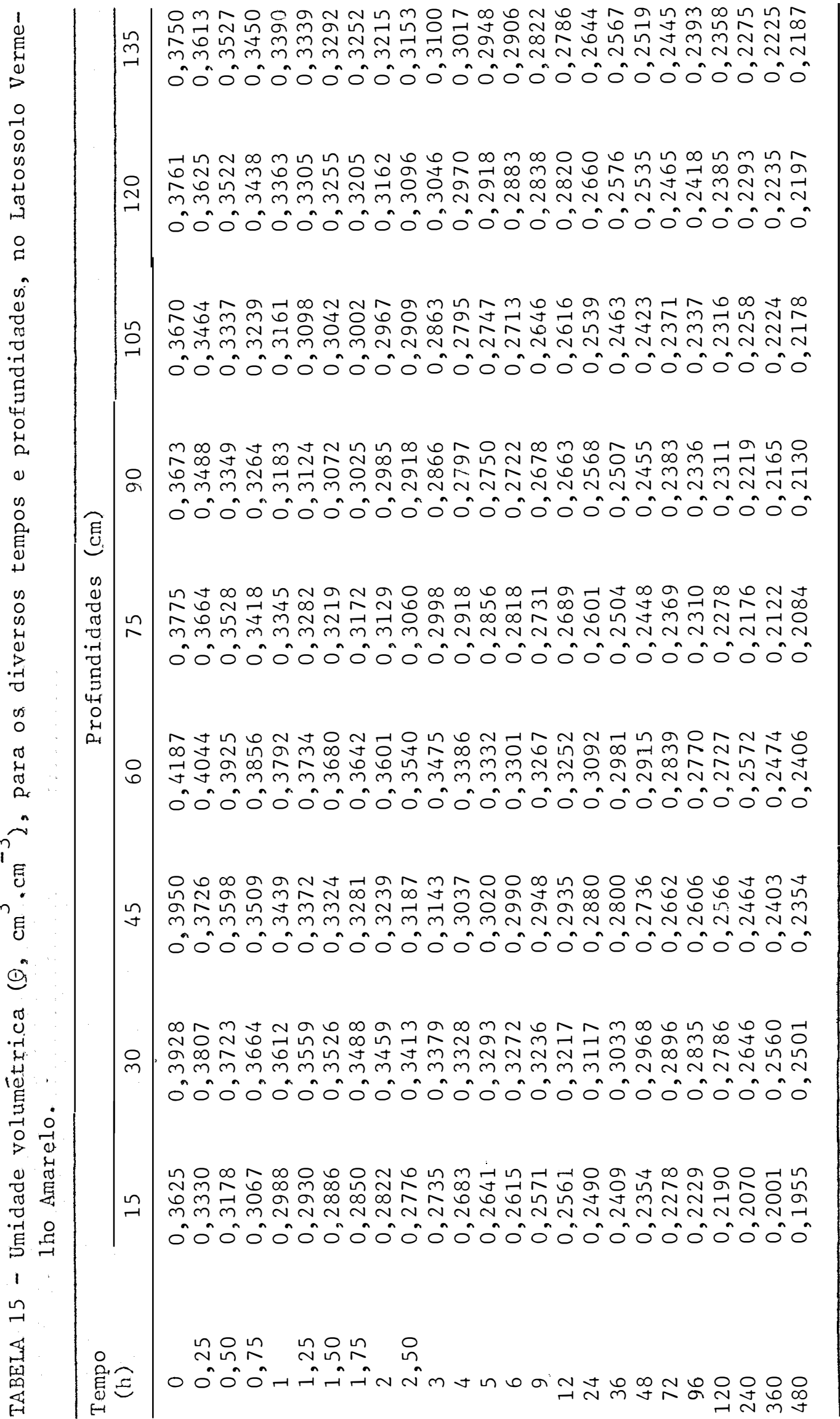




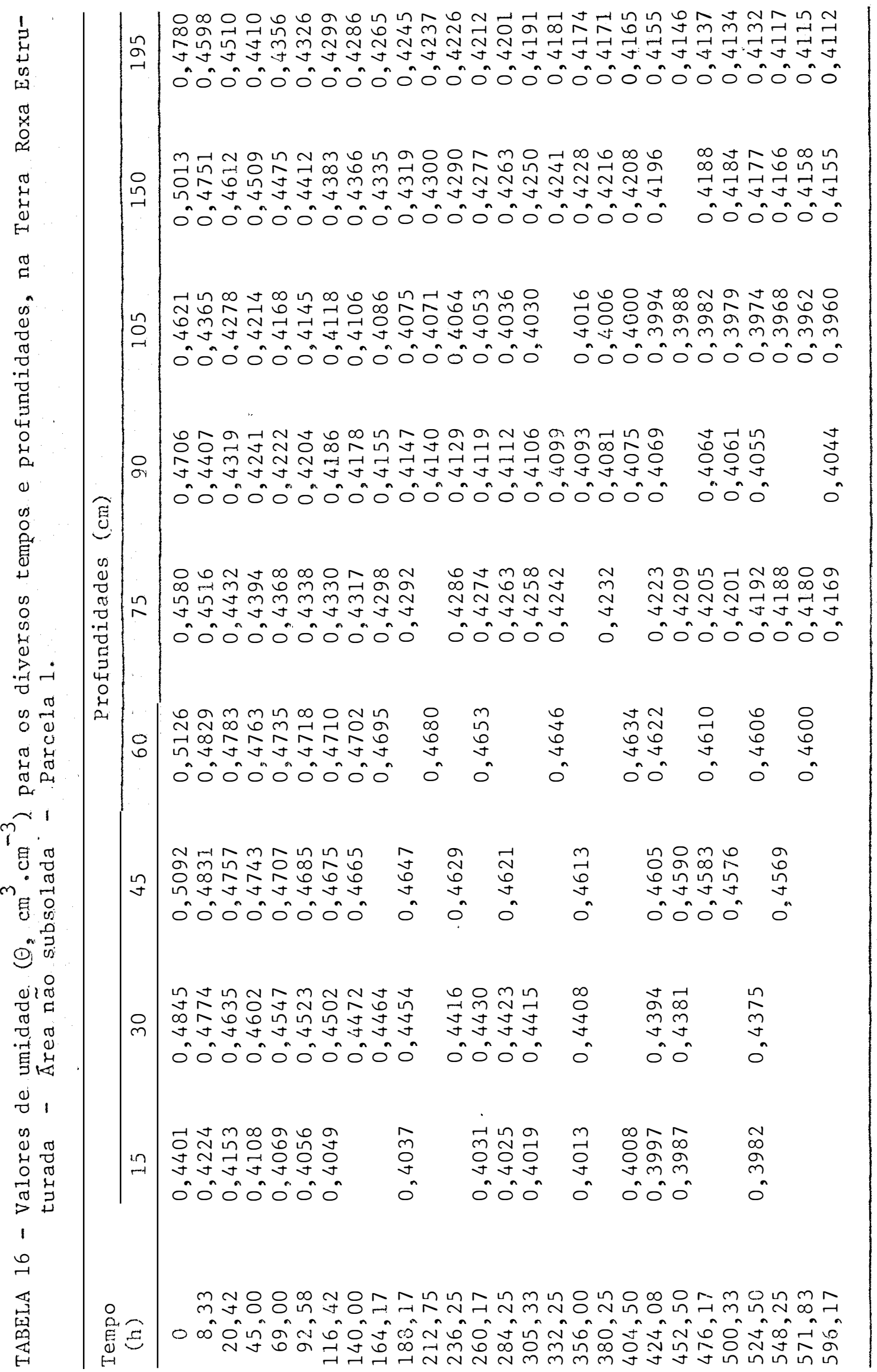




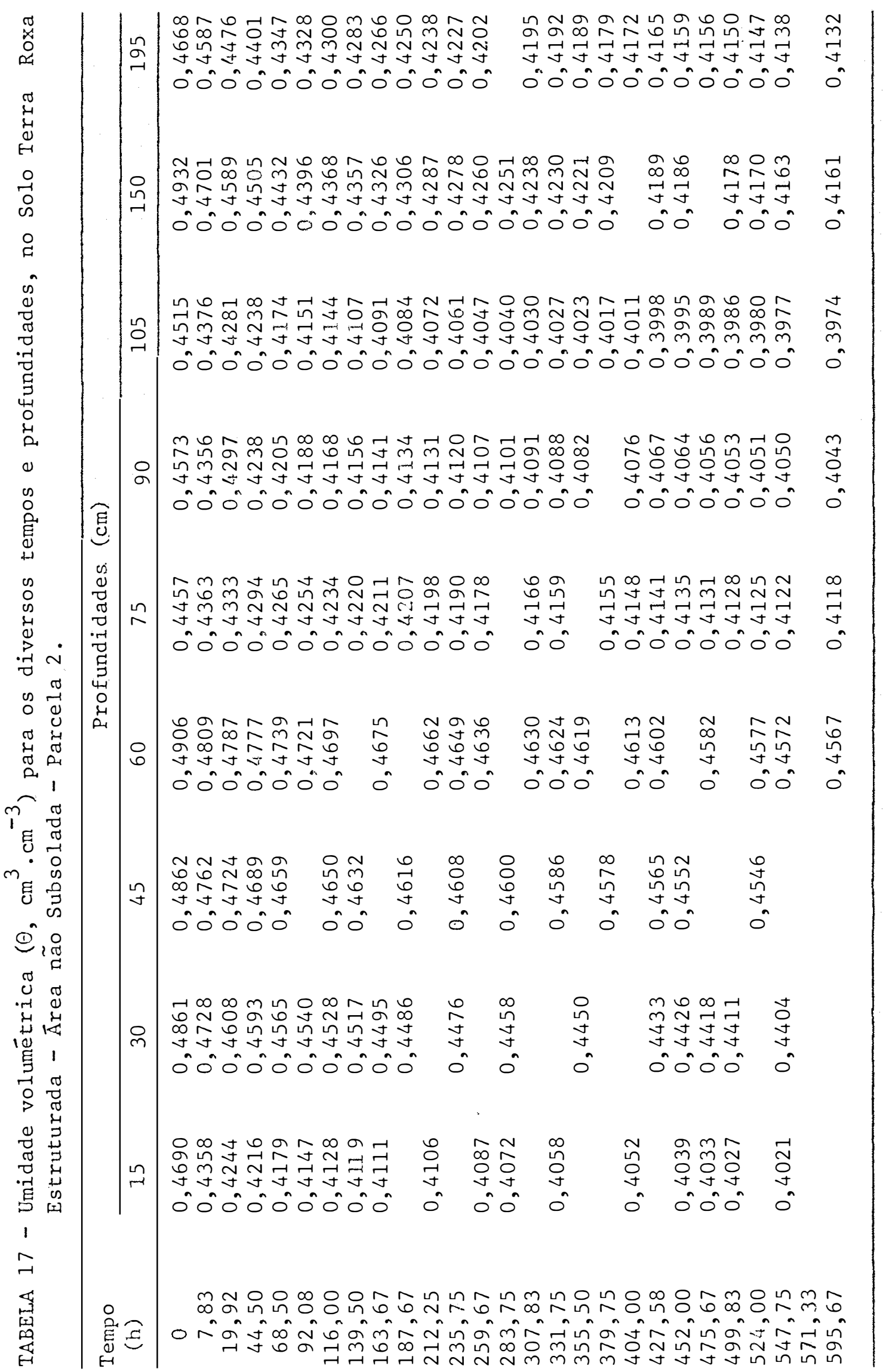




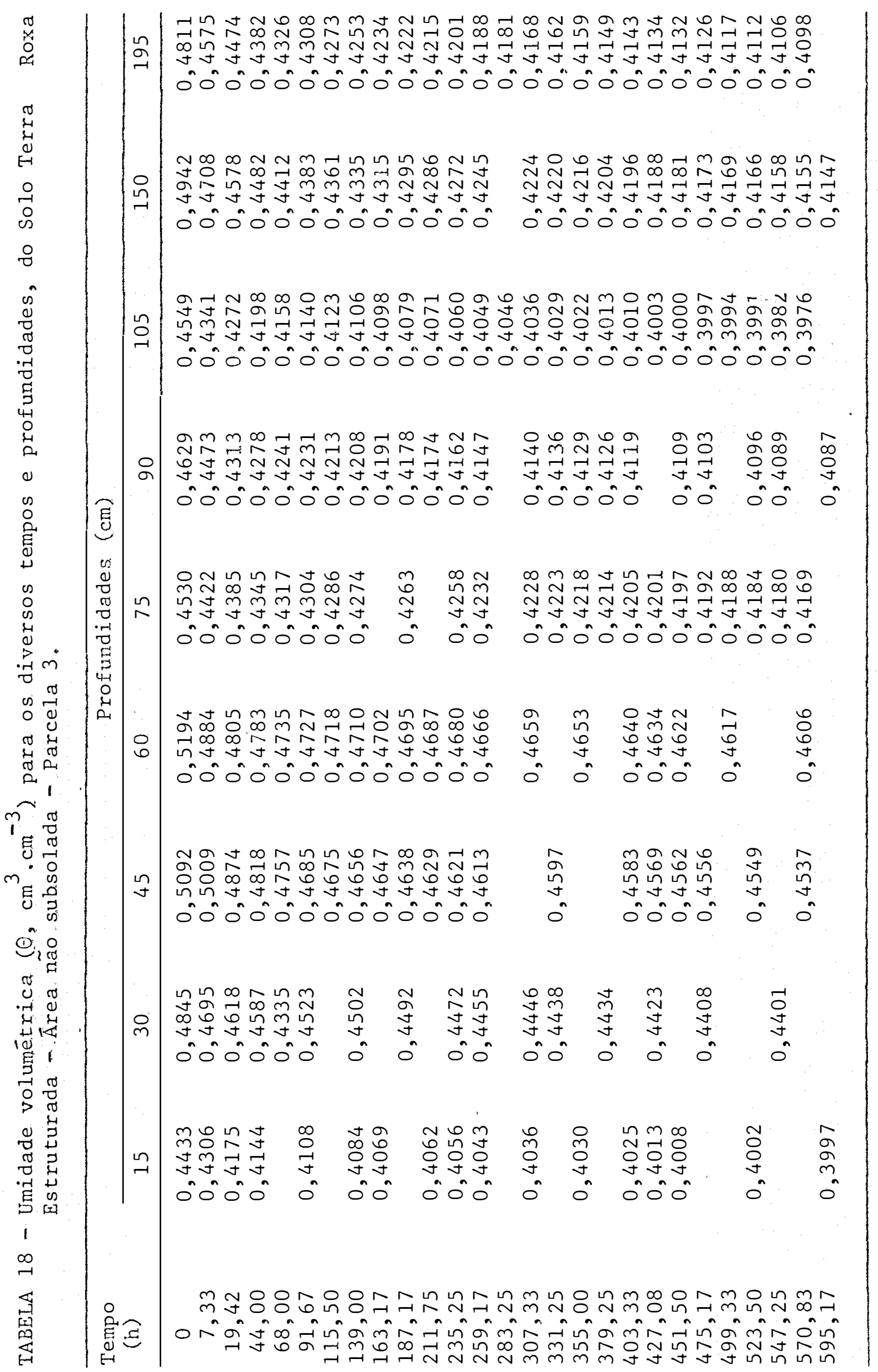




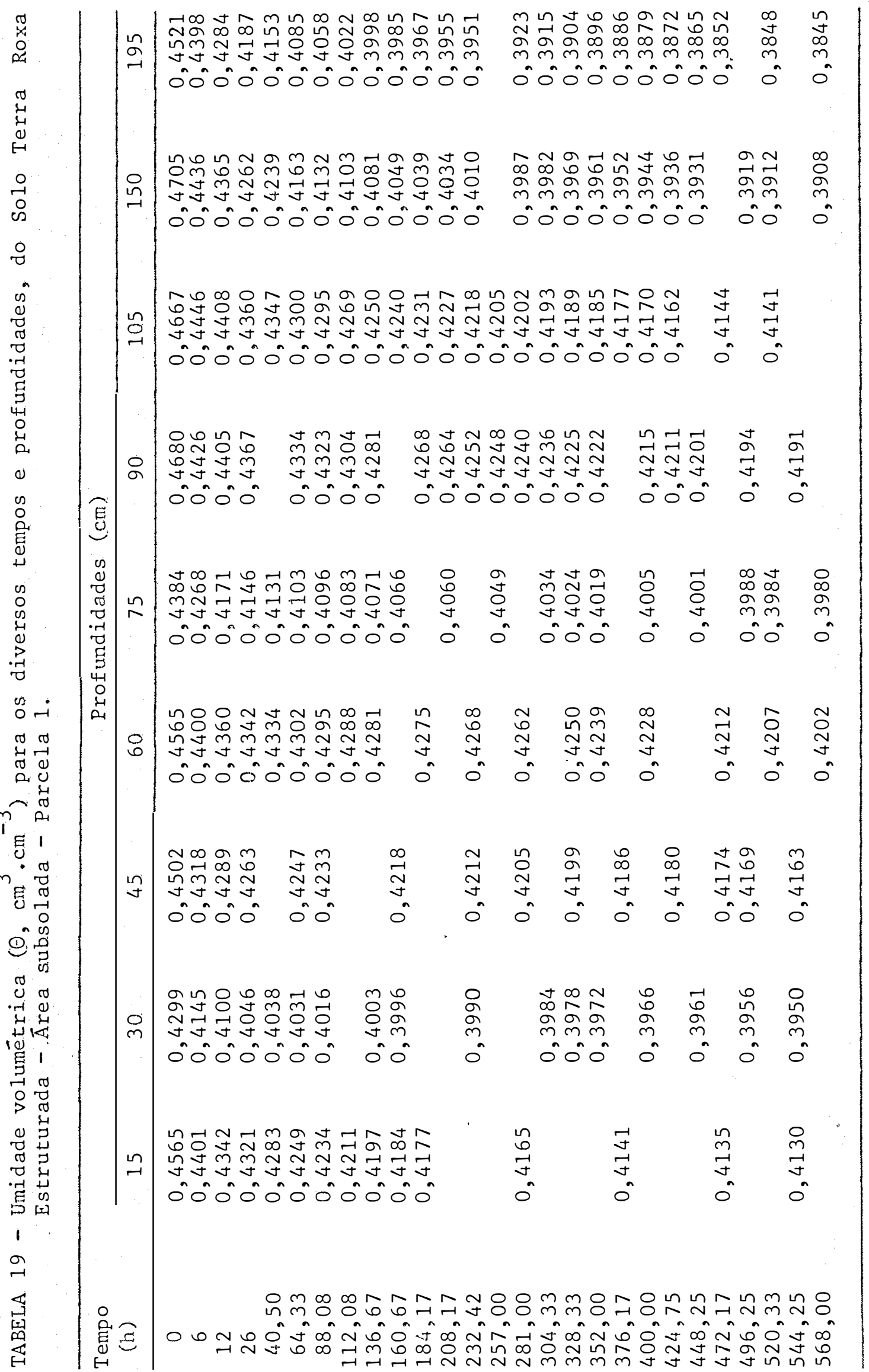




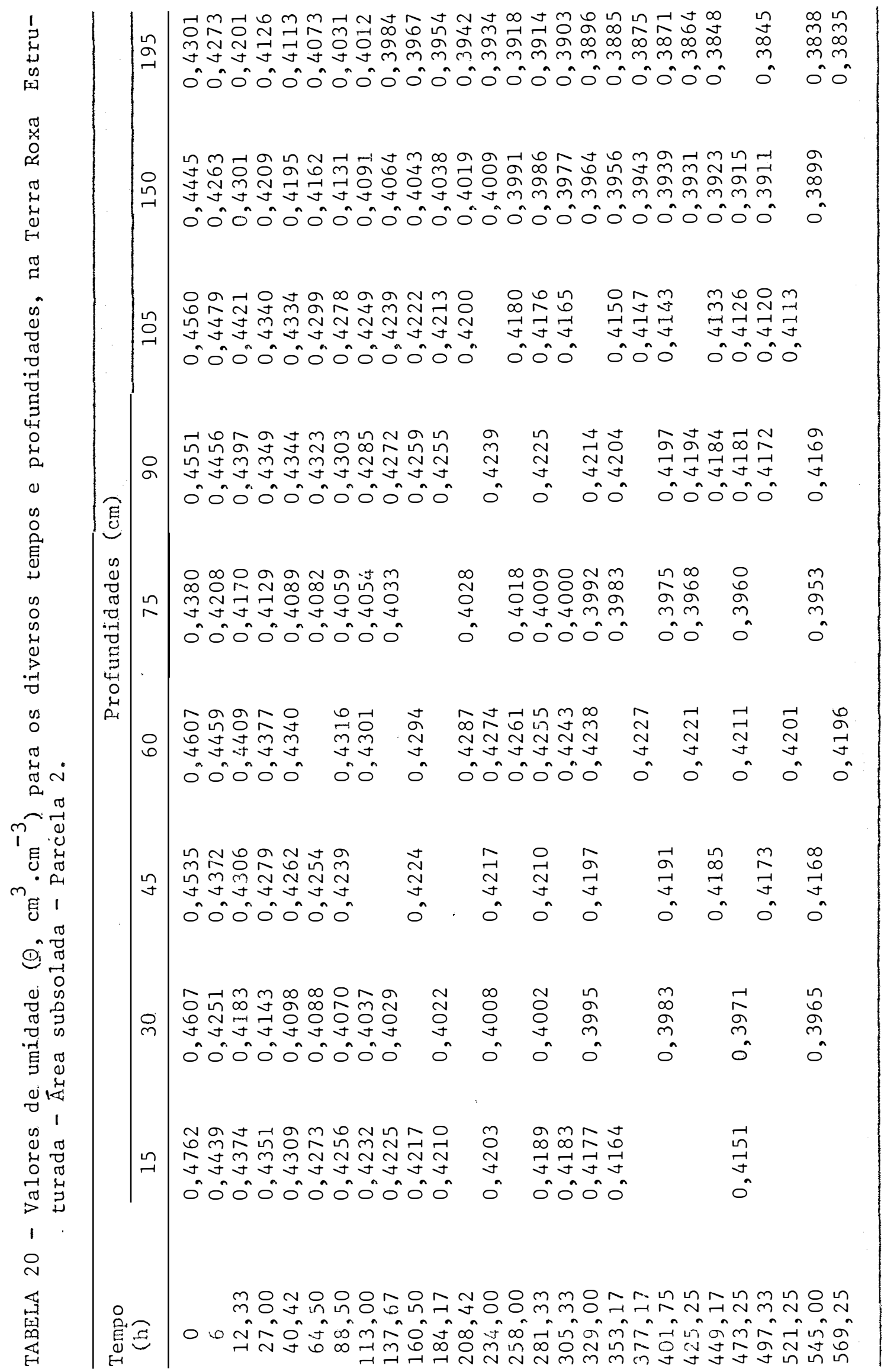




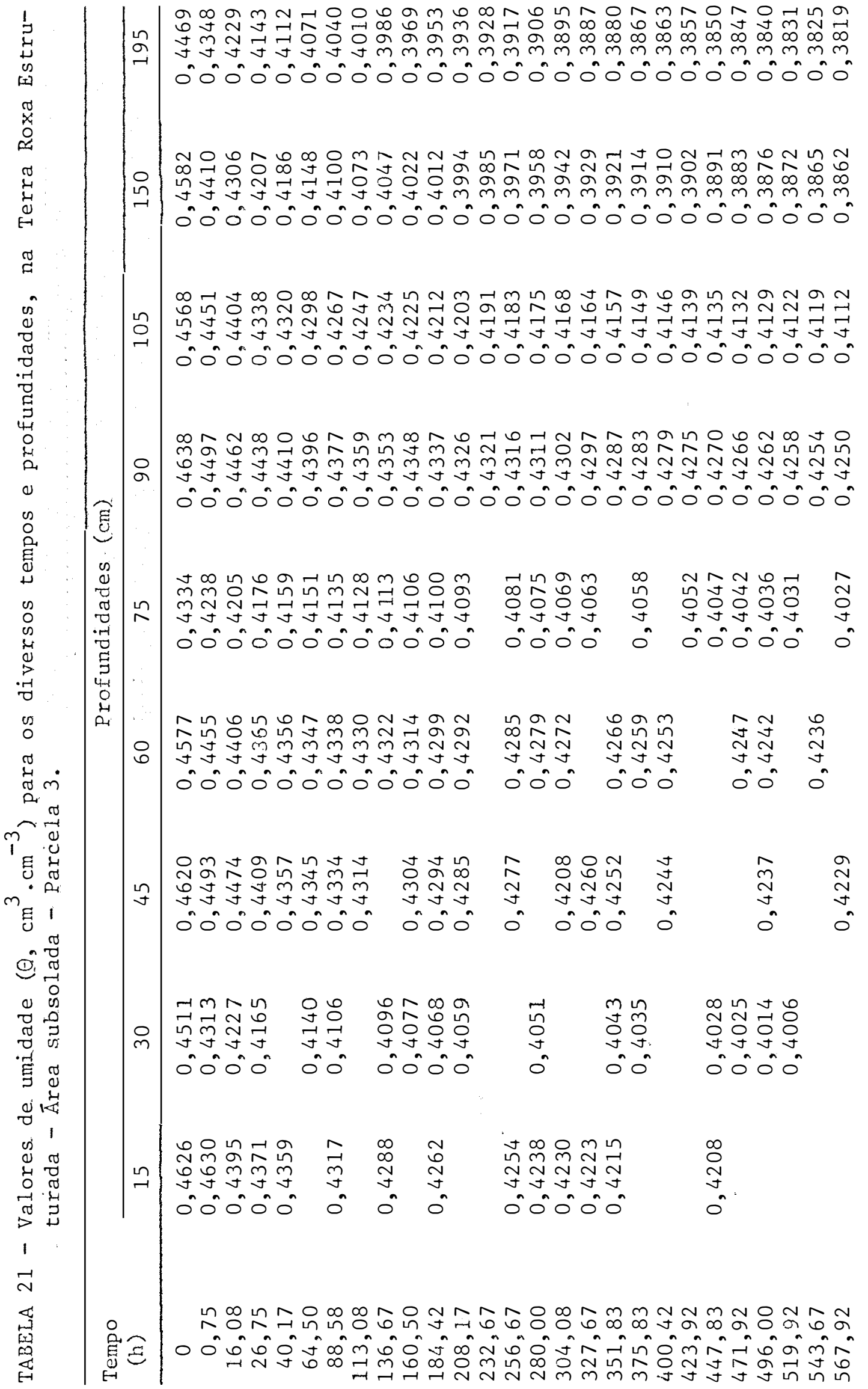




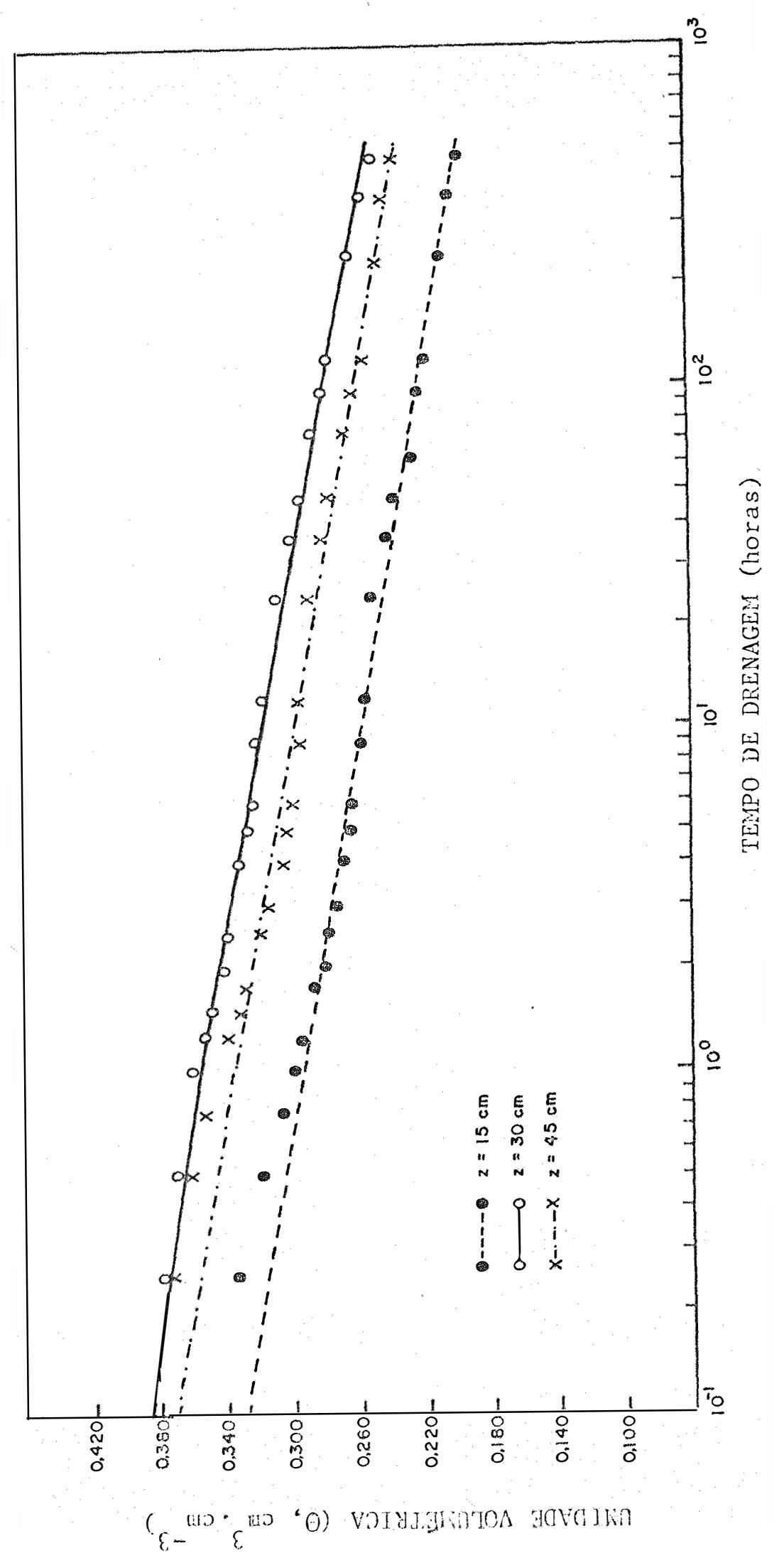

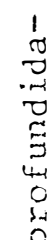

范 

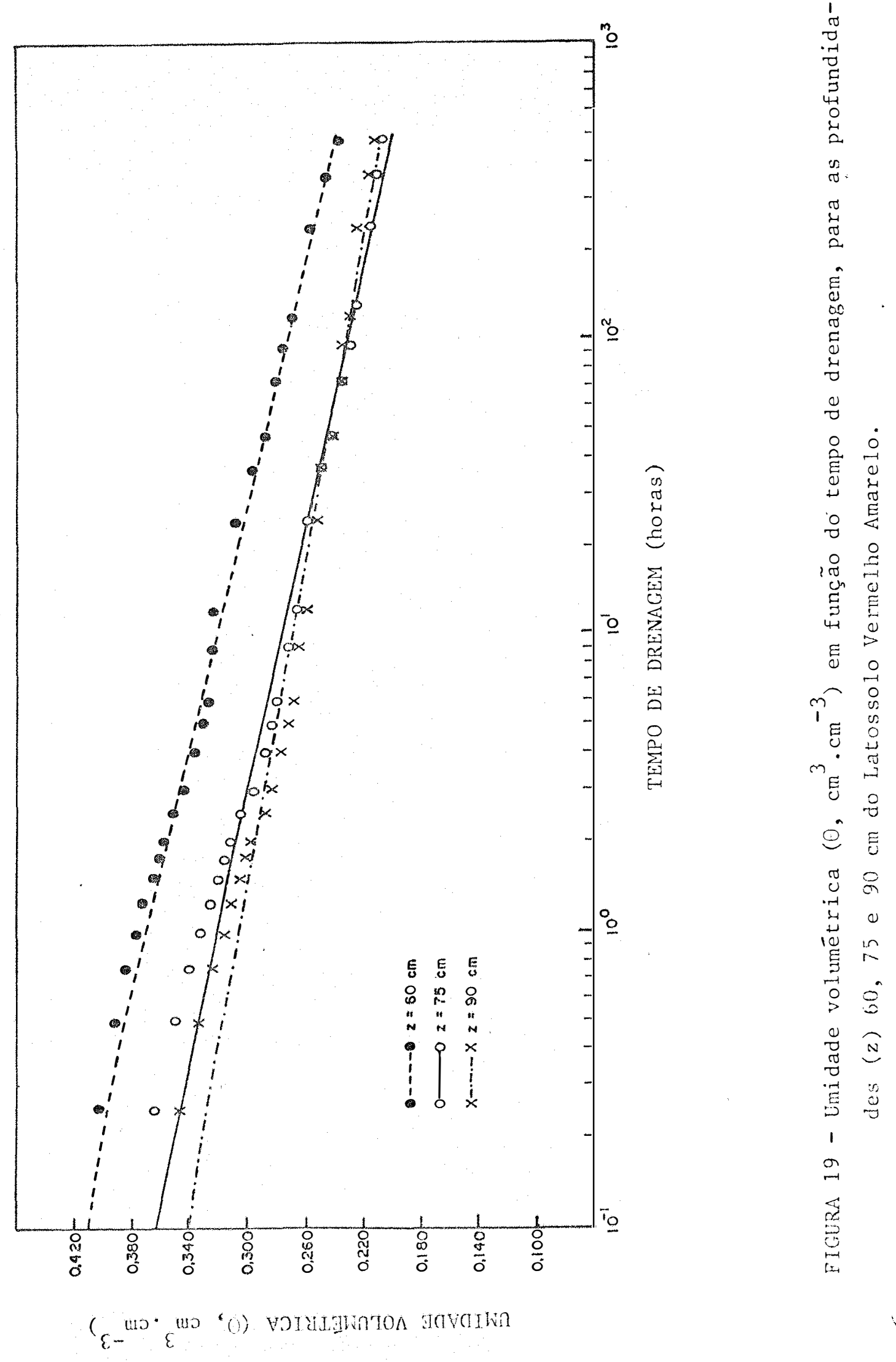

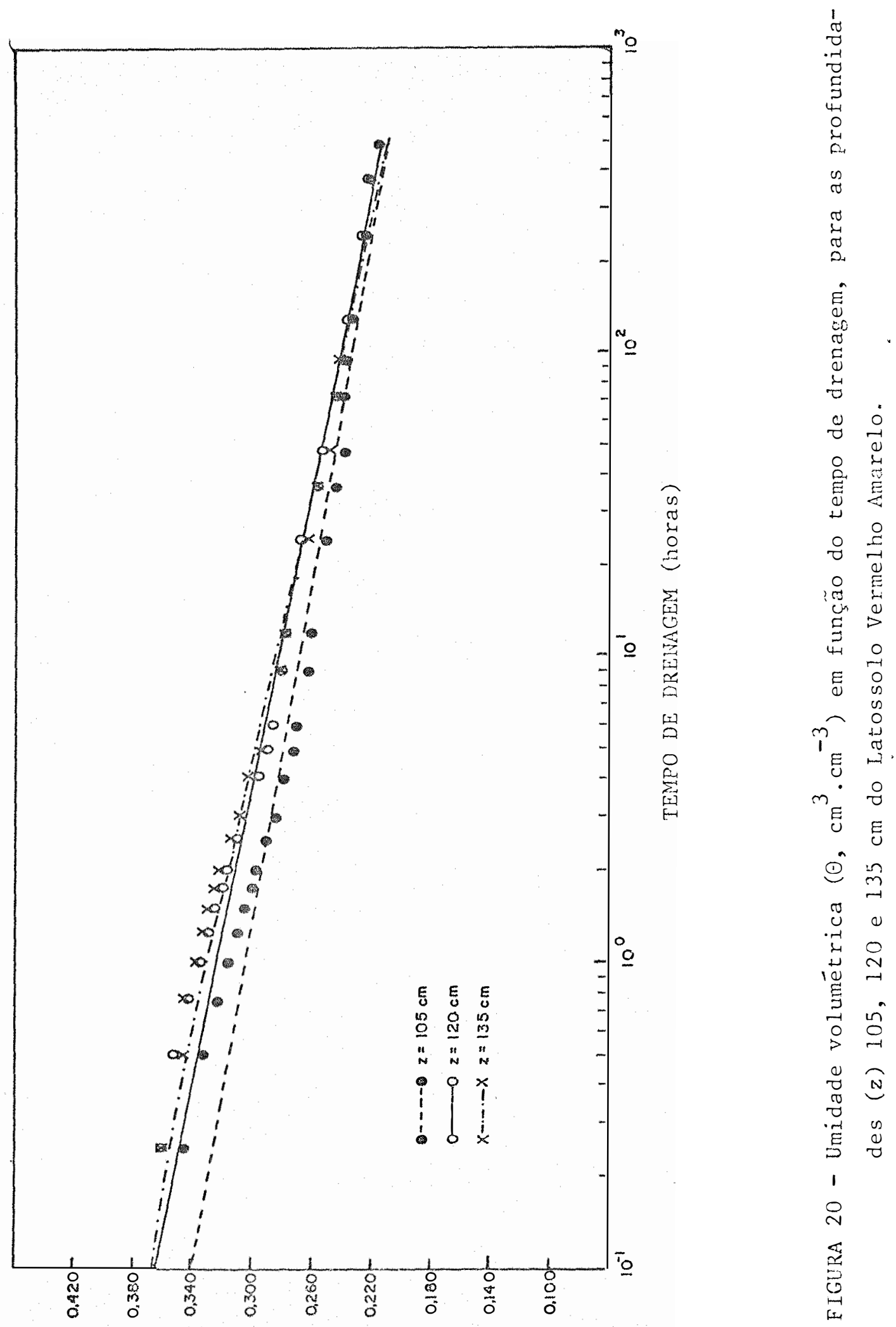

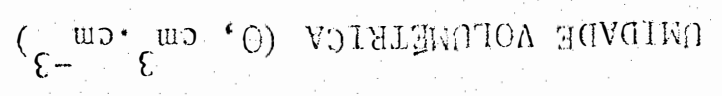



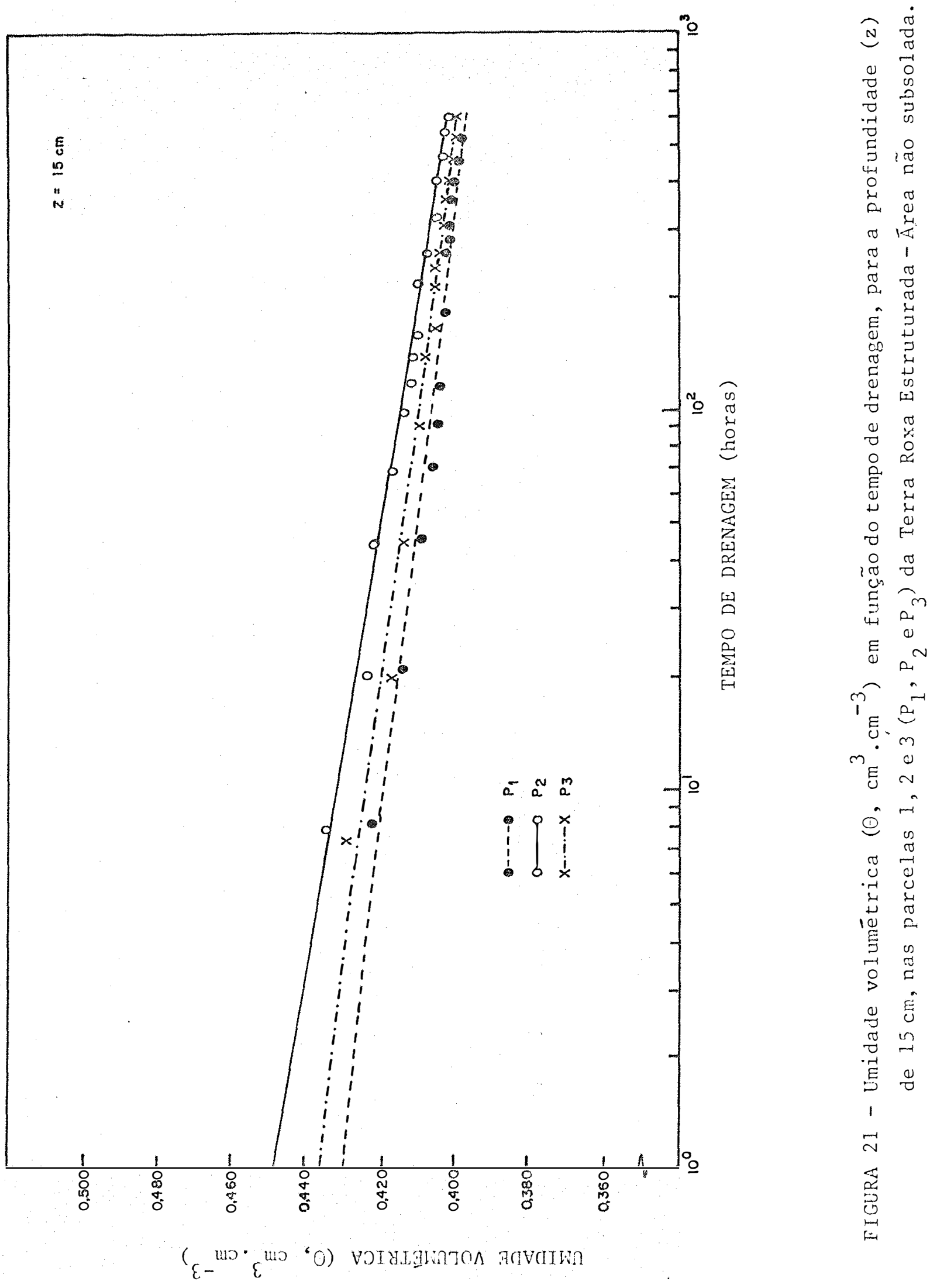

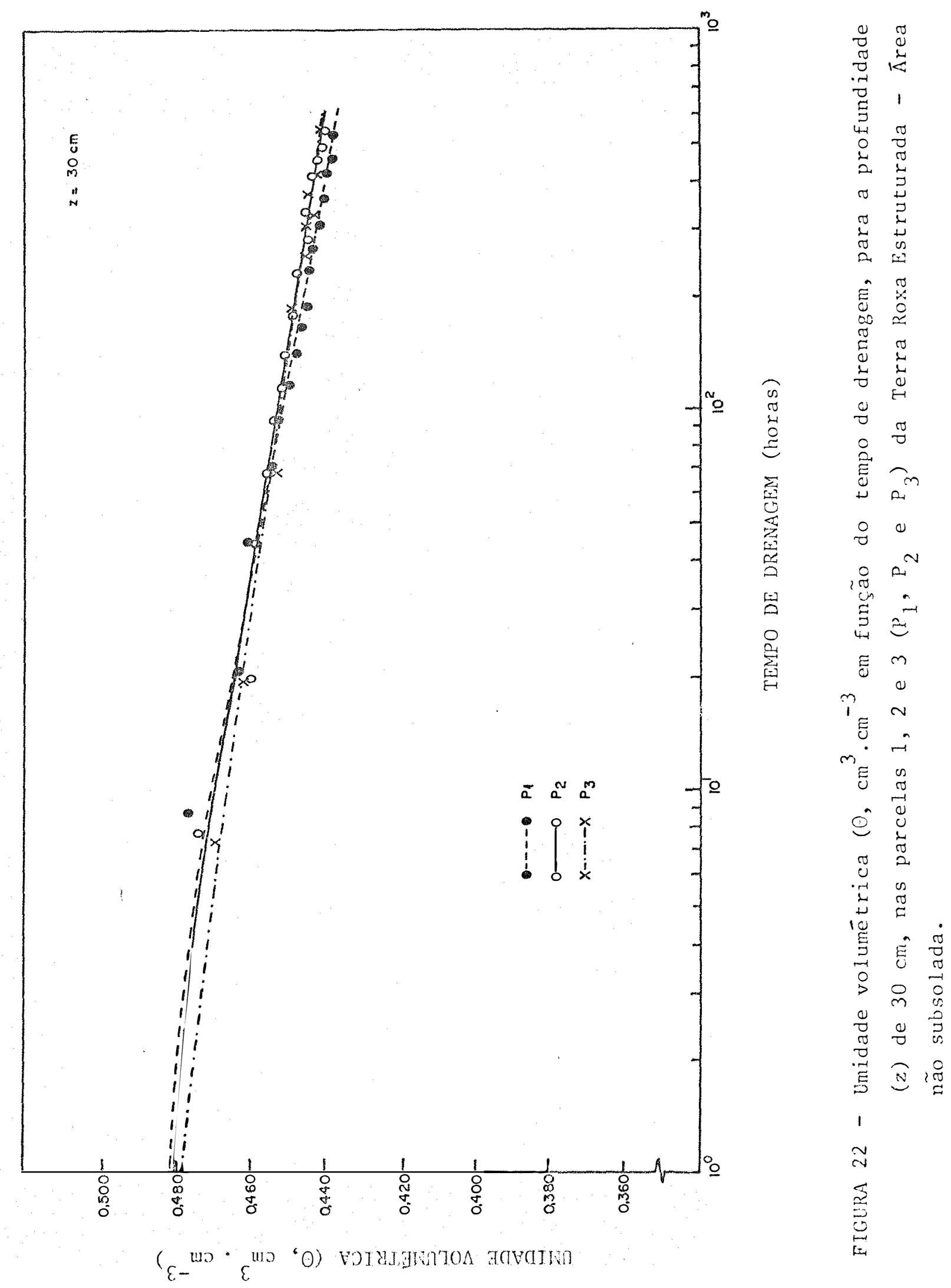


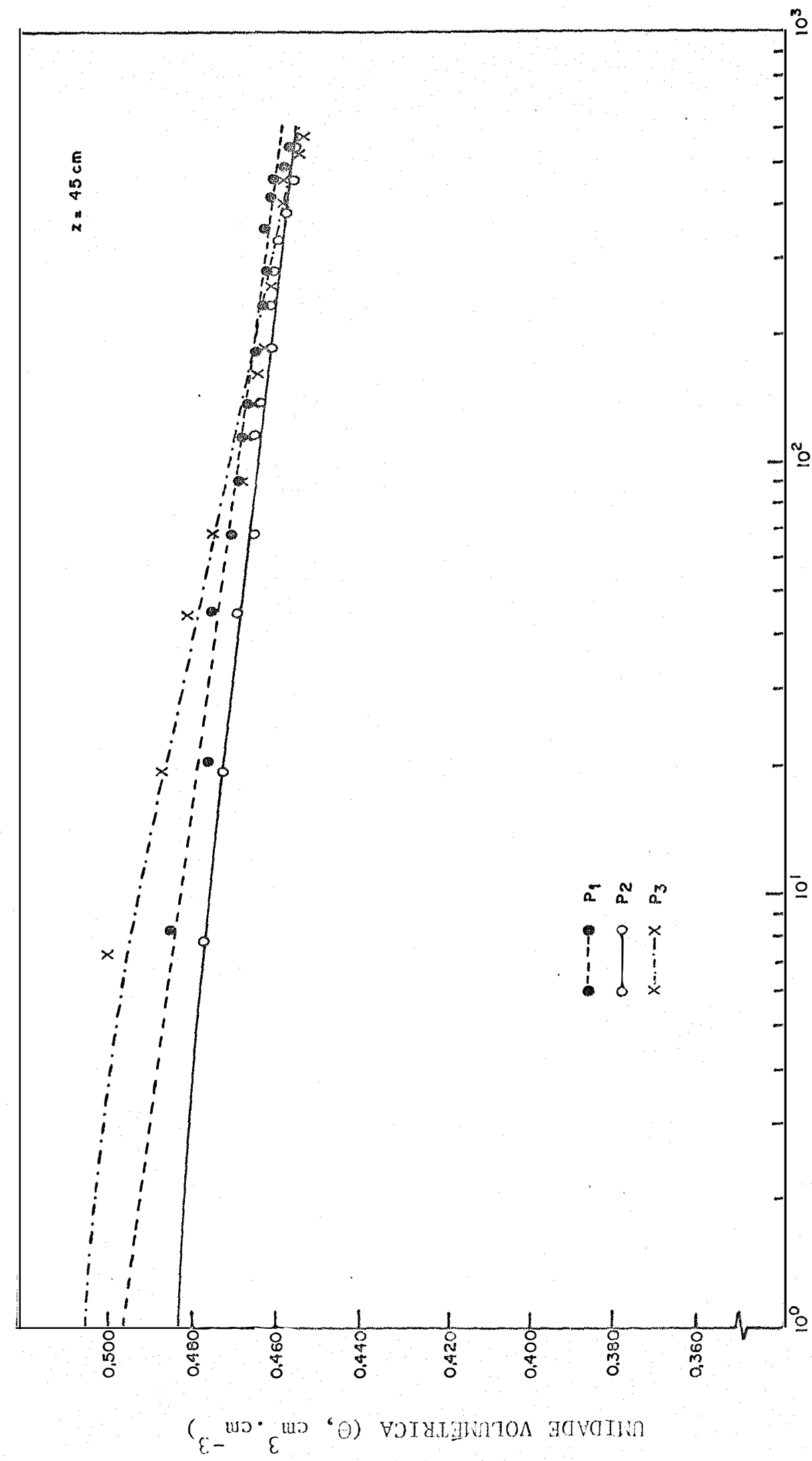

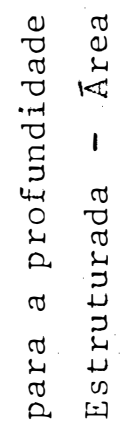

है

$\underset{0}{\infty} x$

¿્d

¿

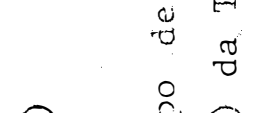

की

$\stackrel{0}{\complement} 0^{\circ}$

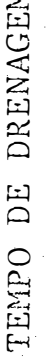

$a^{2}$

密

ह ह

E

व 0

?

ह

$m \cdot \frac{\pi}{\square}$

Q

$\begin{array}{cc}0 \\ 0 \\ -\pi & 0 \\ \pi & 0\end{array}$

10

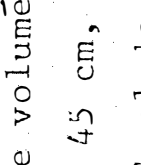

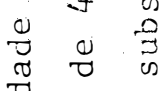

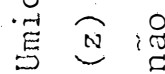

1

n

远 

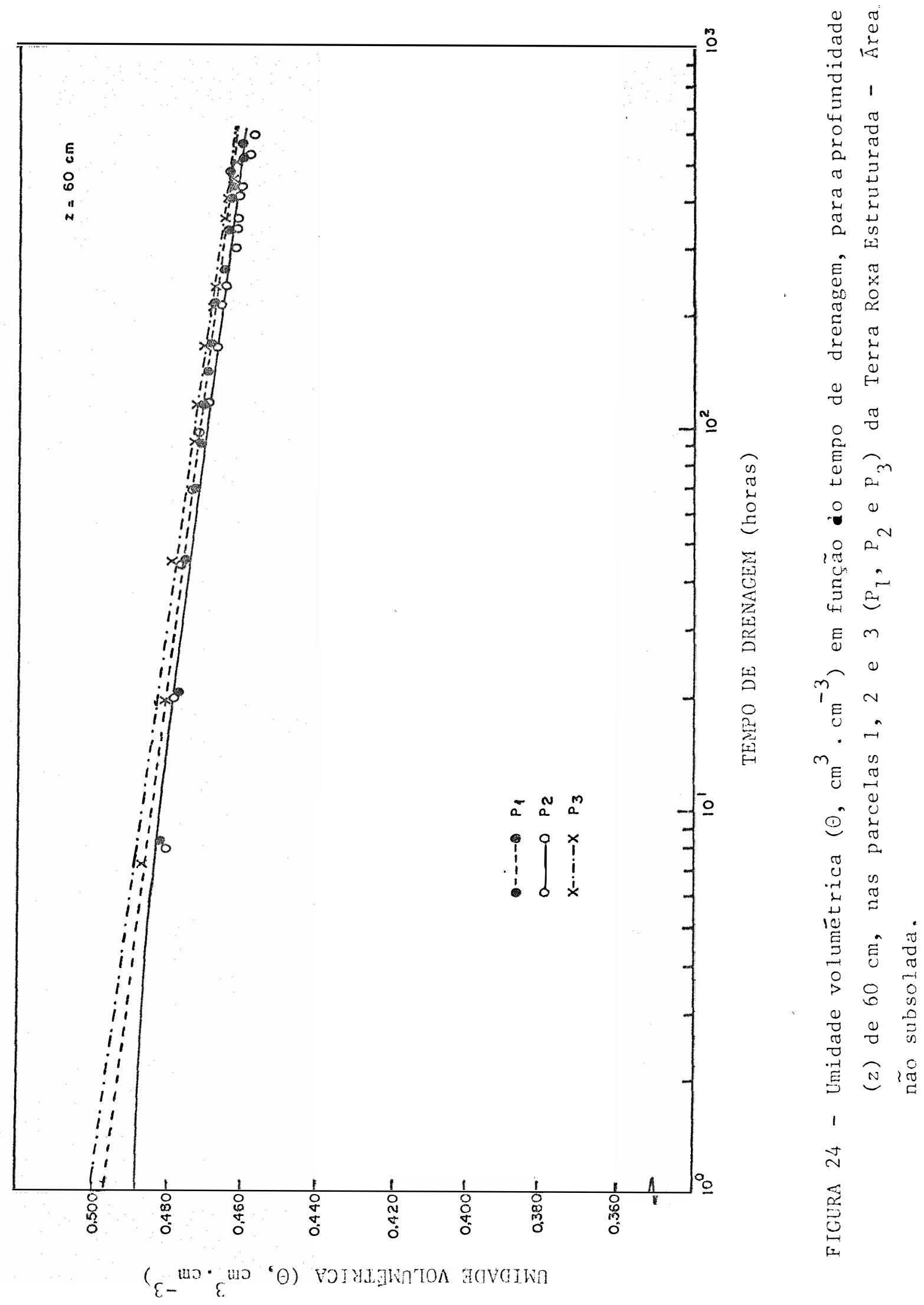

孛 

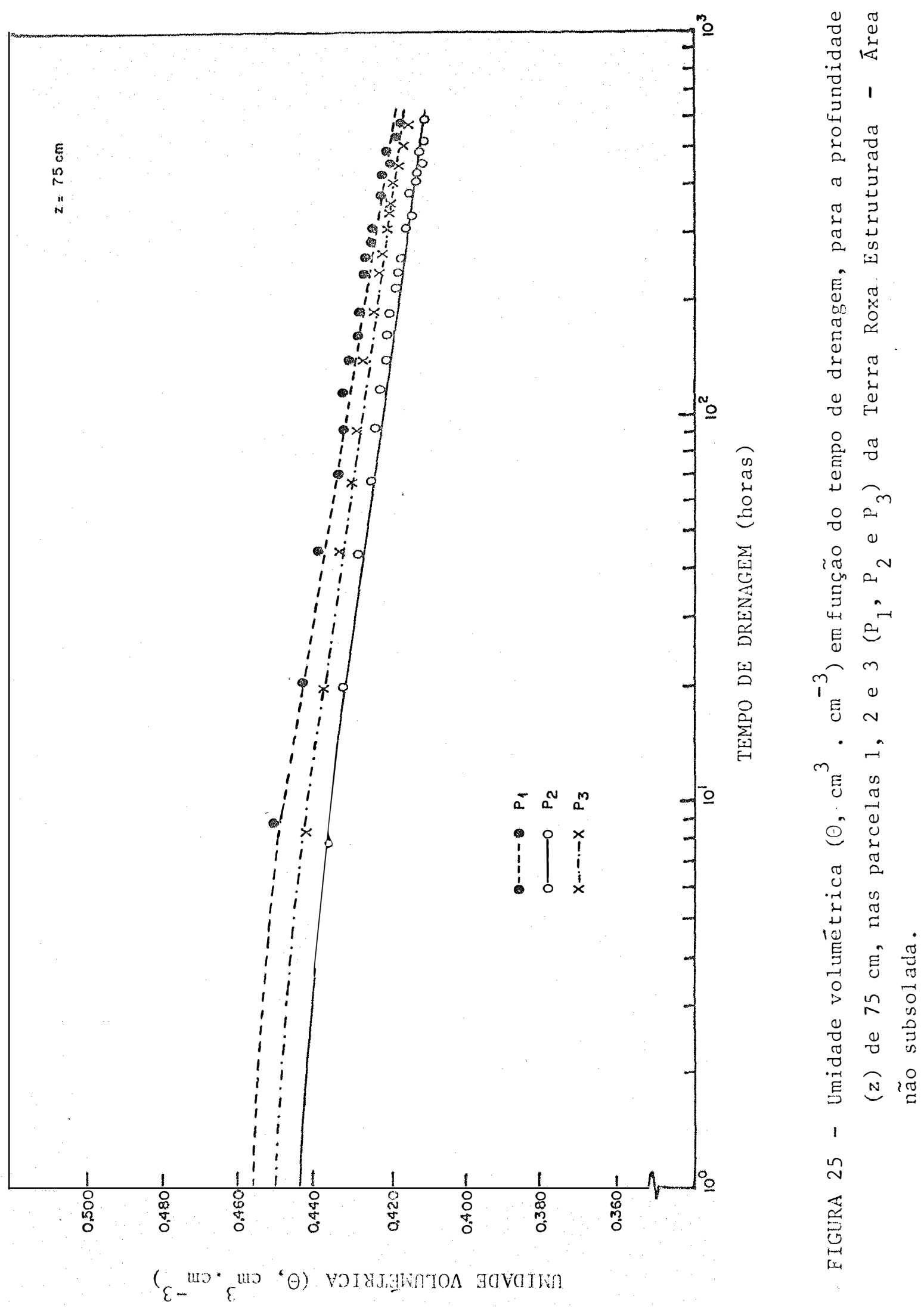

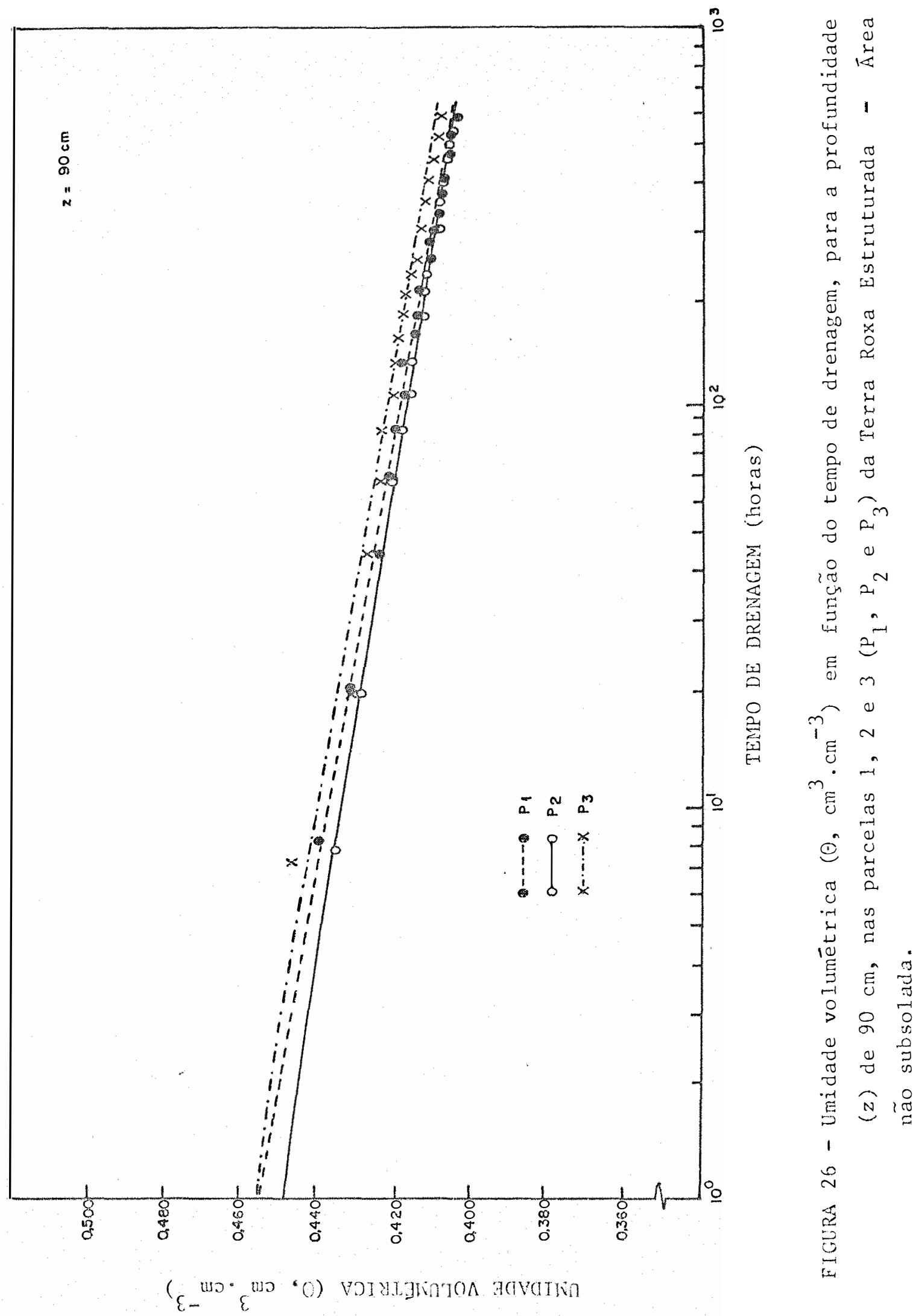

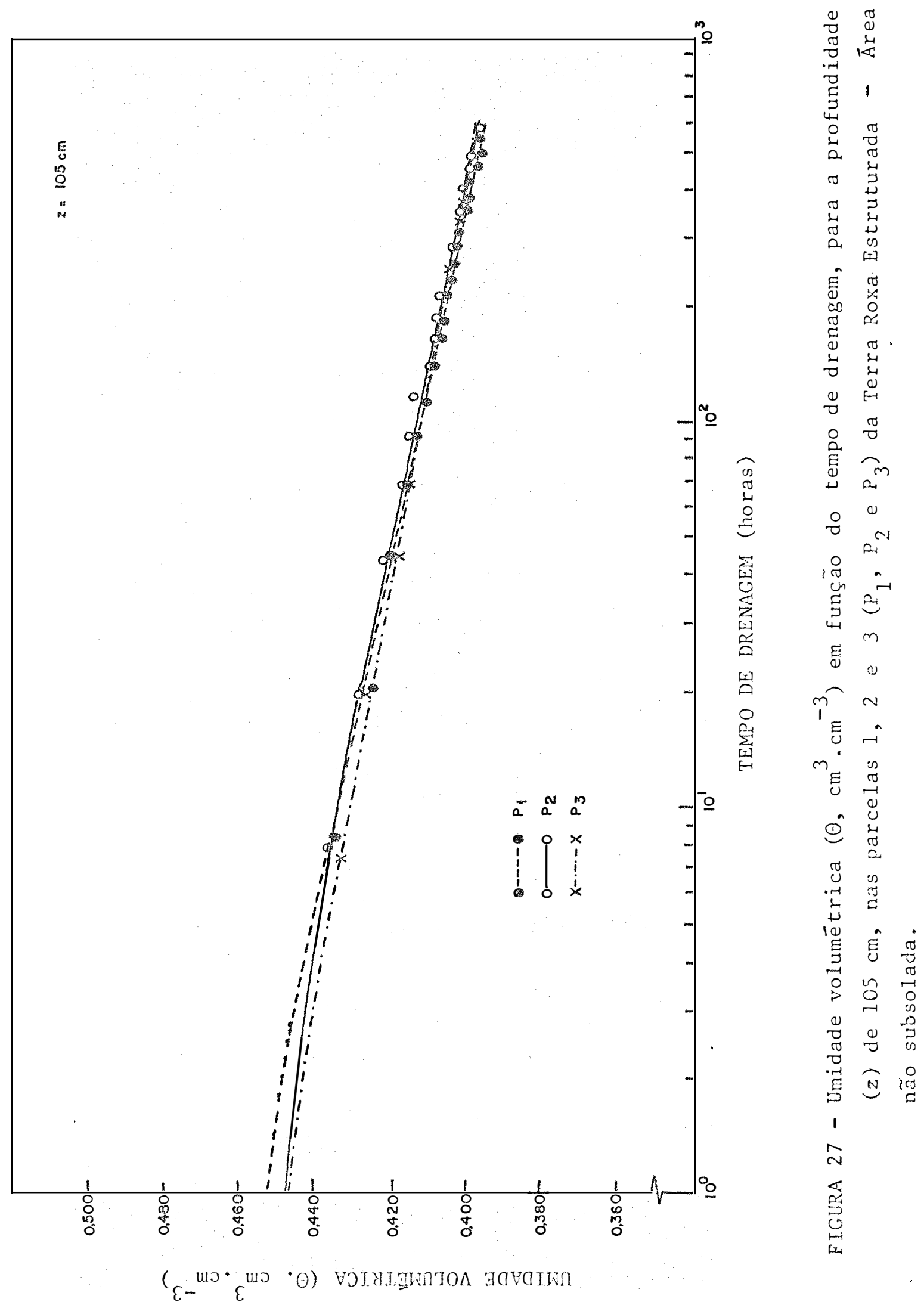


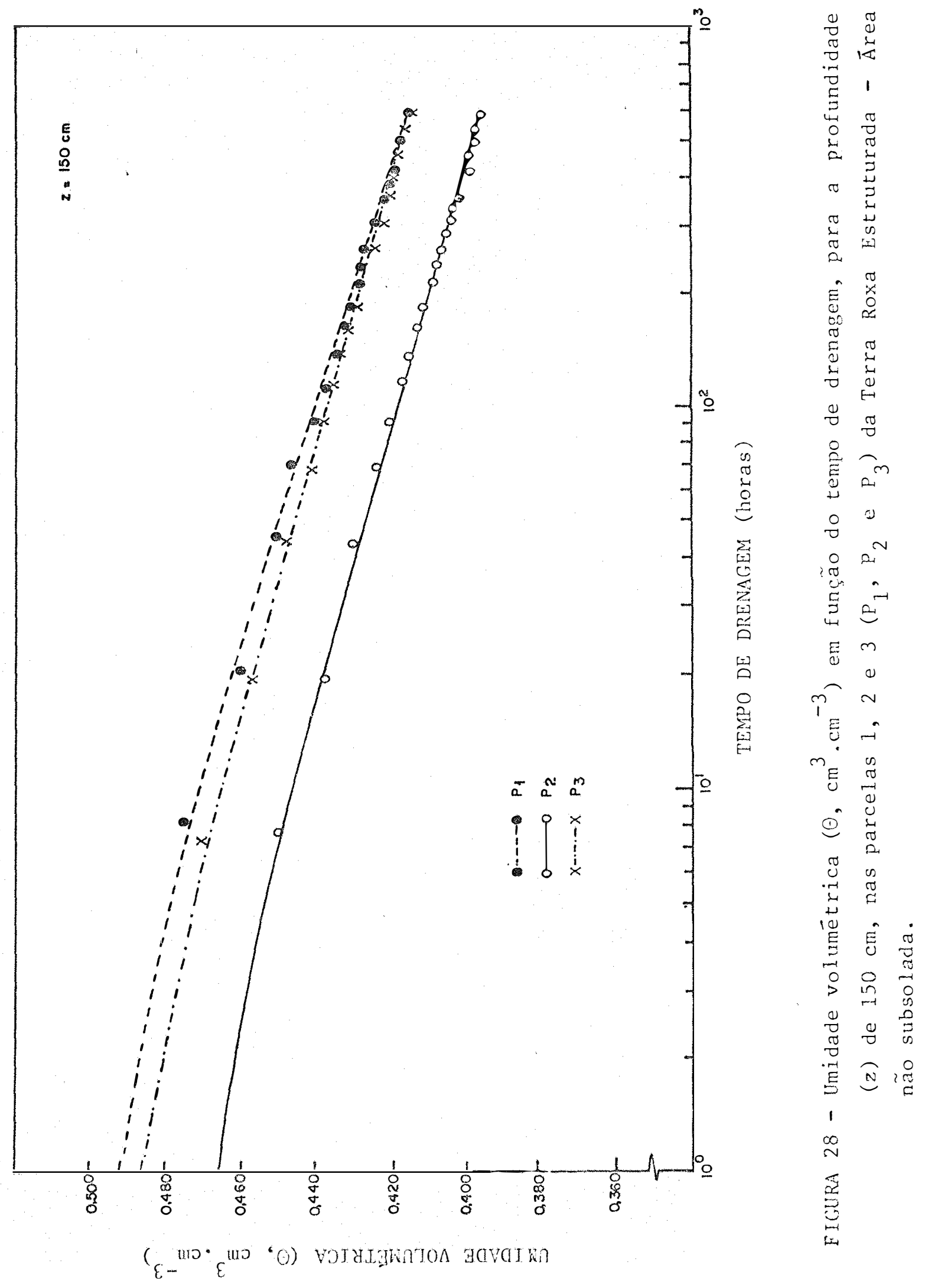



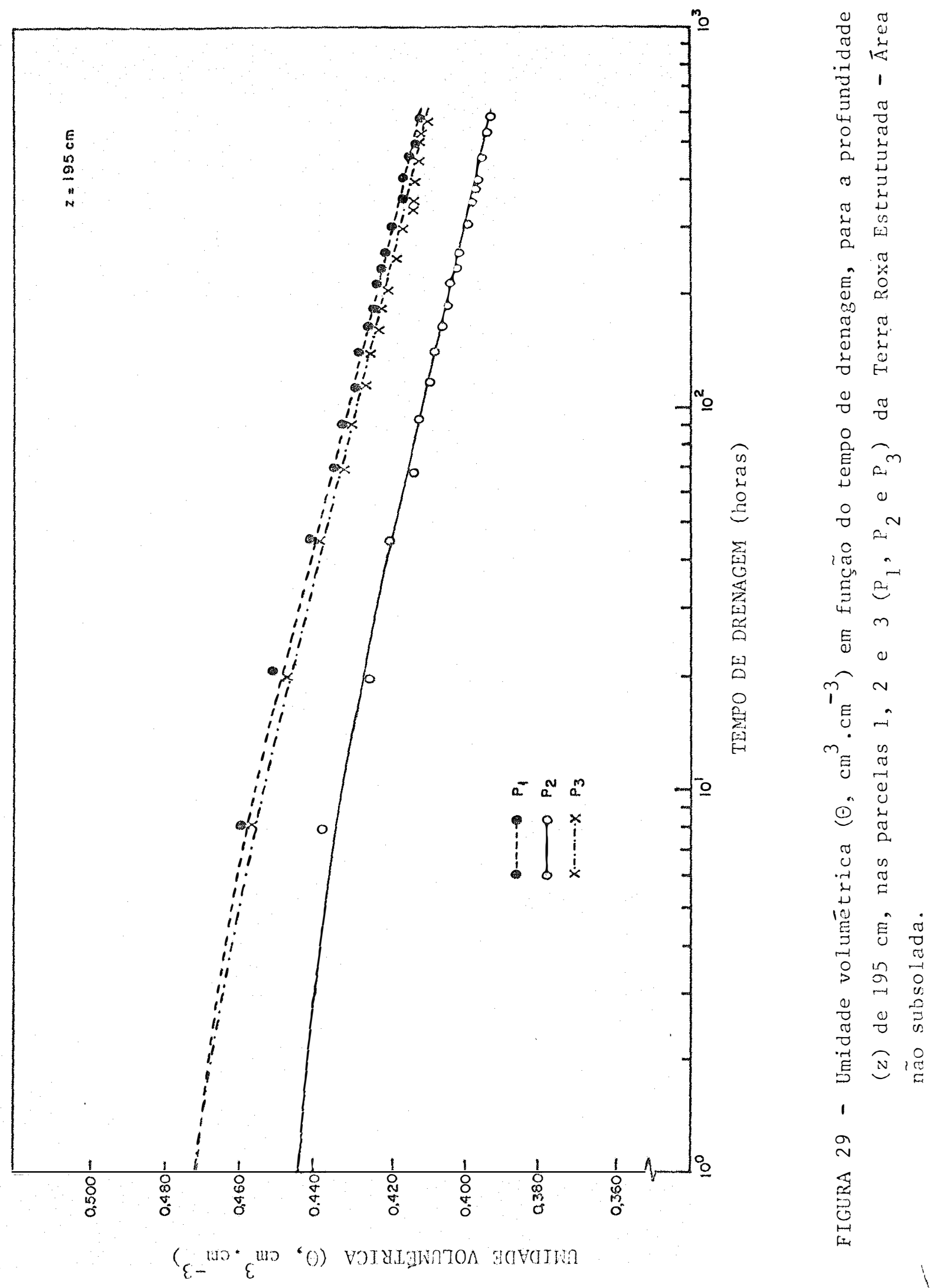


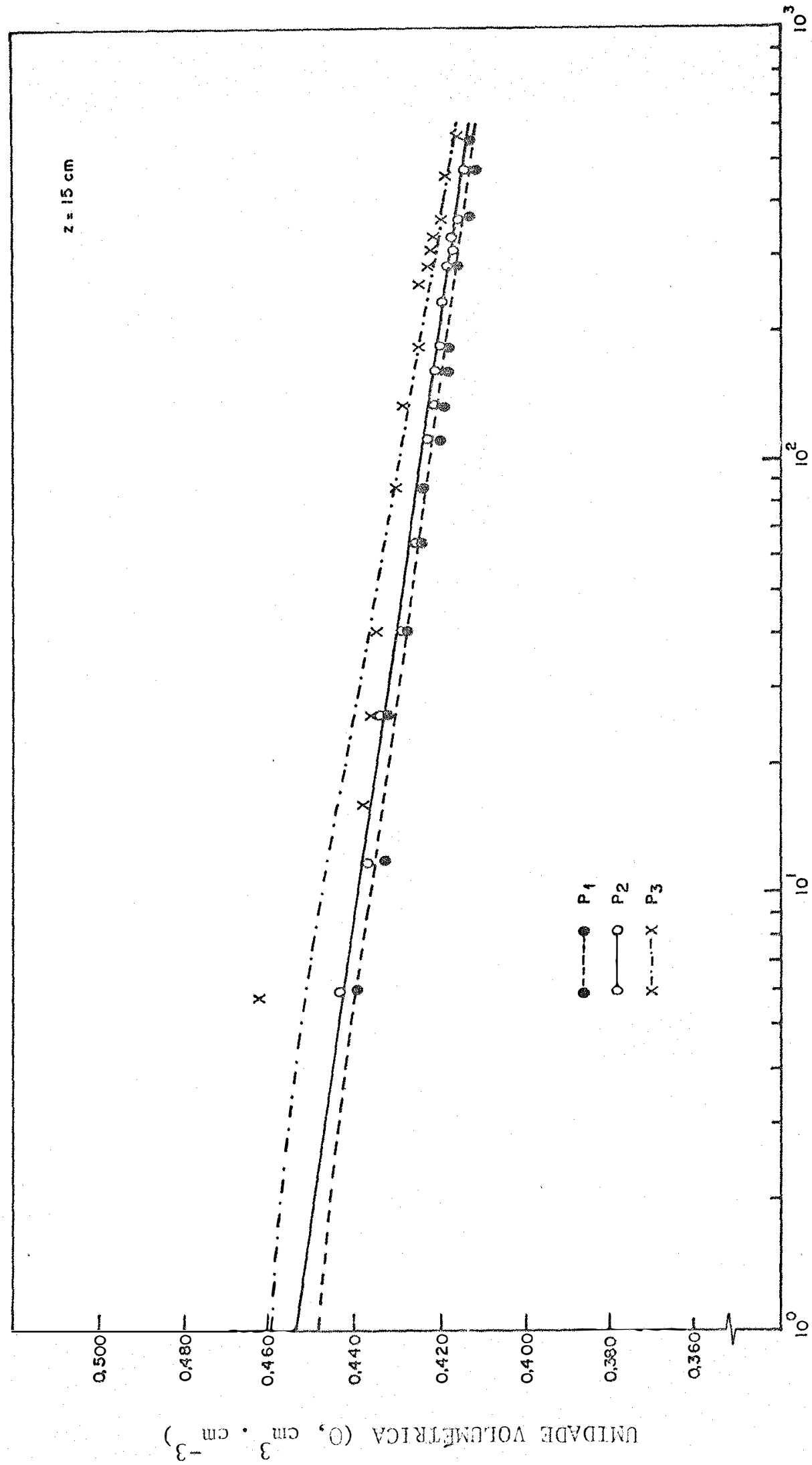

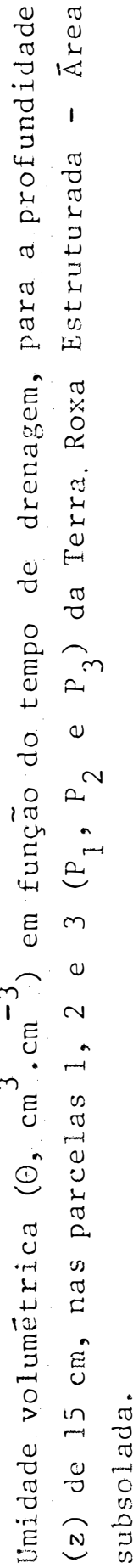

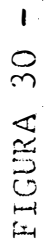




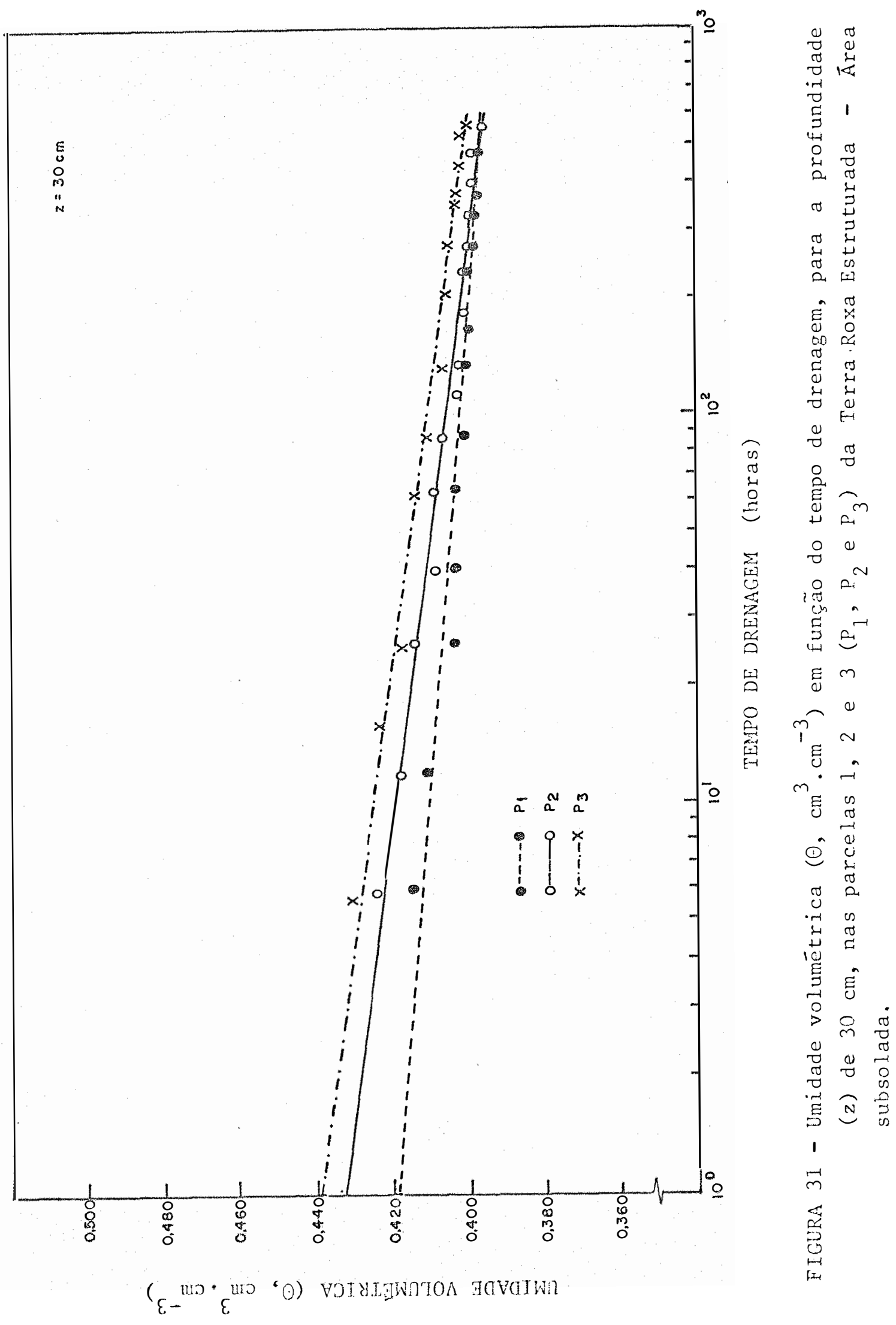




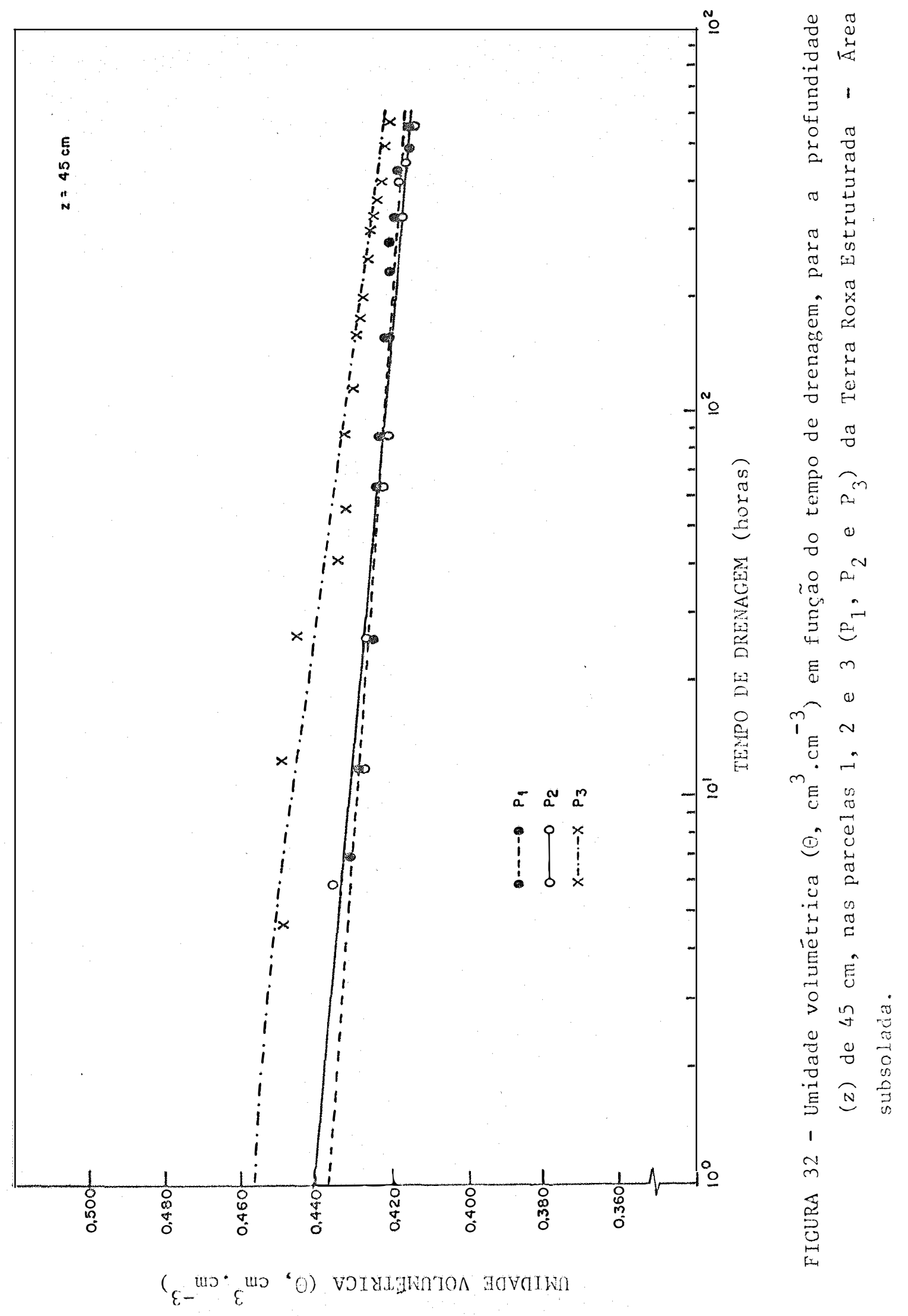



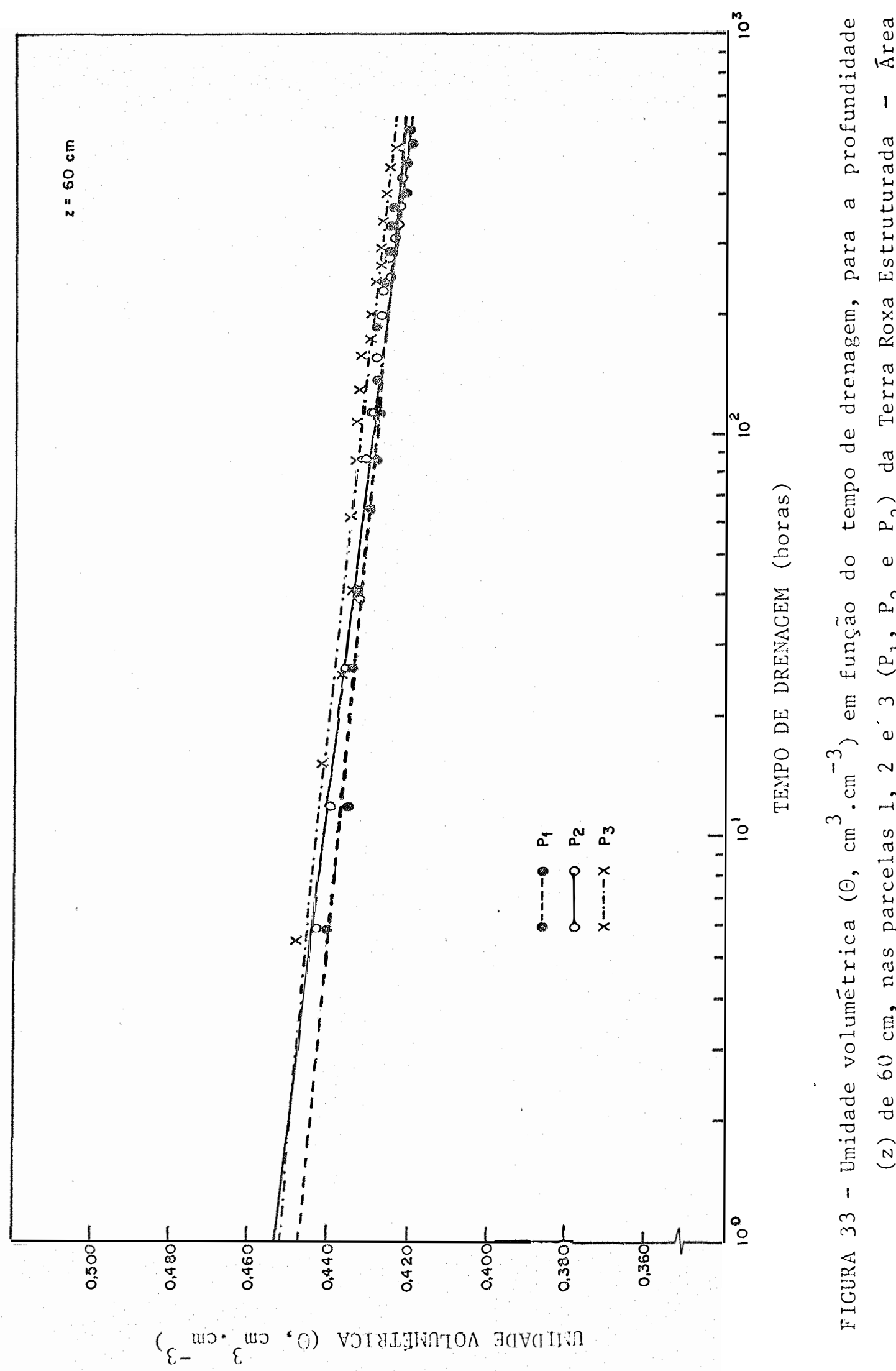

๙ิ

ป

巳 00

$\sum_{i=1} 0 N^{N}$

넌 त्

焉

ज $\mathrm{U} m$

留

$P_{E} N$

至

E

(1)

\%

$\begin{array}{cc}0 \\ 0 \\ -4 & 0 \\ 0 & 0 \\ 0 & 0\end{array}$

\pm .

E

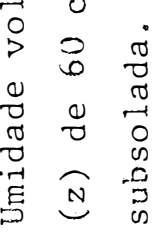

$m$

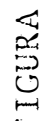




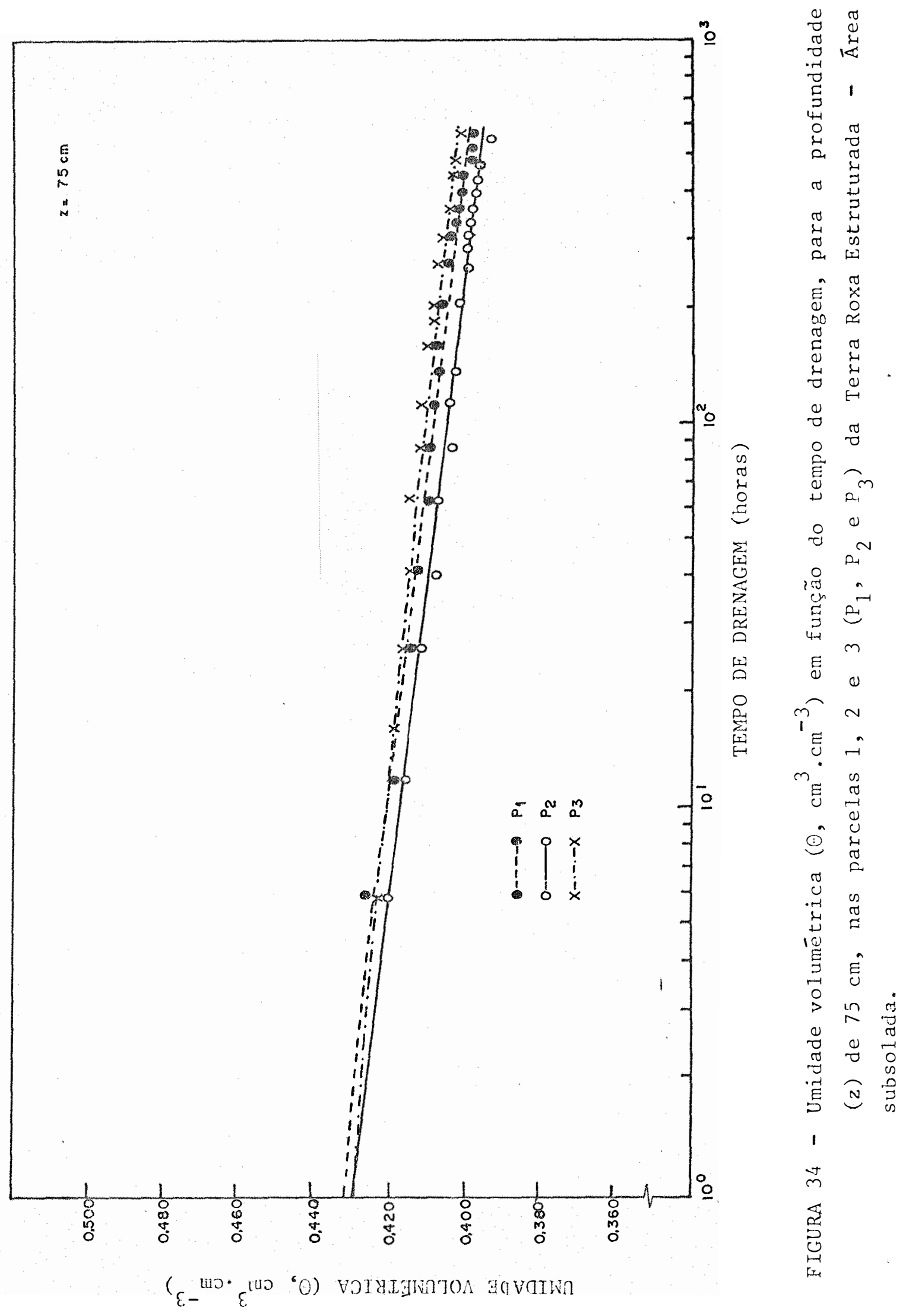




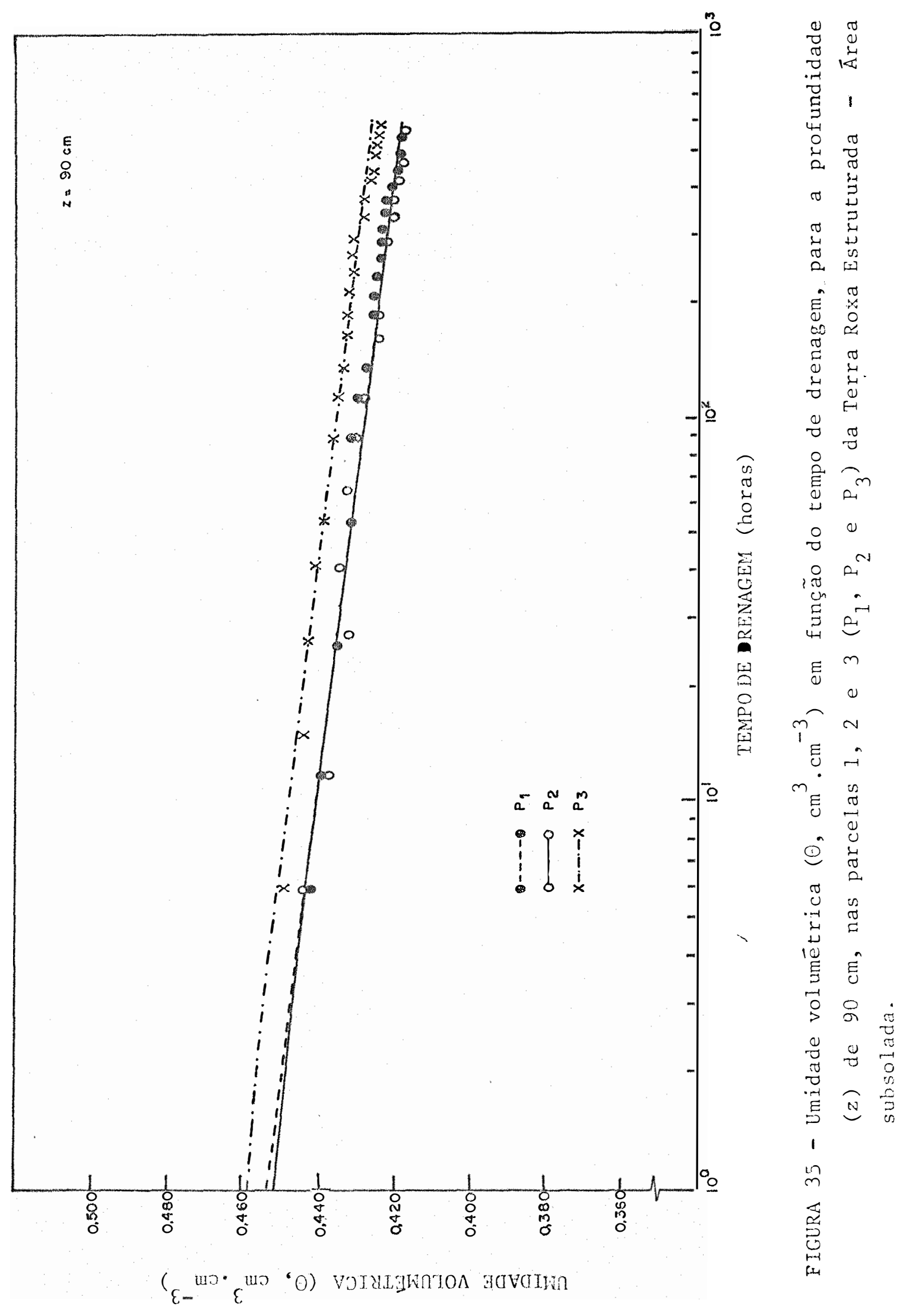




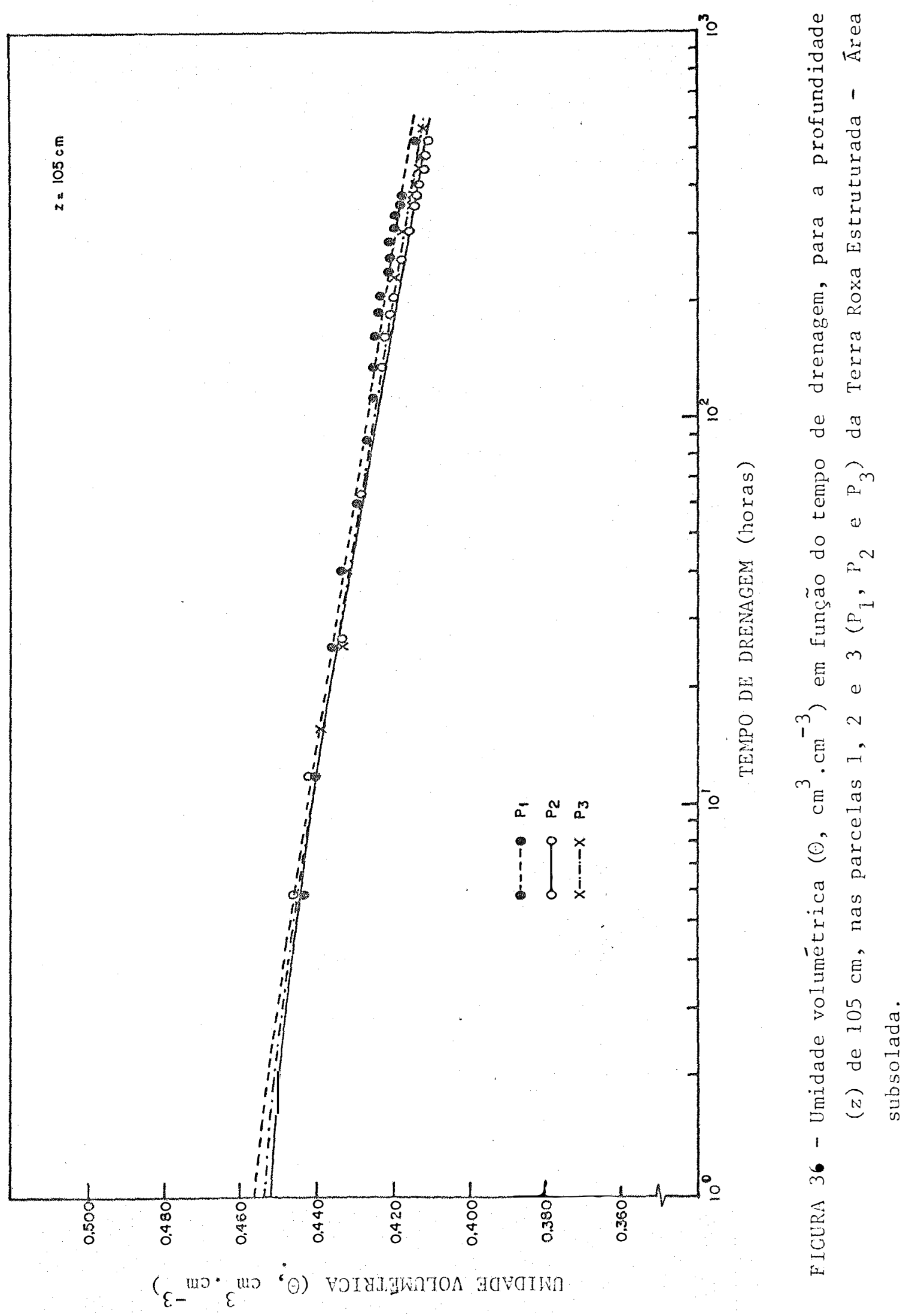



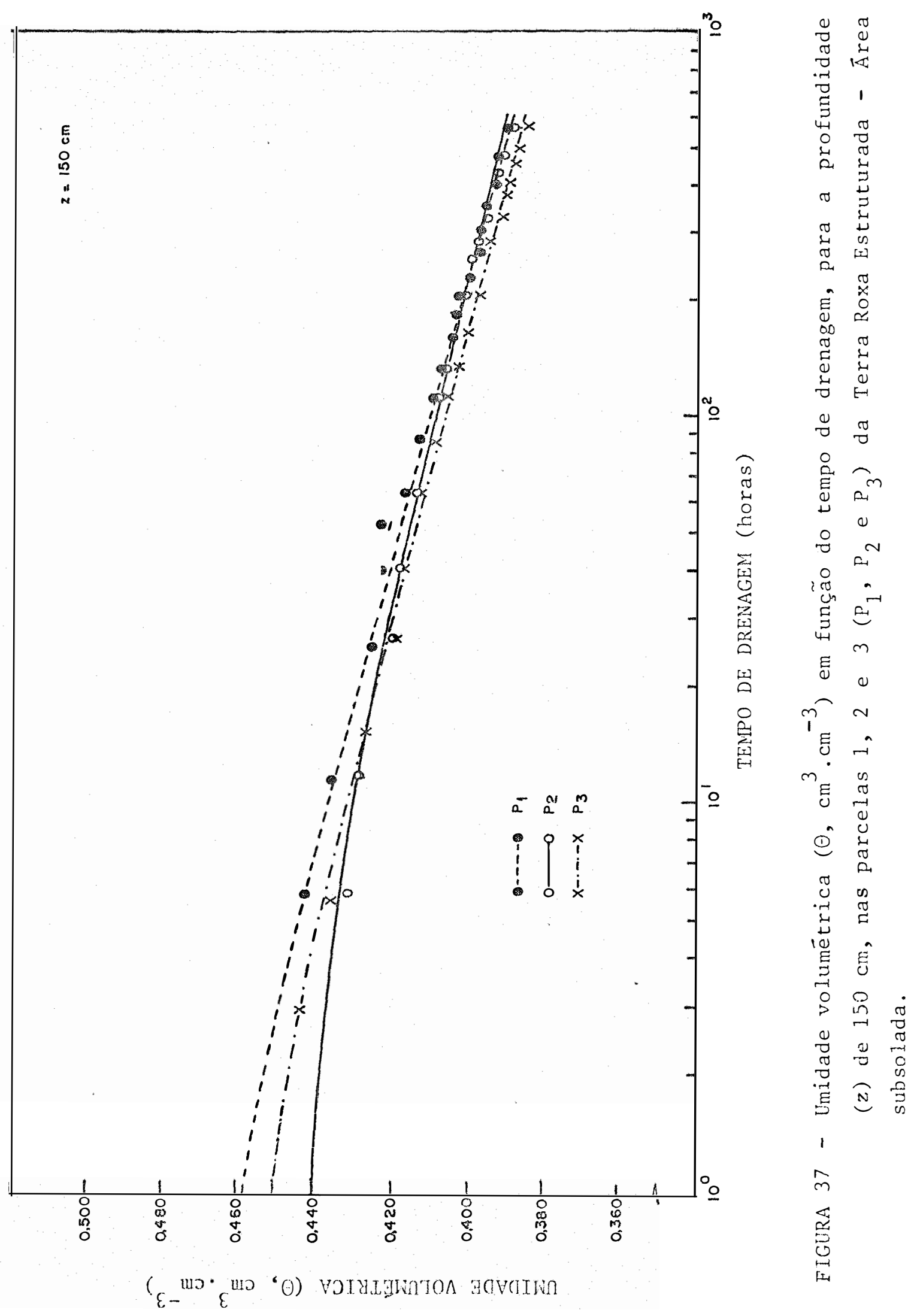

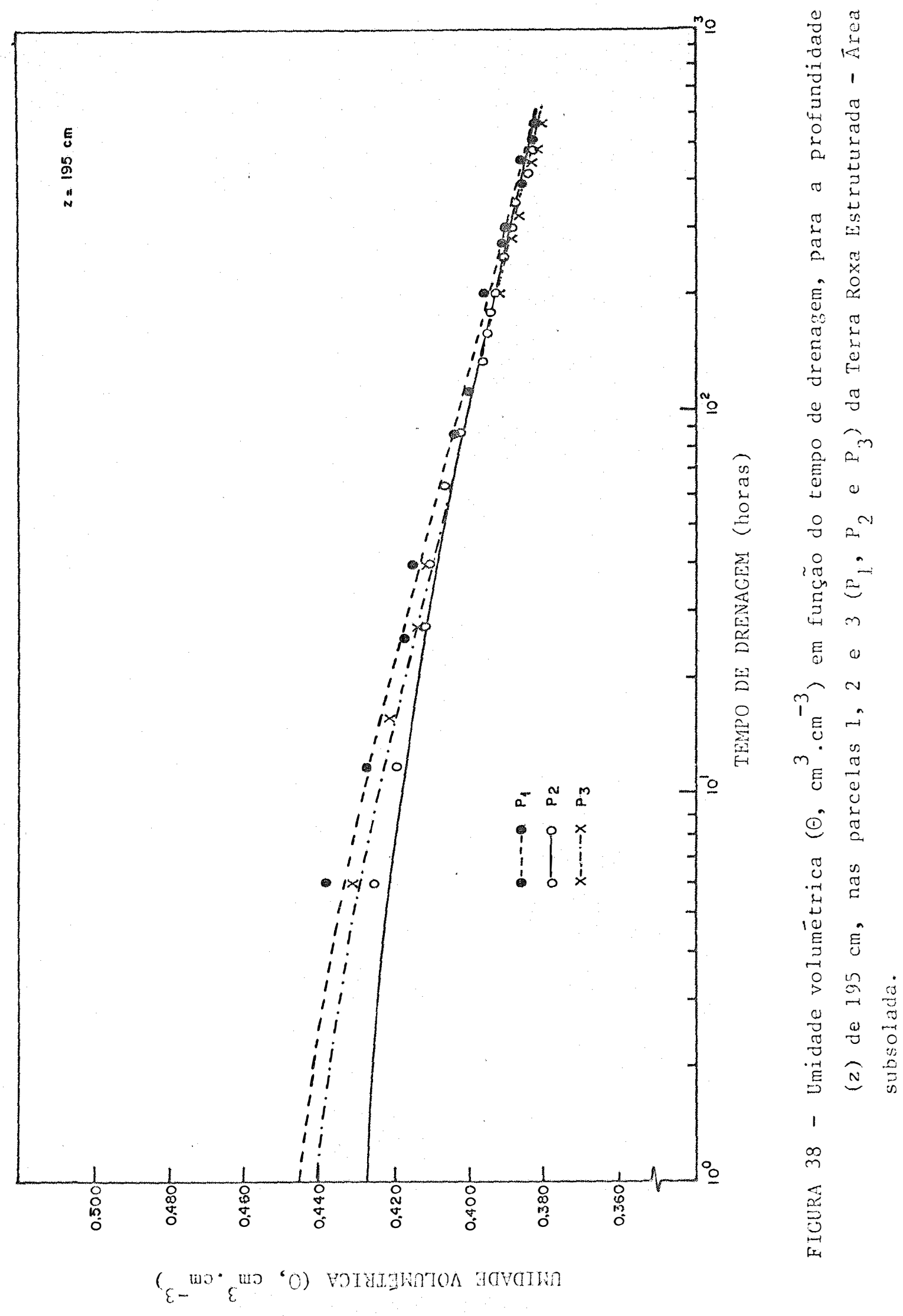


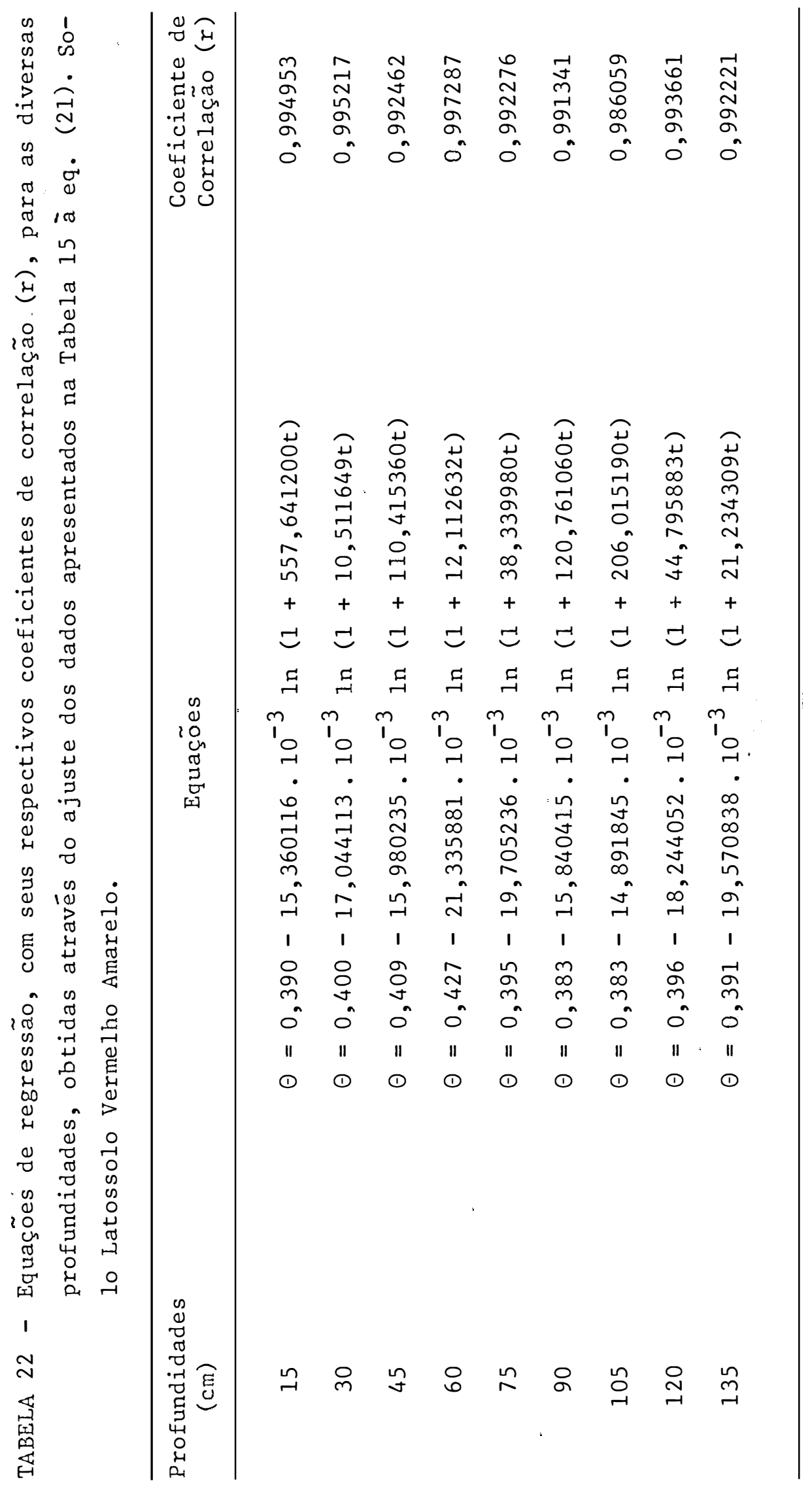




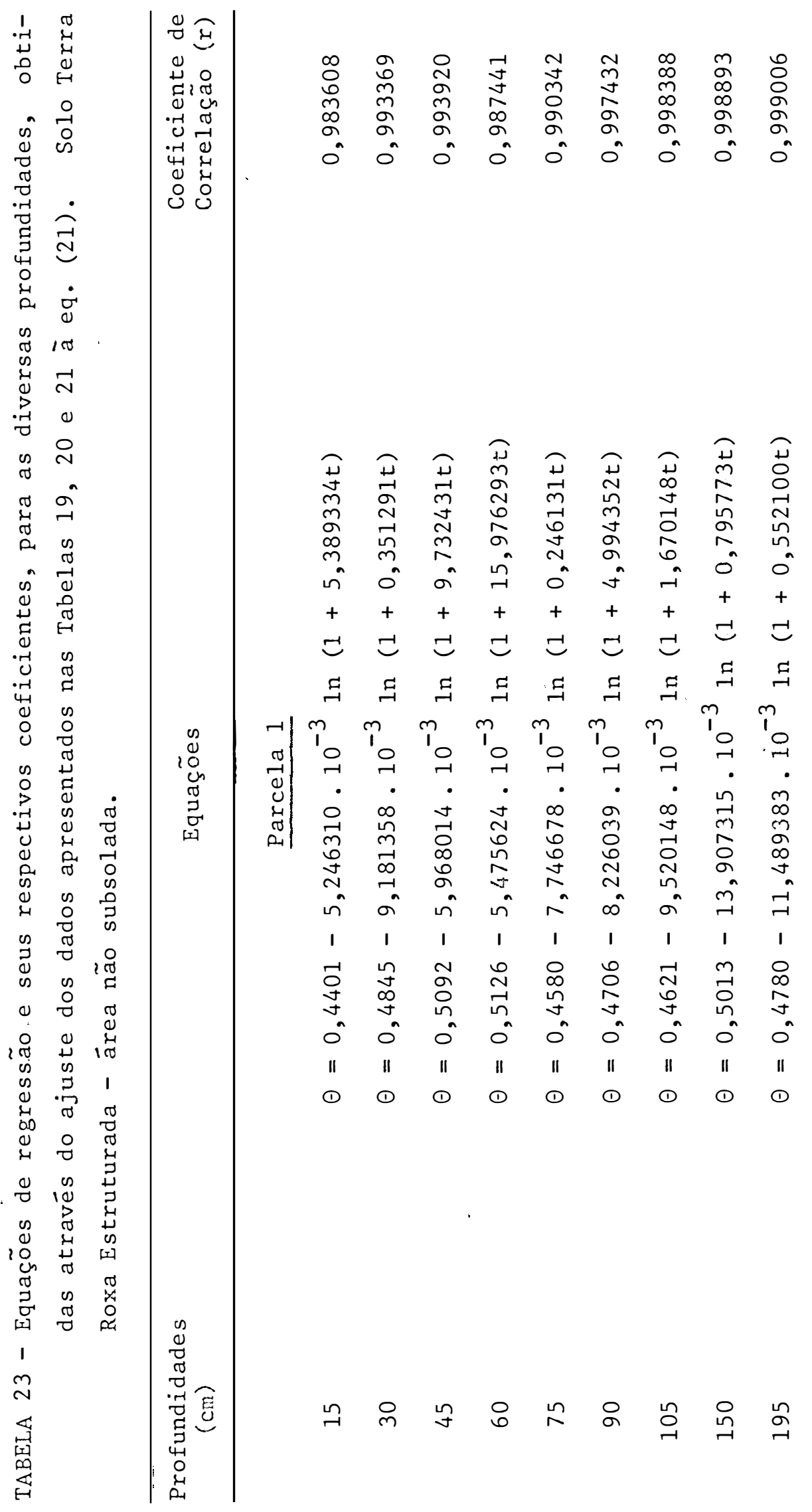




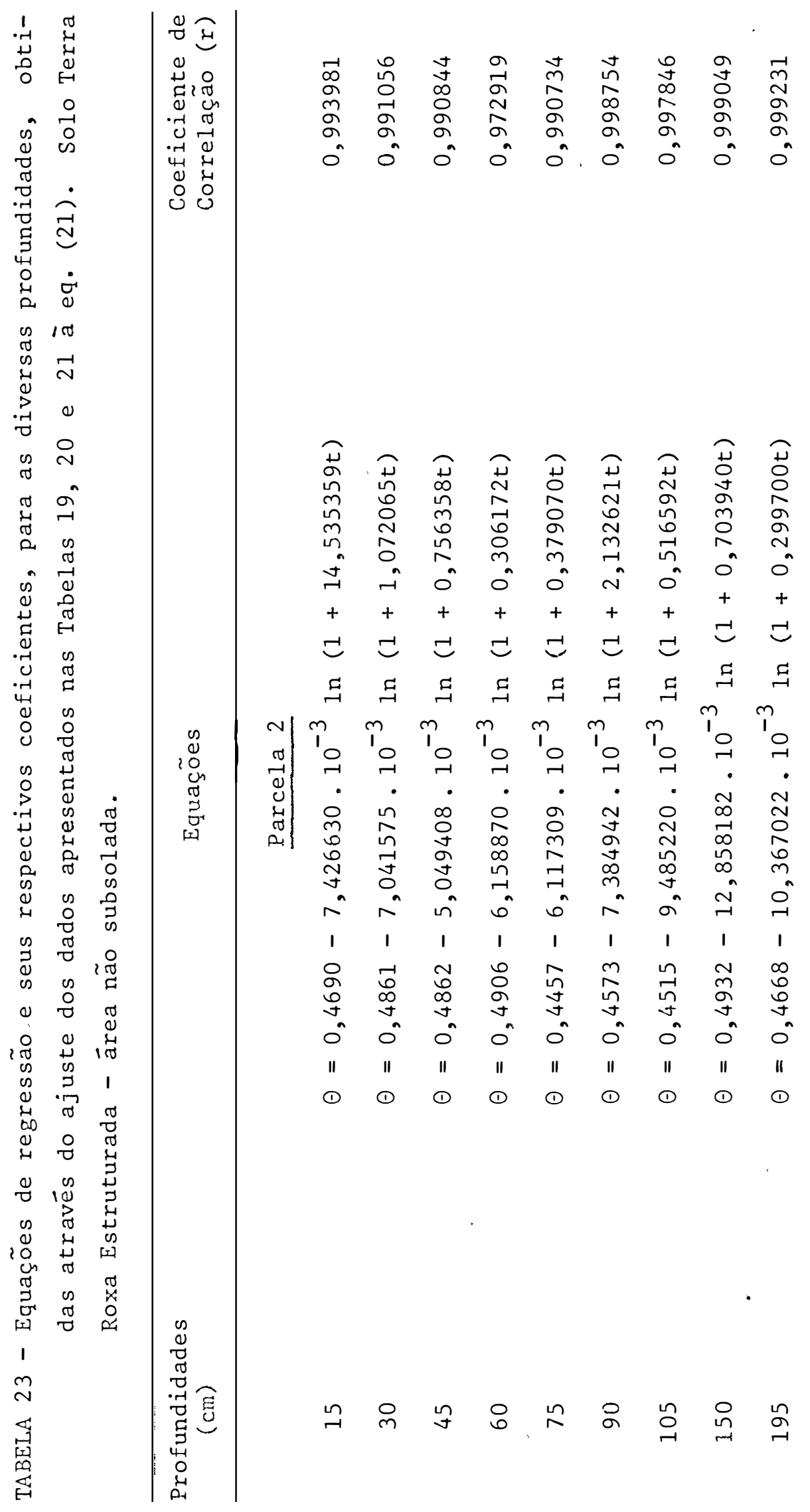




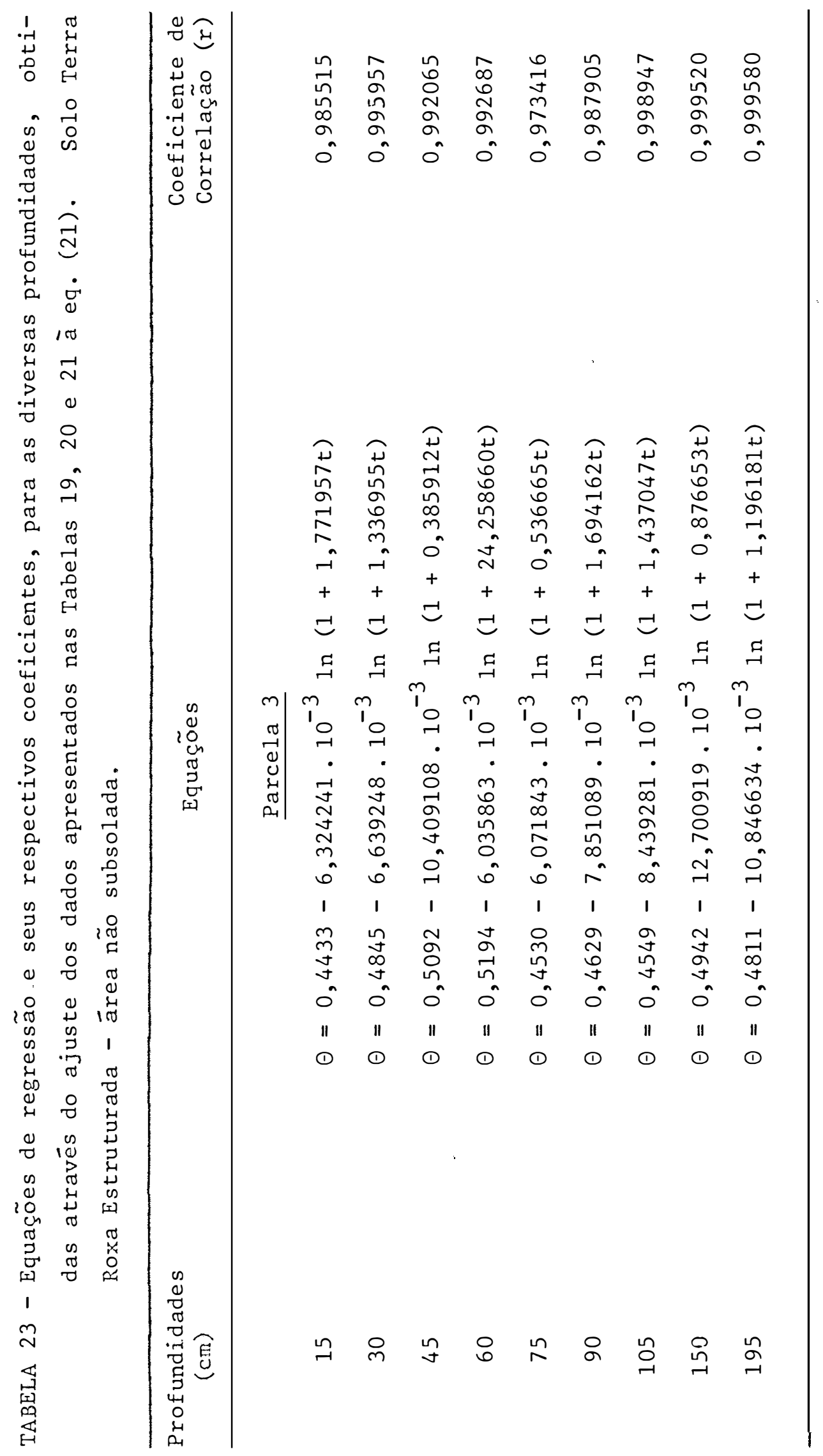




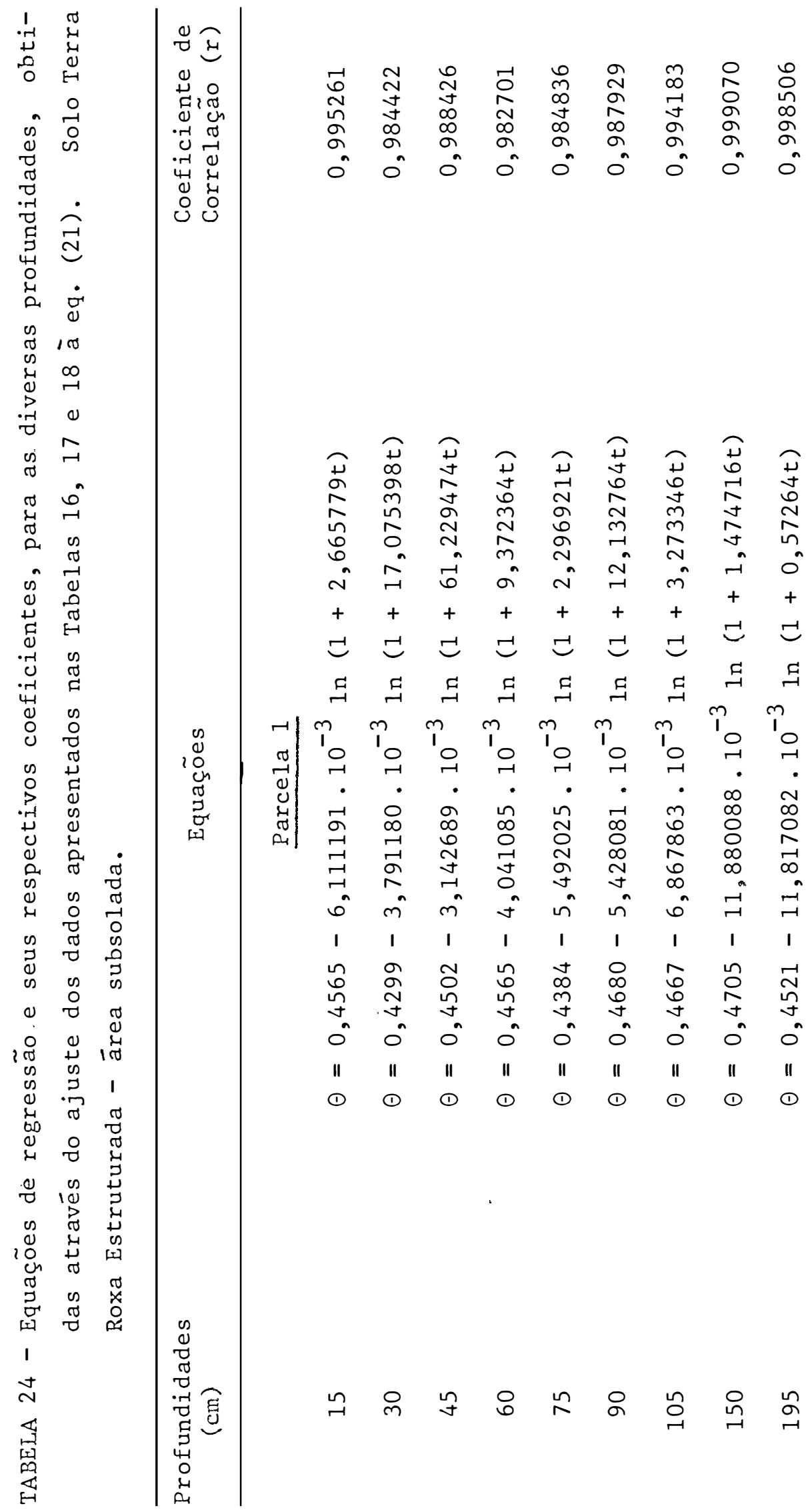




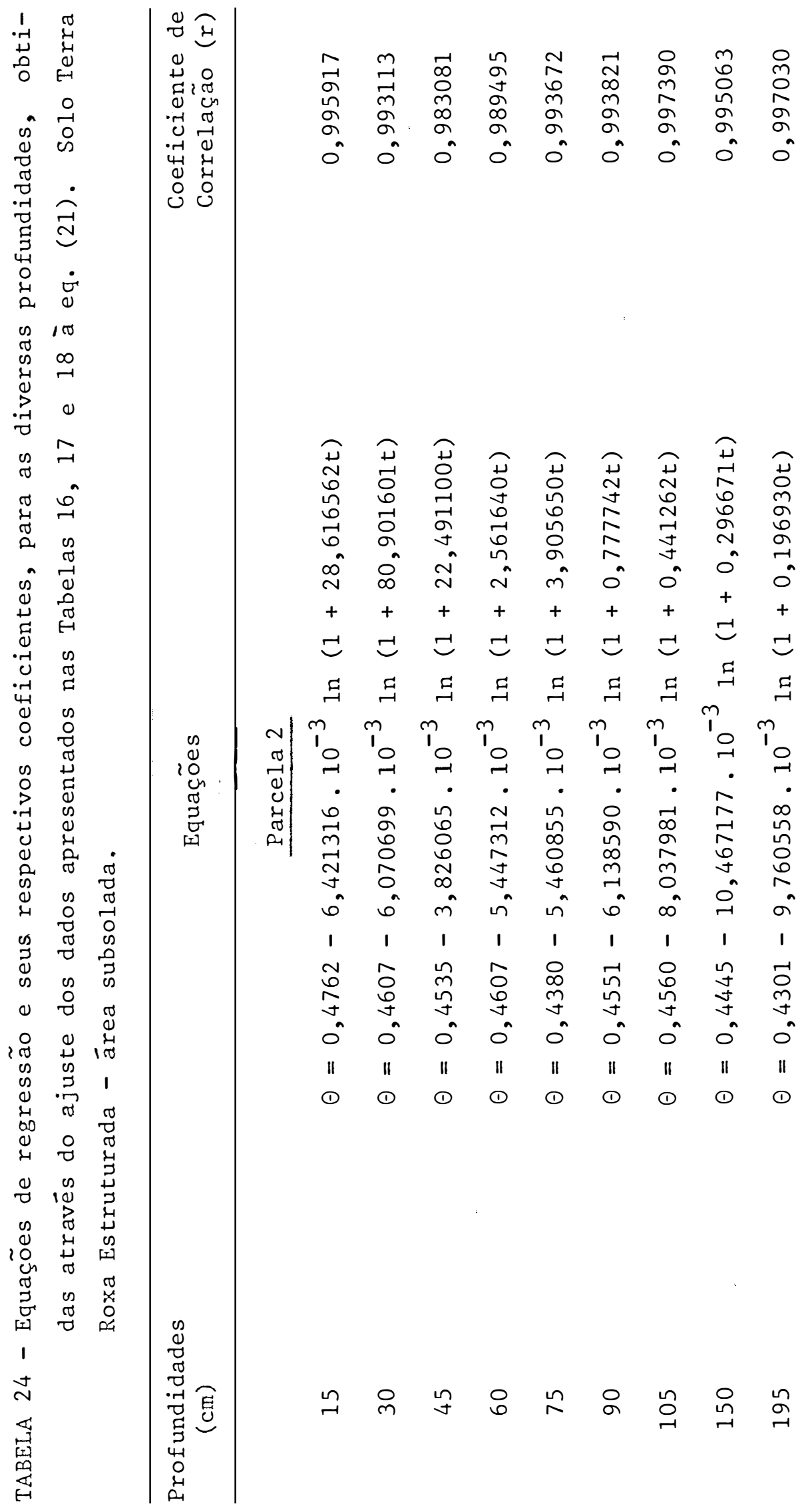




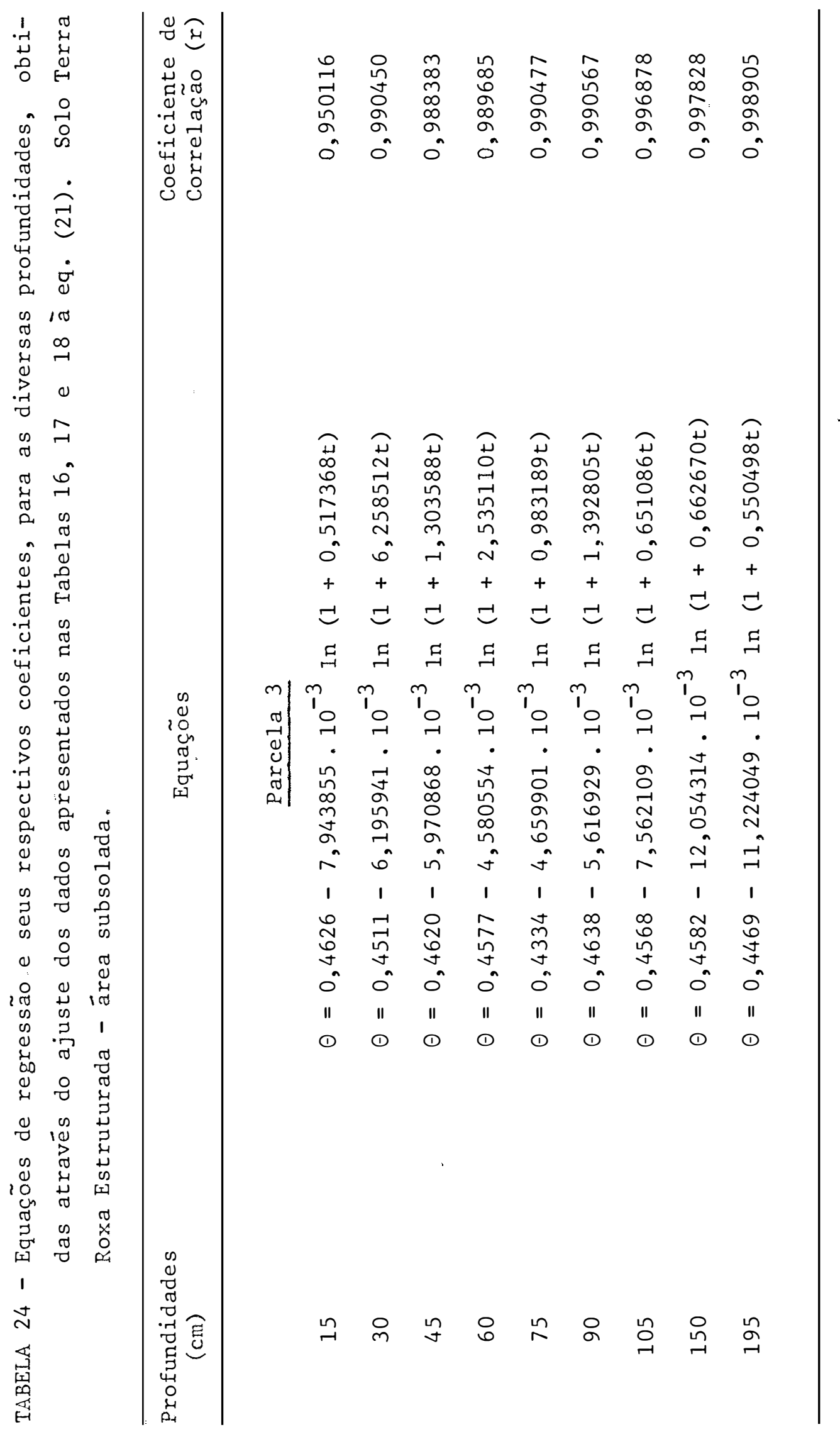




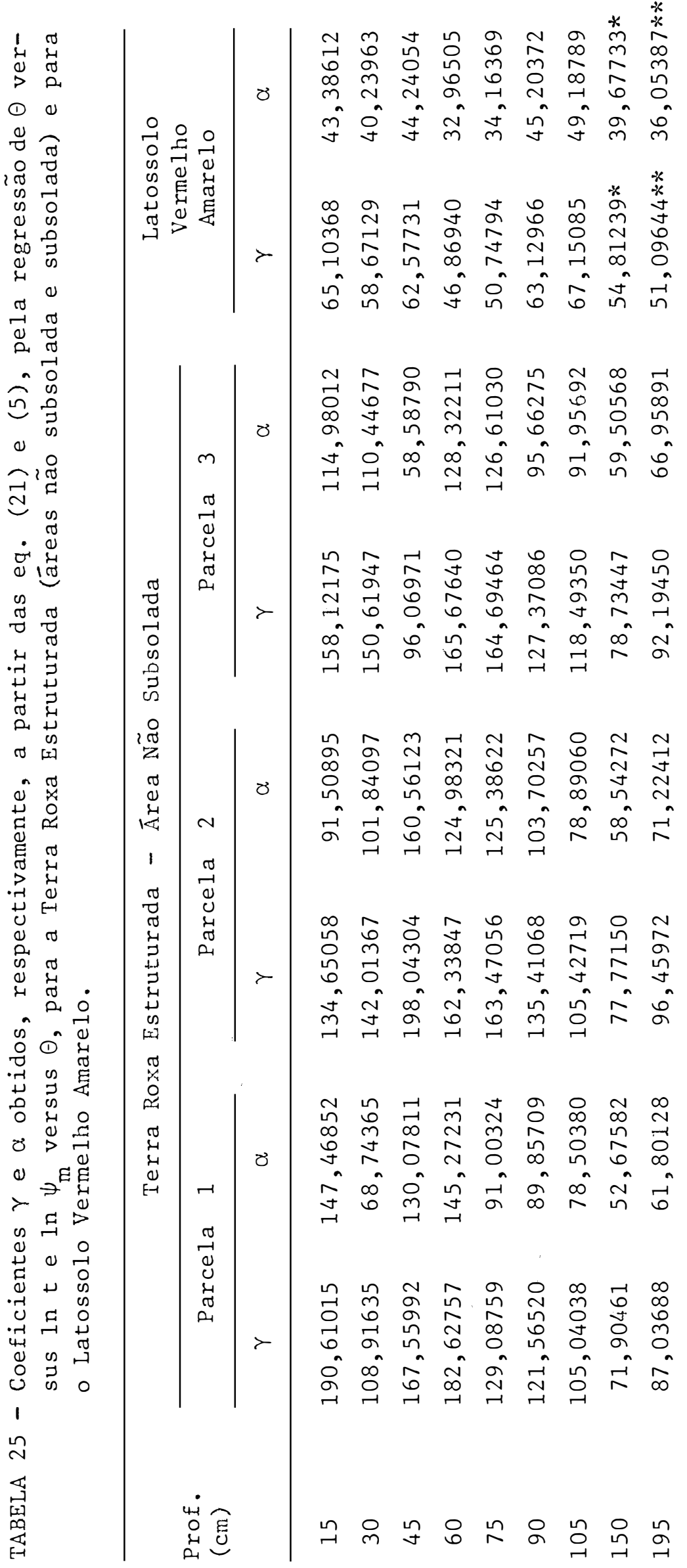




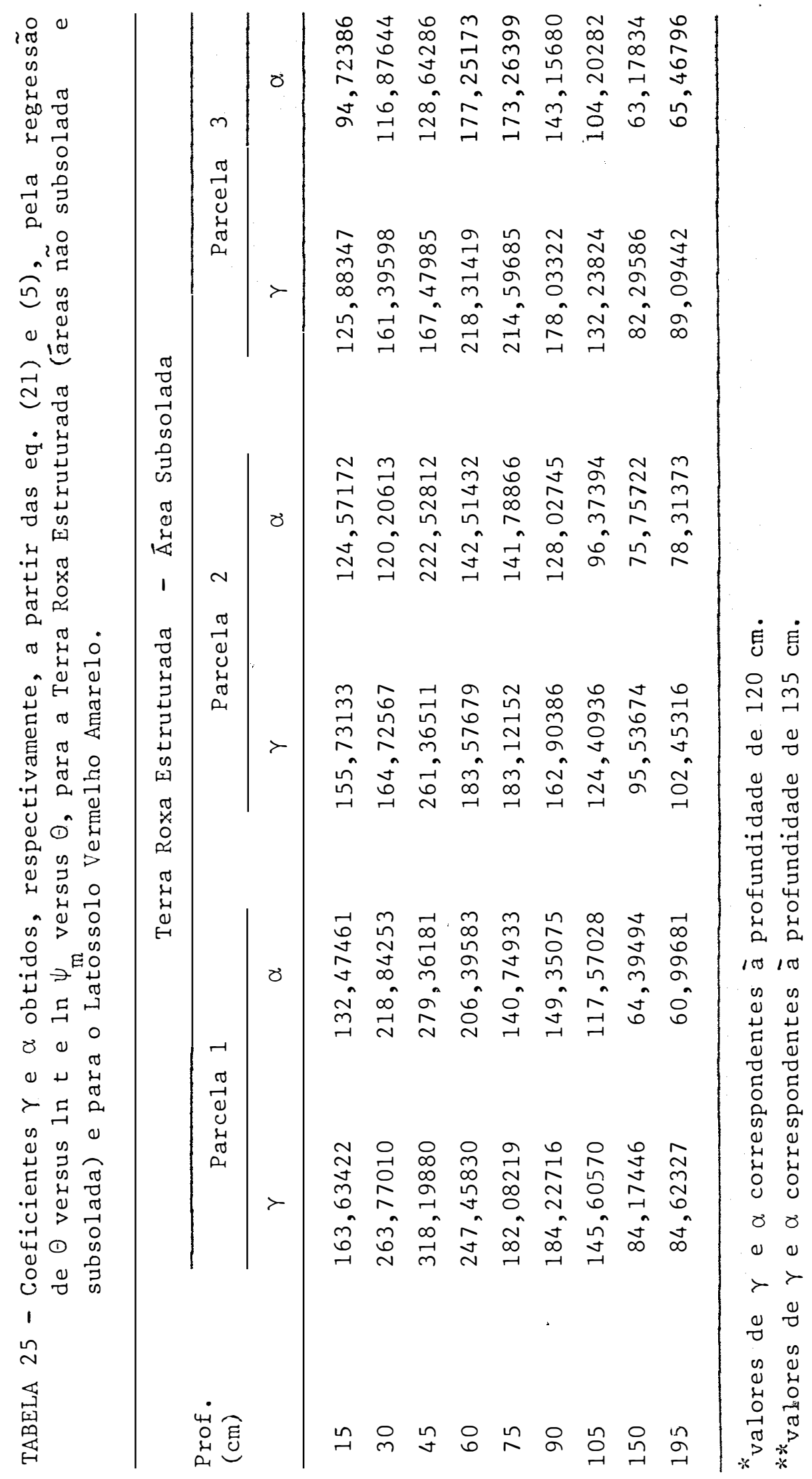




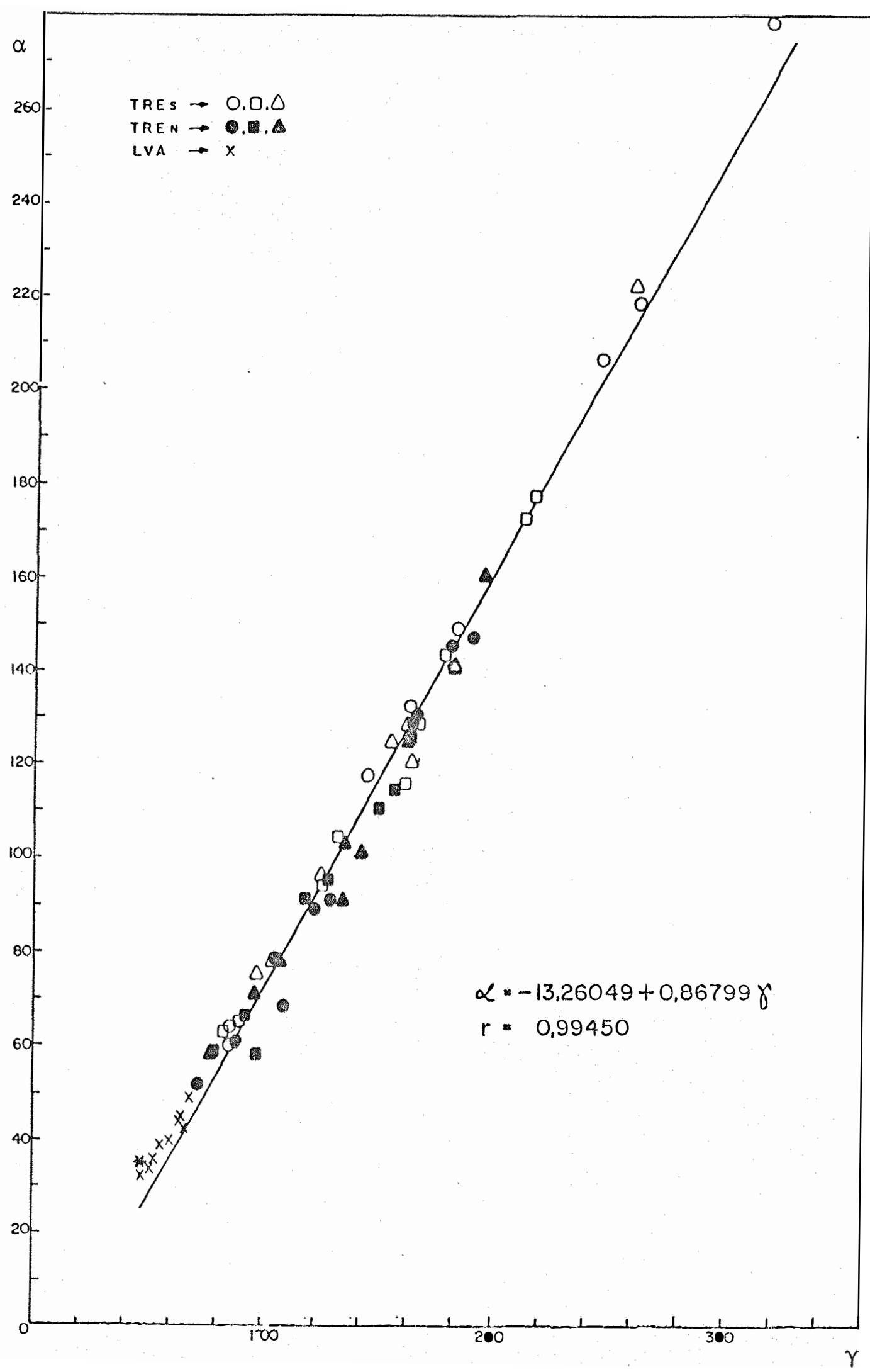

FIGURA 39 - Relação entre $\gamma$ e a para todas as profundidades dos solos estudados. Terra Roxa Estruturada Subsolada (TREs); Terra Roxa Estruturada Näo Subsolada (TREn) e Latossolo Vermelho Amarelo (LVA). 


\section{DISCUSSÃO}

\subsection{Curvas de retenção.}

Fazendo uma análise apenas visual das curvas de retenção para o Latossolo Vermelho Amarelo (Figuras 5 a 8), pode-se notar um bom ajuste dos dados experimentais à eq. (5). Isso de fato confirma-se observando os valores dos coeficientes de correlação destas curvas mostrados na Tabela 7 , os quais foram todos maiores que 0,95. Ainda em termos de uma anālise visual para essas curvas, traçando uma linha ligando os pontos experimentais, esta aproximase à forma de um $\mathrm{S}$ alongado. Este é um fato interessante que será discutido posteriormente, em conjunto com os outros dados da Terra Roxa Estruturada.

No caso da Terra Roxa Estruturada, as curvas de retenção encontram-se nas Figuras 9 a 17. Analisando inicialmente uma possĩvel influência da subsolagem nessas curvas, por profundidade, pode-se perceber que esta praticamente não existiu, uma vez que se observa uma superposição das curvas. Isto pode ser devido ao fato de se tratar de um solo argiloso com elevado estado e grau de agregação. Os agregados se acomodam facilmente, reconstituindo a estrutura original. Este aspecto da subsolagem, no entanto, não faz parte do bojo do presente trabalho, porquanto não será analisado 
em detalhe.

Igualmente ao que ocorreu com o Latossolo Vermelho Amarelo, também para a Terra Roxa Estruturada o ajuste dos pontos experimentais das curvas de retenção à eq. (5) foi excelente, uma vez que até à profundidade de $75 \mathrm{~cm}$, tanto para a área subsolada, como para a não subsolada, o coeficiente de correlação foi, no mínimo, igual a 0,98 (Tabela 8). 0 menor valor do coeficiente foi aproximadamente de 0,93 para a profundidade de $150 \mathrm{~cm}$ na ārea subsolada. Na ärea não subsolada, o menor valor foi de aproximadamente 0,94 para a profundidade de $90 \mathrm{~cm}$. Também nesse solo é visível que, a partir da profundidade de $90 \mathrm{~cm}$, tanto na ārea subsolada como na não subsolada, uma curva manual traçada através dos pontos experimentais mostra a forma de um S alongado, e de maneira mais marcante para a profundidade de $150 \mathrm{~cm}$. Este fenômeno é comum e muitos trabalhos têm sido desenvolvidos (modelos para o ajuste dessas curvas), sendo que, provavelmente, o mais empregado seja o proposto por VAN GENUCHTEN et alii (1980), no qual o autor parte da premissa de que a relação $\psi_{\mathrm{m}}$ vs. $\Theta \vec{e}$ assintótica para os mais altos e os mais baixos valores de umidade. Merece também ser lembrado que a acentuação da forma de $\mathrm{S}$ alongado das curvas de retenção da Terra Roxa Estruturada se inicia a partir da profundidade de $105 \mathrm{~cm}$, que é aproximadamente a transição entre o horizonte $B$ textural e B óxico deste solo, conforme pode ser visto no item 4.1.3. Na descrição desse so1o, pode-se notar também, a partir dessa profundidade, a presença de uma micro-estrutura forte, muito pequena e granular com, provavelmente, agregados altamente estäveis, visto que a \% de argiı̀ dispersa em água (Tabela 1) apresenta valores muito baixos. Além disso, os menores valores de densidade global e os maiores valores dos 
poros com diâmetro maior que $0,05 \mathrm{~mm}$ também são observados a partir da profundidade de $105 \mathrm{~cm}$. Todos estes aspectos refletem seus efeitos na geometria porosa do solo, responsāvel pela retenção de água (BAVER et alii, 1972; TAYLOR \& ASCROFT, 1972), e que, para este solo, seu maior reflexo aparece na profundidade de $150 \mathrm{~cm}$, onde se observa, commaior evidência, a forma de Salongado da curva de retenção.

Analisadas as curvas de retenção dos dois solos, voltemos àquele ponto referente à forma em $\mathrm{S}$ para algumas dessas curvas. A fim de simplificar a discussão, vamos escolher a curva cujo ajuste à eq. (5) apresentou o menor coeficiente de correlação. Esta, conforme pode ser visto na Tabela 8, corresponde à profundidade de $150 \mathrm{~cm}$ da Terra Roxa Estruturada, ārea subsolada (Figura 16).

Nessa Figura 16 (e, evidentemente, em todas as outras curvas de retenção), a curva pontilhada corresponde a linhas retas, cujo número para toda a faixa de tensão, desde zero até $15 \mathrm{~atm}$, normalmente não deve ultrapassar de três. Assim, podese dizer que as equações de regressão linear dessas retas devem representar melhor os pontos da curva de retenção, como bem esclarece a própria Figura 16, apesar da linha sólida (eq. 5) se ajustar aos pontos experimentais com um coeficiente de correlação de aproximadamente 0,93. A idéia de se utilizar segmentos de reta ao invés de um ajuste a uma equação complexa, como a de VAN GENUCHTEN et alii (1980), por exemplo, foi por simplificação e para alcançar o objetivo do trabalho no caso em que esta forma de $\mathrm{S}$ alongado para a curva de retenção se torne de fato necessária. Nessas ciraunstâncias, os três segmentos de reta apresentados na Figura 16 para a Terra Roxa Estruturada, ārea subsolada, também se ajustan para as faixas correspondentes de pares de valores de $\psi_{\mathrm{m}} \mathrm{e}$ 
de $\Theta$, à eq. (5). Ainda com base na hipótese formulada para o trabalho, o cálculo do parâmetro $\gamma$ de acordo como descrito no item 4.4.2, para essa profundidade, correspondeu a valores de umidade que caíram na faixa de 0,35 a $0,50 \mathrm{~cm}^{3} \cdot \mathrm{cm}^{-3}$ (Tabelas 19 a 21 ). O segmento de reta a ser utilizado, neste caso, tem que ser o correspondente aos valores mais altos de umidade da Figura 16.

Seguindo o mesmo procedimento descrito no Capítulo 3 para o cálculo do parâmetro B da eq. (5), isto é, elaborar uma regressão linear entre $1 \mathrm{n}$ de $\psi_{\mathrm{m}}$ e $\theta$, desprezando o nümero 1 que aparece na equação, para o caso desse segmento de reta, a equação obtida foi:

$$
\ln \psi_{\mathrm{m}}=-11,0532660+8,713479
$$

A fim de que o ajuste da curva aos pontos experimentais da faixa de unidade correspondente fosse o melhor possível (umalinha reta), foi arbitrado para o parâmetro $\theta_{0}$ o valor $1 \mathrm{~cm}^{3}$. $\mathrm{cm}^{-3}$, pois este valor permite que a eq. (5) represente de fato uma linha reta, uma vez que o que interessa è o parâmetro B, que é o mesmo, independente dos valores do parâmetro de $\Theta_{0}$. Mudando o parâmetro $\Theta_{0}$ o que muda é o valor do parâmetro A; o valor de $\mathrm{B}$ não se altera. Desse modo, para a faixa de umidade de aproximadamente 0,35 a aproximadamente $0,60 \mathrm{~cm}^{3} \cdot \mathrm{cm}^{-3}$, a equação representativa da reta apresentada na Figura 16, com a forma da eq. (5), è

$$
\psi_{m}=0,096348\left[e^{-11,053266(\theta-1)}-1\right]
$$

Deve, portanto, ficar claro que a eq. (26) é Eisicamente válida apenas para esta faixa de umidade $\left(0,35\right.$ a $\left.0,60 \mathrm{~cm}^{3}\right)$ da 
Figura 16.

\subsection{Curvas de drenagem}

Conforme demonstrado por LIBARDI et alii. (1980) e confirmado por muitos autores (LUXMOORE et alii, 1980; DANE, 1980; SCHUH et alii, 1984; JONES \& WAGENET, 1985), o ajuste da eq. (21) a pontos experimentais também foi excelente no presente caso, como pode ser observado nas Figuras 18 a 20 para o Latossolo Vermelho Amarelo e Figuras 21 a 38 para a Terra Roxa Estruturada e comprovado pelos coeficientes de correlação (Tabelas 22 a 24).

As repetições dessas curvas para cada profundidade são um fato que tambēm merece ser discutido. Analisando inicialmente as curvas de drenagem representativas da ārea não subsolada da Terra Roxa Estruturada (Figuras 21 a 29), nota-se que as profundidades que apresentaram maior diferença entre as repetições foram as de 150 e $195 \mathrm{~cm}$, as quais são as representativas do horizonte óxico. Para o horizonte B textural (que corresponde a profundidades menores que $105 \mathrm{~cm}$ ), tambëm se observam-diferenças entre as repetições, todavia de maneira menos marcante do que para as duas profundidades do horizonte óxico. Além disso, essa maior diferença entre as repetições no horizonte óxico da ärea não subsolada, ē com relação à parcela 2 , uma vez que as duas outras parcelas são praticamente coincidentes. Isto mostra que no local onde foi montada a parcela 2, o comportamento da água no solo, principalmente no horizonte óxico, foi diferente em relação aos 1ocais em que foram montadas as parcelas 1 e 3 . A discrepância entre as repetições talvez fosse ainda maior se as curvas de retenção 
fossem elaboradas em cada parcela e não como no presente caso, em que estas curvas de retenção foram feitas apenas para as duas áreas, não subsolada e subsolada. Este assunto constitui-se num dos mais atuais na Ciência do Solo, qual seja, o da variabilidade espacial de propriedades do solo, e está sendo muito explorado e analisado através da teoria das variáveis regionalizadas (NIELSEN et alii, 1983; VIEIRA et alii, 1983). Infelizmente, paraopresente caso, não pode ser utilizada porque a aplicação dessa teoria exige que as medidas ou amostragens sejam feitas de uma maneira ordenada e numa quantidade relativamente grande.

Com relação às parcelas subsoladas nas mesmas profundidades do horizonte óxico (150 e $195 \mathrm{~cm}$ ), jā não se verifica, como nas parcelas não subsoladas, a diferenciação maior da parcela 2 em relação às outras duas. De uma maneira geral, as variações entre parcelas são aproximadamente semelhantes para todas as profundidades. Face ao que foi dito anteriormente, a respeito do problema da variabilidade espacial, torna-se difícil dizer se esta maior uniformidade das parcelas 1, 2 e 3 das profundidades 150 e $195 \mathrm{~cm}$ é ou não devido ao processo de subsolagem.

\subsection{Método proposto}

A partir das curvas de retenção ou, mais especificamente, de seus ajustes pela eq. (5), obtém-se, seguindo o procedimento descrito no item 3, o parâmetro B da eq. (5) que,por sua vez, $\vec{e}$ igual à diferença entre os parâmetros $\alpha$ e $\gamma$ (eq. 7). 
Utilizando as curvas de drenagem discutidas no item anterior e seguindo o procedimento para o cálculo da relação entre a umidade e o tempo de drenagem (item 4.4.2), calculam-se os valores do parâmetro $\gamma$, uma vez que este é o coeficiente angulardacurva $\Theta$ versus in $t$, para tempos relativamente longos. Os valores destes dois parâmetros, $\alpha$ e $\gamma$, para todas as profundidades estudadas dos dois solos, encontram-se dispostos na Tabela 25 e colocados graficamente na Figura 39. Esta figura mostra que $\alpha$ se relaciona 1inearmente com $\gamma$ com um coeficiente de correlação de 0,99. Isso comprova a hipótese desse trabalho de uma maneira até certo ponto, universal, visto que os solos estudados são distintos (um argiloso e outro de textura média). Desta maneira, a partir apenas da curva de retenção, obtém-se o valor da condutividade hidräulica relativa, conforme será demonstrado a seguir.

A partir da eq. (1), observa-se que:

$$
K_{r}=\frac{K(\Theta)}{K_{0}}=e^{\gamma\left(\Theta-\Theta_{0}\right)}
$$

onde, como jā esclarecido anteriormente, $\mathrm{K}_{\mathrm{r}}=\mathrm{K}(\Theta) / \mathrm{K}_{0}$, é denominado condutividade hidráulica relativa, sendo $\mathrm{K}_{0}$ o valor da condutividade hidráulica do solo saturado, e $\mathrm{K}(\Theta)$ o valor da condutividade hidrāulica do solo à umidade $\Theta$.

Considerando a relação entre $\alpha$ e $\gamma$ universal, conforme mostra a Figura 39, e sua equação representativa

$$
\alpha=-13,26049+0,86799 \gamma \quad(r=0,99450)
$$

e lembrando que $\mathrm{B}$ (eq. 5) é igual à diferença entre $\alpha$ e $\gamma$ (eq. 7), 
resulta:

$$
\gamma=-\frac{B+13,26049}{0,13201}
$$

Substituindo a eq. (29) na eq. (27), obtém-se a equação universal para a condutividade hidráulica relativa em função da umiáade do solo, isto é:

$$
\mathrm{K}_{r}=\frac{\mathrm{K}(\Theta)}{\mathrm{K}_{0}}=\mathrm{e}^{-\frac{\mathrm{B}+13,26049}{0,13201}\left(\Theta-\Theta_{0}\right)}
$$

Elaborando-se, assim, a partir de amostras indeformadas, a curva de retenção de água de um determinado solo e ajustando-a à eq. (5), calcula-se o parâmetro B e, consequentemente, o valor de $K_{r}$, uma vez que $\Theta_{0}$ pode ser facilmente determinado ou calculado a partirdas densidades global e das partículas do solo. Mas, caso se deseje obter o valor absoluto da condutividade hidráu1ica, hä necessidade de se determinar ovalor de $\mathrm{K}_{0}$, que pode ser feito pelos métodos tradicionais de laboratório (KLUTE, 1965).

O estudo da variabilidade espacial do solo é, naturalmente, realizado com maior validade em condições de campo. Conforme jā foi mencionado, algumas propriedades são de difícil avaliação, como por exemplo, a condutividade hidráulica, cujo procedimento, pelo método do "perfil instantāneo", descrito no Capítulo 4, ē bastante trabalhoso (LIBARDI et alii, 1980). Com o método proposto atravës deste trabalho, esse problema pode ser facilmente resolvido, face à simplicidade do 
método, mais simples inclusive que o método de van GENUCHTEN et alii (1980), e reflete de fato as condições de campo, visto que a relação entre $\alpha$ e $\gamma$ foi obtida com o parâmetro $\gamma$ determinado sob condições de campo, e parece ser universal.

Tendo em vista o que foi discutido no final do item 6.1, a respeito da linha pontilhada mostrada na Figura 16 para representar a curva de retenção na profundidade de $150 \mathrm{~cm}$, ärea subsolada, é evidente que a utilização da eq. (26), para transformar em umidade os dados de potencial matricial, obtidos com tensiômetros instalados no campo, para posterior elaboração das curvas de drenagem; deve levar à obtenção de um valor de $\gamma$ diferente daquele obtido para a curva toda (linha sólida da Figura 16), e que se encontra plotado, com o valor de a correspondente, na Figura 39.

Utilizando, assim, a eq. (26), para a qual $B=\alpha-\gamma=$ $=-11,053266$, fez-se a curva de drenagem e, a partir da regressão 1inear de $\Theta$ versus $\ln t$ (tempo), obteve-se o valor de 46,079339 para $\gamma$ e, consequentemente, o valor de 46,079339-11,053266 = 35,026073 para $\alpha$. Plotando este par de valores $\alpha$ e $\gamma$ no grä́fico da Figura 39 , obteve-se o ponto lá representado por um asterisco, o qual, como se pode notar, caiu numa posição em que se pode dizer pertencer à reta representativa das variações de $\alpha$ e $\gamma$ (eq. 28), comprovando, portanto, a universalidade das eq. (28) e (30).

Ao se utilizar a eq. (26), para represen-

tar a curva de retenção na faixa de umidade correspondente, para transformar $\psi_{\mathrm{m}}$ em $\Theta$ e, então, calcular o valor de $\gamma$, é claro que a equação da condutividade hidráulica relativa deve ter a mesma forma da eq. (27); mas, uma vez que $\gamma$ e $\theta_{0}$ são diferentes, ela também o será. Portanto, enquanto que, para a curva toda (linha sólida da 
Figura 16), tem-se a equação

$$
\mathrm{K}_{\mathrm{r}}=\frac{\mathrm{K}(\Theta)}{\mathrm{K}_{0}}=\mathrm{e}^{84,174460(\Theta-0,6082)}
$$

para a linha pontilhada (porção reta inferior do gräfico da Figura 16), a equação da condutividade hidráulica relativa será:

$$
K_{r}=\frac{K(\Theta)}{K_{0}^{*}}=e^{46,079339(\Theta-1)}
$$

ou, em termos genéricos,

$$
K_{r}=\frac{K(\theta)}{K_{0}^{*}}=e^{\gamma *(\theta-\theta *)}
$$

Reportando-se novamente à Figura 16, verifica-se que as curvas, cheia e pontilhada, que originaram as eq. (31) e (32), respectivamente, se cruzam no valor de umidade igual a $0,470 \mathrm{~cm}^{3} . \mathrm{cm}^{-3}$. Consequentemente, neste valor comum de umidade para as duas curvas, o $\mathrm{K}(\Theta)$ da eq. (31) deve ser igual ao $K(\Theta)$ da eq. (32). Com isso, explicitando-se o valor de $\mathrm{K}(\Theta)$ dessas duas equações e nelas substituindo $\Theta$ pelo valor de umidade onde as curvas se cruzam $\left(0,470 \mathrm{~cm}^{3} \cdot \mathrm{cm}^{-3}\right)$, pode-se encontrar a relação entre $\mathrm{K}_{0}$ e $\mathrm{K}_{0}^{*}$ e então expressar a eq. (32) em termos de $\mathrm{K}_{0}$ e não de $\mathrm{K}_{0}^{*}$, uma vez que $K_{0}^{*}$ e um valor não real, correspondente à umidade $\Theta=1,0 \mathrm{~cm}^{3}$. $\mathrm{cm}^{-3}$, como jā explicado anteriormente.

Seguindo-se este procedimento, a relação entre $\mathrm{K}_{0}$ e $\mathrm{K}_{0}^{*}$ para esta profundidade (150 cm, ärea subsolada) é: 


$$
\mathrm{K}_{0}^{*}=35,956 \cdot 10^{4} \mathrm{~K}_{0}
$$

Substituindo-se, portanto, a eq. (34) na eq. (32) temse a expressão da condutividade hidräulica relativa obtida a partir da linha pontilhada da Figura 16, mas expressa em termos de $\mathrm{K}_{0}$, o valor real da condutividade hidráulica do solo saturado, isto é,

$$
K(\Theta)=35,956 \cdot 10^{4} K_{0} e^{46,079339(\Theta-1)}
$$

ou, em termos genéricos,

$$
K(\Theta)=k \cdot K_{0} e^{\gamma *(\Theta-\Theta *)}
$$

ou, ainda, tendo em vista a universalidade da eq. (29),

$$
K(\theta)=k \cdot K_{0} e^{-\frac{B+13,26049}{0,13201}}\left(\theta-\theta_{0}^{*}\right)
$$

onde $k \bar{e}$ a relação entre $K_{0}^{*}$ e $K_{0}$ e $\theta_{0}^{*}$ um valor arbitrado de $\theta_{0}$, que dê um bom ajuste do segmento de reta da curva de retençãoà eq. (5). Desta maneira, havendo interesse em se calcularovalor absoluto da condutividade hidráulica de um determinado solo que tenha um comportamento semelhante a este que se tem tomado como exemplo (Figura 16), basta determinar, pelos métodos tradicionais, (KLUTE, 1965), o valor de $K_{0}$ e, então, substitui-lo na eq. (36) cujos parâmetros $k$, $\gamma^{*}$ e $\theta$ o para tal solo são obtidos da maneira acima explicada.

Ainda utilizando como exemplo a profundidade de 150 cm da ārea subsolada, não esquecendo que o que para ela está se comentando é válido para todas as outras, e tendo em vista o fato de 
tudo indicar que a relação entre $\alpha$ e $\gamma$ mostrada na Figura 16 é universal ou no mínimo válida para todas as profundidades desses dois solos, é fácil obter o valor da condutividade hidrāulica para as outras faixas de umidade mostradas na Figura 16, que correspondem aos dois segmentos de reta (linha pontilhada) nela traçados, correspondentes aos valores mais baixos de umidade. Para tanto, basta calcular o valor de B (eq. 5) para esses segmentos de reta, substitui-lo na eq. (29) e calcular o valor de $\gamma$ correspondente. Calculado esse valor, obtém-se automaticamente uma equação do tipo da eq. (32) e, então, uma equação final do tipo da eq. (35) para as faixas de umidade correspondentes a esses segmentos de reta.

Dessa forma, com base no que foi descrito, pode-se elaborar a sequência de passos necessários para a aplicação do mëtodo proposto:

1) Obter, com amostras de solo com estrutura indeformada, a curva de retenção, a mais completa possĩvel, não esquecendo do ponto de saturação.

2) Ajustar os dados experimentais à eq. (5), desconsiderando o número 1 e os valores próximos ou na saturação e, por regressâo 1 inear de $1 \mathrm{n} \psi_{\mathrm{m}}$ versus $\Theta$, calcular o parâmetro $B$.

3) Se o ajuste dos pontos experimentais à eq. (5) for perfeito, aplicar diretamente a eq. (30) para o cálculo de $\mathrm{K}_{\mathrm{r}}$.

4) Se o ajuste destes pontos não for satisfatório, traçar segmentos de reta que melhor se ajustem aos pontos experimentais, de tal manejra que esses segmentos também se ajustem à eq. (5) com um valor de $\Theta_{0}$ arbitrado que dê o melhor ajuste para cada segmento; neste caso:

a) calcular o valor de $B$ para cada segmento de reta e substitui- 
lo na eq. (29) para o cálculo de $\gamma$;

b) com este valor de $\gamma$ calculado e o $\Theta_{0}$ arbitrado $\left(\Theta_{0}^{*}\right)$, montar a eq. (27) ;

c) na intersecção entre a curva representativa de todos os pontos (alínea 2) e a dos segmentos de reta (alínea 4), calcular o valor de $\Theta$ graficamente;

d) com este valor de $\Theta$, calcular a relação entre $K_{0}^{*}$ e $K_{0}$ a partir das eq. (27) e (33) e, então, calcular $K(\Theta)$ em função de $\mathrm{K}_{0}$ a partir da eq. (36).

5) O cálculo de $K_{0}$, a fim de que o valor absoluto de $K(\theta)$ possa ser obtido diretamente através da eq. (30) ou eq. (37), pode ser feito com as mesmas amostras utilizadas para a obtenção da curva de retenção, pelos métodos tradicionais de medida desse parâmetro sob condições de laboratório. 


\section{CONCLUSÕES}

Com base nos resultados obtidos, o objetivo do presente trabalho foi atingido, chegando-se, portanto, a um novo método de determinação da condutividade hidrāulica em função da umidade do so1o, com fundamento teórico, que é a aplicação de uma equação universal da forma

$$
K(\Theta)=k k_{0} e^{\gamma\left(\Theta-\beta \Theta_{0}\right)}
$$

onde

$$
\gamma=\frac{B+13,26409}{0,13201}
$$

sendo que a constante $B$ é facilmente obtida a partir do ajuste dos dados experimentais da curva de retenção a uma equação da forma abaixo, onde A é uma constante

$$
\psi_{\mathrm{m}}=\mathrm{A}\left[\mathrm{e}^{\mathrm{B}\left(\Theta-\beta \Theta_{0}\right)}-1\right]
$$

Os valores da condutividade hidräulica do solo saturado, $K_{0}$, e a umidade de saturação, $\Theta_{0}$, da curva de retenção, também são facilmente determinados.

Quando uma única curva $\psi_{\mathrm{m}}$ versus $\Theta \bar{e}$ suficiente para ajustar todos os pontos à equação acima, então $k=\beta=1$, e com 
o valor de $B$ obtido desse ajuste, obtém-se facilmente $K(\theta)$. No caso, entretanto, em que uma única curva mostrar não ser suficiente, traçam-se também segmentos de reta que melhor se ajustem aos pontos experimentais e que também se ajustem à equação do tipo acima de $\psi_{\mathrm{m}}$ versus $\Theta$. Neste caso, arbitra-se o valor da constante $\beta \Theta_{\bullet}$, para o cálculo de B de cada segmento. Consequentemente, para cada segmento, existe um valor de $\gamma$, o qual é calculado pela equação acima que mostra que ele é função apenas de B. Como sempre vai existir um ponto em que as duas linhas (a curva única para todos os pontos e o segmento de reta) se cruzam, calcula-se facilmente o valor da constante $k$, porque neste ponto de intersecção das curvas, o valor de $\Theta$ é comum a ambas e, consequentemente, $\mathrm{K}(\Theta)$. Basta, portanto, igualar a equação de todos os pontos para a qual $k=\beta=1$, com as de cada segmento de reta para as quais $k \neq 1$ e $\beta \neq 1$. 


\section{REFERÊNCIAS BIBLIOGRĀFICAS}

AHUJA, L.A.; GREEN, R.E.; CHONG, S-K; NIELSEN, D.R. A simplified functions approach for determining soil hydraulic conductivities and water characteristics in situ. Water Res. Res., Washington, 16 (5): 947-953, 1980.

ALEMI, M.H.; NIELSEN, D.R.; BIGGAR, J.W. Determining the hydraulic conductivity of soil cores by centrifugation. Soil Sci. Soc. Am. J., Madison, $\underline{40}(2): 212-218,1976$.

ANDERSON, J.L. \& BOUMA. Relationships, between saturated hydraulic conductivity and morphometric data of an argillic horizon. Soil Sci. Soc. Am. Proc., Madison, 37(3): 408-413, 1973.

BAVER, L.D.; GARDNER, W.H.; GARDNER, W.R. Fisica de suelos. 4 a. ed. Mexico, Union Tipografica Editorial Hispano-Americana, 1972. 529 p.

BLACK, T.A.; GARDNER, W.R.; THURTELL, G.W. The prediction of evaporation, drainage, and soil water storage for a bare soil. Soil Sci. Soc. Am. Proc., Madison, 33: 655-660, 1969.

BRADY, N.C. Natureza e propriedades dos solos. 5a. ed. São Paulo, Livraria Freitas Bastos S.A., 1979. 647 p. 
BUCKINGHAM, E. Studies on the movement of soil moisture. USDA Bur. Soils, Bull. 38. 1907.

BURDINE, N.T. Relative permeability calculation from size distribution data. Am. Soc. Agric. Eng., 10: 400-404, 1953.

CAMARGO, A.; PINTO, H.S.; PEDRO Jr., M.J.; ALFONSI, R.R.; ORTOLANI, A.A. Clima do Estado de São Paulo. In: SAEESP. Inst. Agronômico. Zoneamento agrícola do Estado de São Paulo, vol. 1. 1974.

CAMPBELL, G.S. A simple method for determining unsaturated conductivity from moisture retention data. Soil Sci., Baltimore, $117(6): 311-314,1974$.

CATANI, R. \& JACtNTHO, O.A. Análise quỉmica para avaliar a fertilidade do solo. Piracicaba, ESALQ/USP, Boletim Técnico-Científico, 1974. $54 \mathrm{p}$.

CAVALCANTE, L.F.; REICHARDT, K.; LIBARDI, P.L. Determinação da condutividade hidräulica do solo durante a redistribuição da água. R. bras. Ci. Solo, Campinas, 2: 77-79, 1978.

CERVELLINI, A.; SALATI, E.; BARROS FERRAZ, E.S.; VILLA NOVA. N.A.; REICHARDT, K.; DECICO, A.; OMETTO, J.C.; PEDRO Jr., M.J. Anālise. dos dados meteorológicos de Piracicaba. Piracicaba, ESALQ/USP, Boletim Científico no 36, 1973. 26 p.

CHILDS, E.C. \& COLLIS-GEORGE, N. The permeability of porous materials. Roy. Soc. Proc., Londres, A-201: 392-405, 1950.

CHO, T.; NOMURA, Y.; YANO, T.; SHIKASKO, S.; INOUE, M. The use of neutron moisture meter in studies of soil water regimes. Water 
management in a sand dune area. Tottori University, Faculty of Agriculture. 1976. 48 p. A report for the Coordinated Research Programme on the Use of Radiation and Isotope Techniques in Studies of Soil Water Regime. International Atomic Energy Agency.

CHO, T.; NOMURA, Y.; YANO, T.; SHIKASKO, S.; INOUE, M.. The use surface-type and a depth-type neutron moisture meter in studies of soil water regimes - Water management in a sand dune area. Tottori University, Faculty of Agriculture. 1977. 85 p. A report for the Coordinated Research Programme of Radiation and Isotope Techniques in Studies of Soil Water Regime. International Atomic Energy Agency.

CHONG, S-K.; GREEN, R.E.; AHUJA, L.R. Simple in situ determination of hydraulic conductivity by power function descriptions of drainage. Water Res. Res., Washington, 17(4): 1109-1114, 1981.

DANE, J.H. Comparison of field and laboratory determined hydraulic conductivity values. Soil Sci. Soc. Am. J., Madison, 44: 228231, 1980.

DANE, J.H. \& KRUSKA, S. In situ determination of soil hydraulic properties during drainage. Soil Sci. Soc. Am. J., Madison, 47(4): 619-624, 1983 .

DARCY, H. Les fontaines publique de la Ville de Dijon. Victor Dalmont, Paris. 1856.

DAVIDSON, J.M.; NIELSEN, D.R.; BIGGAR, J.W. The measurement and description of water flow through Columbia Silt Loam and Hesperia Sandy Loam. Hilgardia, Berkeley, 34(15): 601-617, 1963. 
DAVIDSON, J.M.; STONE, L.R.; NIELSEN, D.R.; LARUE, M.E. Field measurement and use of soil properties. Water Res. Res., Washington, 5: 1312-1321, 1969.

DERR, B.D.; MATELSKI, R.P.; PETERSEN, G.W. Soil factors influencing percolation test performance. Soil Sci. Soc. Am. Proc., Madison, 33: $942-946,1969$.

DOERING, E.J. Soil-water diffusivity by the one-step method. Soil Sci., Baltimore, 99(5): 323-326, 1965.

FIELD, J.A.; PARKER, J.C.; POWELL, N.L. Comparison of field and laboratory measured and predicted hydraulic properties of a soil with macropores. Soil Sci., Baltimore, 138 (6): 385-396, 1984.

GARDNER, W.R. Calculation of capillary conductivity from pressure plate outflow data. Soil Sci. Soc. Am. Proc., Madison, 20: 317$320,1956$.

GARDNER, W.R. Note on the separation and solution of diffusion type equations. Soil Sci. Soc. Am. Proc., Madison, 26 (4): 404, 1962.

GARDNER, W.R.; HILLEL, D.; BENYAMINI, Y. Post-irrigation movement of soil water. 1. Redistribution. Water Res. Res., Washington, $\underline{6}(3): 851-861,1970$.

GREEN, R.E. \& COREY, J.C. Calculation of hydraulic conductivity: a further evaluation of some predictive methods. Soil Sci. Soc. Am. Proc., Madison, 35: 3-8, 1971.

GROHMANN, F.; BRUNINI, O.; REICHARDT, K. Condutividade hidrāulica do solo. Campinas, Instituto Agronômico. Circular n? 53, 1976. 28 p. 
HILLEL, D.; KRENTOS, V.D.; STYLLIANOU, Y. Procedure and test of an internal drainage method for measuring soil hydraulic characteristics in situ. Soil Sci., Baltimore, 114(5): 395-400, 1972.

JACKSON, R.D. On the calculation of hydraulic conductivity. Soil Sci. Soc. Am. Proc., Madison, 36: 380-383, 1972.

JACKSON, R.D.; VAN BAVEL, C.H.M.; REGINATO, R.J. Examination of the pressure-plate outflow method for measuring capillary conductivity. Soil Sci., Baltimore, 96: 249-256, 1963.

JAYNES, D.B. \& TYLER, E.J. Using soil physical properties to estimate hydraulic conductivity. Soil Sci., Baltimore, 138(4): 298-305, 1984.

JONES, A.J. \& WAGENET, R.J. In situ estimation of hydraulic conductivity using simplified methods. Water Res. Res., Washington, 20(11): 1620-1626, 1984.

KIEHL, E.J. Manual de Edafologia. Relações solo-planta. São Paulo, Editora Agronômica Ceres Ltda, 1979. 263 p.

KLUTE, A. Laboratory measurement of hydraulic conductivity of saturated soil. In: BLACK, C.A., ed. Methods of soil analysis. Madison, Am. Soc. Agron. Inc. 1965. cap. 13, p. 210-252.

KLUTE, A. The determination of the hydraulic conductivity and diffusivity of unsaturated soils. Soil Sci., Baltimore, 113(4): 264-276, 1972 .

KUNZE, R.J. \& KIRKHAM, Simplified accounting for membrane impedance in capillary conductivity determinations. Soil Sci. Soc. Am. Proc., Madison, 26: 421-426, 1962. 
LALIBERTE, G.E. \& COREY, A.T. Hydraulic properties of disturbed and undisturbed samples. In: Permeability and capillarity of soils. ASTM STP 417, Amer. Soc..Testing Materials, 1967, p. $56-71$

LEMOS, R.C. \& SANTOS, R.D. Manual de descrição e coleta de solo no campo. 2a. ed. Campinas, SBCS e SNLCS, 1982. 45 p.

LIBARDI, P.L. Condutividade hidráulica do solo em condições de campo. Piracicaba, 1978. 113 p. (Doutorado-Escola Superior de Agricultura "Luiz de Queiroz" da Universidade de São Paulo).

LIBARDI, P.L. Balanço de nitrogênio em culturas agrícolas. Piracicaba, 1984. 113 p. (Livre-Docência - Escola Superior de Agricultura "Luiz de Queiroz" da Universidade de São Paulo).

LIBARDI, P.L.; REICHARDT, K.; NIELSEN, D.R.; BIGGAR, J.W. Simple field methods for estimating soil hydraulic conductivity. Soil Sci. Soc. Am. J., Madison, 44: 3-7, 1980.

LUXMOORE, R.J.; GRIZZARD, T.; PATTERSON, M.R. Hydraulic properties of Furllerton Cherty Silt Loam. Soil Sci. Soc. Am. J., Madison, 45: 692-698, 1981 .

MARSHALL, T.J. A relation between permeability and size distribution of pores. J. Soil Sci., Oxford, 9(1): 1-8, 1958.

MILLER, E.E. \& ELRICK, D.E. Dynamic determination of capillary conductivity extended for non-negligible membrane impedance. Soil Sci. Soc. Am. Proc., Madison, 22(6): 483-486, 1958.

MILLING'ION, R.T. \& QUIRK, J.P. Permeability of porous media. 
Nature, London, 183: 387-388, 1959.

MILLINGTON, R.J. \& QUIRK, J.P. Transport in porous media. Trans. of 7th Int. Congr. Soi1 Sci., Madison, 1.3: 97-106, 1960.

MUALEM, Y. A new model for predicting the hydraulic conductivity of unsaturated porous media. Water Res. Res., Washington, 12(3): $513-522,1976$.

NIELJSEN, D.R.; BIGGAR, J.W.; ERH, K.T. Spatial variability of fieldmeasured soil-water properties. Hilgardia, Berkeley, 42(7): 215$259,1973$.

NIELSEN, D.R.; DAVIDSON, J.M.; BIGGAR, J.W.; MILLER, R.J. Water movement through Panoche Clay Loam soil. Hilgardia, Berkeley, 35(17): 491-506, 1964 .

NIELSEN, D.R.; KIRKHAM, D.; PERRIER, E.R. Soil capillary conductivity: comparison of measured and calculated values. Soil Sci. Soc. Am. Proc., Madison, 24: 157-160, 1960.

NIELSEN, D.R.; TILLOTSON, P.M.; VIEIRA, S.R. Analysing fieldmeasured soil-water properties. Agric. Water Manag., New York, 6: 93-108, 1983 .

OGATA, G. \& RICHARDS, L.S. Water content changes following irrigation of bare field soil that is protected from evaporation. Soil Sci. Soc. Am. Proc., Madison, 21: 355-356, 1957.

PAULETTO, E.A. Estudo sobre dispersão de amostra de terra. Piracicaba, 1978. 68 p. (Mestrado - Escola Superior de Agricultura "Luiz de Queiroz" da Universidade de São Paulo). 
PERSINGER, I.D. \& YAHNER, J.E. Relation of percolation rates to soil texture on several Indiana soils. J. Soil Water Conserv., Baltimore, 25(5): 189-191, 1970.

PREVEDELLO, B.M.S.; PREVEDELLO, C.L.; LIBARDI, P.L. Simplificação analítica do método do perfil instantâneo para a obtenção da condutividade hidrāulica não saturada em condições de campo. R. bras. Ci. Solo, Campinas, 5: 93-97, 1981.

RANZANI, G.; FREIRE, O.; KINJO, T. Carta de solos do município de Piracicaba. Centro de Estudos de Solos, ESALQ/USP. Piracicaba, SP, 1966. $85 \mathrm{p}$.

REICHARDT, K. \& LIBARDI, P.L. An analysis of soil water movement in the field. I. Hydrological field site characterization. CENA, Piracicaba, BC-021, 21 p. 1974.

REICHARDT, K.; LIBARDI, P.L.; NIELSEN, D.R. Unsaturated hydraulic conductivity determination by a scaling technique. Soil Sci., Baltimore, 120(3): 165-168, 1975.

RICHARDS, L.A. Capillary conduction of liquids through porous medium. Physics, 1: 318-333, 1931.

RICHARDS, L.A.; GARDNER, W.R.; OGATA, G. Physical processes determining water loss from soil. Soil Sci. Soc. Am. Proc., Madison, 20: 310-314, 1956.

RICHARDS, S.J. \& WEEKS, L.V. Capillary conductivity values from moisture yield and tension measurements on soil columns. Soil Sci. Soc. Am. Proc., Madison, 17(3): 206-208, 1953. 
ROSE, C.W.; STERN, W.R.; DRUMMOND, J.E. Determination of hydraulic conductivity as a function of depth and water content for soil in situ. Aust. J. Soil Res., Melbourne, 3: 1-9, 1965.

SAUNDERS, L.C.U.; LIBARDI, P.L.; REICHARDT, K. Condutividade hidräulica da Terra Roxa Estruturada em condições de campo. R. bras. Ci. Solo, Campinas, 2: 164-167, 1978.

SCHUH, W.M.; BAUDER, J.W.; GUPTA, S.C. Evaluation of simplified methods for determining unsaturated hydraulic conductivity of layered soils. Soil Sci. Soc. Am. J., Madison, 48: 730-736, 1984.

SIDOROPOULOS, E.R. \& YANNOPOULOS, S. Simplified determination and sensitivity analysis of soil-moisture retention curves and hydraulic conductivity. J. Hydrol., Amsterdam, 74: 295-309, 1984. SISSON, J.B.; FERGUSON, A.H.; VAN GENUCHTEN, M.Th. Simple method for predicting drainage from field plots. Soil Sci. Soc. Am. J., Madison, 44: 1147-1152, 1980.

STEPHENS, D.B. \& REHFELDT, K.R. Evaluation of closed-form analytical models to calculate conductivity in a fine sand. Soil Sci. Soc. Am. J., Madison, 49: 12-19, 1985.

SWARTZENDRUBER, D. Soil water behavior as described by transport coefficients and functions. Adv. Agron., New York, 18: 327-370, 1966.

TALSMA, T. Prediction of hydraulic conductivity from soil water retention data. Soil Sci., Baltimore, 140(3): 184-188, 1985.

TAYLOR, S.A. \& ASHCROFT, G.L. Physical edaphology. The Physics of irrigated and nonirrigated soils. San Francisco, W.H. Freeman 
and Company, 1972. 533 p.

U.S.D.A. Soil taxonomy: a basic system of soil classification to making and interpreting soil surveys. Washington, Agriculture Handbook n? 436, 1979. 754 p.

VACHAUD, G. Determination of the hydraulic conductivity of unsaturated soils from an analysis of transient flow data. Water Res. Res., Washington, 3(3): 697-705, 1967.

VAN BAVEL, C.H.M.; STIRK, G.B.; BRUST, K.J. Hydraulic properties of a clay soil and the field measurement of water uptaken by roots: I. Interpretation of water content and pressure profiles. Soil Sci. Soc. Am. Proc., Madison, 32 (3): 310-317, 1968.

VAN GENUCHTEN, M.Th. A closed-form equation for predicting the hydraulic conductivity of unsaturated soils. Soil Sci. Soc. Am. J., Madison, 44: 892-898, 1980.

VAN GENUCHTEN, M.Th. \& NIELSEN, D.R. On describing and predicting the hydraulic properties of unsaturated soils. Annales Geophysicae, 3(5): $615-628,1985$.

VIEIRA, S.R.; HATFIELD, J.L.; NIELSEN, D.R.; BIGGAR, J.W. Geostatistical theory and application to variability of some agronomical properties. Hilgardia, Berkeley, 51(3): 1-75, 1983.

WATSON, K.K. An instantaneous profile method for determining the hydraulic conductivity of unsaturated porous materials. Water. Res. Res., Washington, 2: 709-715, 1966.

WIND, G.P. Capill ary conductivity data estimated by a simple method. In: Water in the unsaturated zone, vol. 1, p. 181-191. 1966. 